\title{
Sanitary Landfill Supplemental Test Final Report
}

by

D. J. Altman

Westinghouse Savannah River Company

Savannah River Site

Aiken, South Carolina 29808

C. J. Berry

R. Brigmon

M. M. Franck

T. C. Hazen

F. A. Washburn
A. Bourquin
CDM
D. Mosteller
CDM

This paper was prepared in connection with work done under the above contract number with the U.S. Department of Energy. By acceptance of this paper, the publisher and/or recipient acknowledges the U. S. Government's right to retain a nonexclusive, royalty-free license in and to any copyright covering this paper, along with the right to reproduce and to authorize others to reproduce all or part of the copyrighted paper. 


\title{
SANITARY LANDFILL
}

\author{
SUPPLEMENTAL TEST
}

\section{FINAL REPORT}

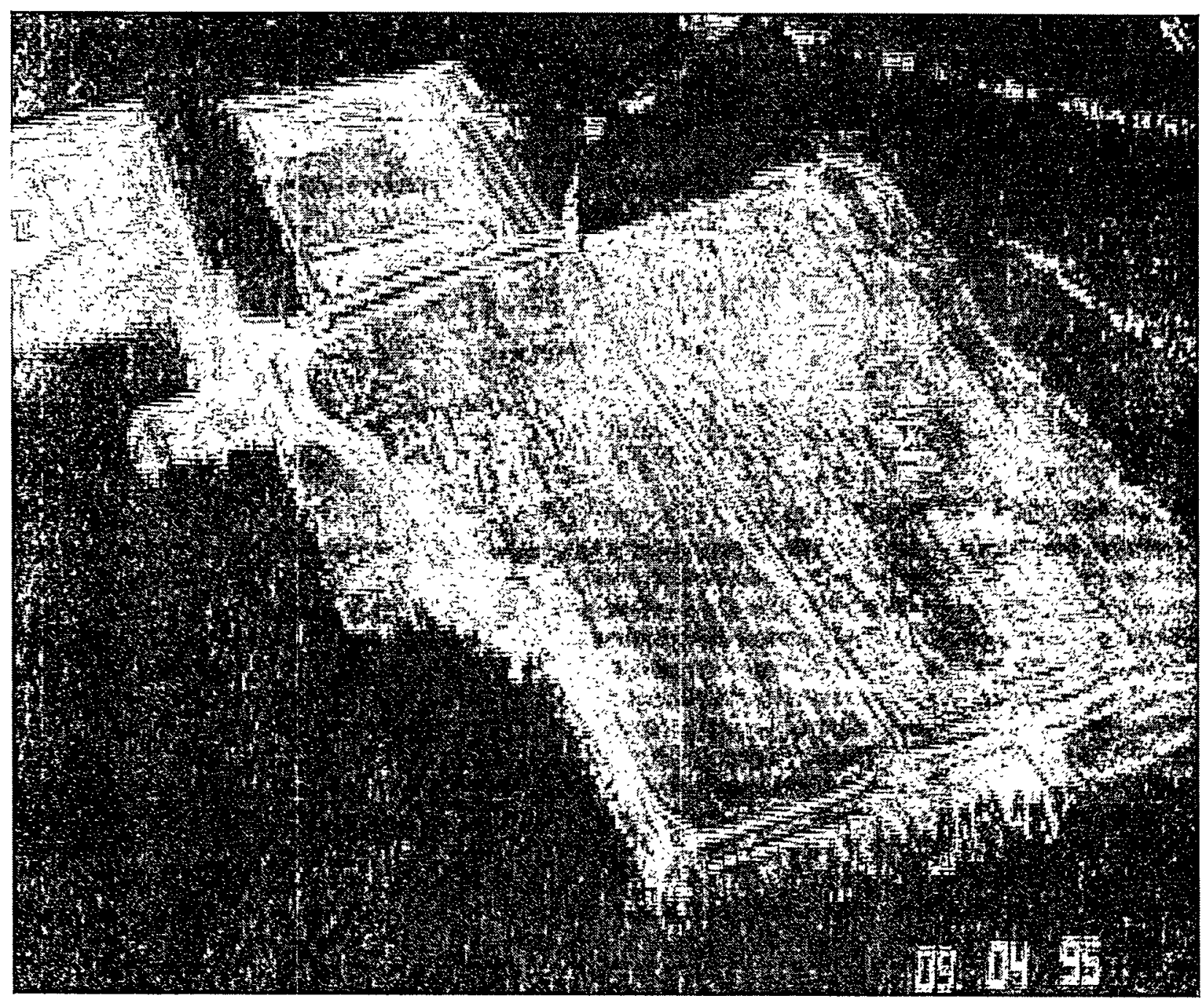

Westinghouse Savannah River Company

Savannah River Site

Aiken, SC 29808

Prepared for the U.S. Department of Energy under Contract No. DE-AC09-89SR18035 


\section{DISCLAIMER}

This report was prepared as an account of work sponsored by an agency of the United States Government. Neither the United States Government nor any agency thereof, nor any of their employees, makes any warranty, express or implied, or assumes any legal liability or responsibility for the accuracy, completeness, or usefulness of any information, apparatus, product, or process disclosed, or represents that its use would not infringe privately owned rights. Reference herein to any specific commercial product, process, or service by trade name, trademark, manufacturer, or otherwise does not necessarily constitute or imply its endorsement, recommendation, or favoring by the United States Government or any agency thereof. The views and opinions of authors expressed herein do not necessarily state or reflect those of the United States Government or any agency thereof.

This report has been reproduced directly from the best available copy.

Available to DOE and DOE contractors from the Office of Scientific and Technical Information, P.O. Box 62, Oak Ridge, TN 37831; prices available from (615) 576-8401.

Available to the public from the National Technical Information Service, U.S. Department of Commerce, 5285 Port Royal Road, Springfield, VA 22161.

Acknowledgments

This work was funded by the United States Department of Energy (DOE), Office of Environmental Management EM-40 and EM-30. We are especially grateful to the late Steve Wright DOE-Savannah River who funded this project through community outreach funds after a severe EM-40 budget shortfall caused all work to stop in the middle of the initial well installation. We will sorely miss Steve who through the years was one of Savannah River Site's best proponents of environmental research and development activities and technology transfer. We are also grateful to the many people in the Westinghouse Savannah River Company Environmental Restoration Department who fostered this work and aided us in obtaining the information, documentation, and funding necessary to implement this technology at SRS. We thank the technicians, clerks and staff of the Environmental Sciences Section of Savannah River Technology Center who aided us in this project at various times. We are also very grateful to Tom Hayes and the Gas Research Institute who provided all the methane used in this project, and much of the original research funding on methanotrophic treatment technology that allowed this technology to be applied. 


\section{SANITARY LANDFILL}

\section{SUPPLEMENTAL TEST}

\section{FINAL REPORT}

Prepared for the U.S. Department of Energy under Contract No. DE-AC09-89SR18035 


\section{DISCLAIMER}

Portions of this document may be illegible in electronic image products. Images are produced from the best available original document. 


\section{Forward}

This work was performed as part of a corrective action plan for the Savannah River Site Sanitary Landfill. This work was performed for the Westinghouse Savannah River Company Environmental Restoration Department as part of final implementation of a groundwater remediation system for the SRS Sanitary Landfill. Primary regulatory surveillance was provided by the South Carolina Department of Health and Environmental Control and the U.S. Environmental Protection Agency (Region IV). The characterization, monitoring and remediation systems in the program generally consisted of a combination of innovative and baseline methods to allow comparison and evaluation. The results of these studies will be used to provide input for the full-scale groundwater remediation system for the SRS Sanitary Landfill.

This report summarizes the performance of the Sanitary Landfill Supplemental Test data, an evaluation of applicability, conclusions, recommendations, and related information for implementation of this remediation technology at the SRS Sanitary Landfill.

This test was performed in addition to and after the Sanitary Landfill In Situ Bioremediation Optimization Test and provides supplemental information to that contained in the "Sanitary Landfill In Situ Bioremediation Optimization Final Report", Reference 10.2. 
Sanitary Landfill

WSRC-RP-97-17

Supplemental Test

Revision 1

Final Report

April 1,1998

\section{Executive Summary:}

The Sanitary Landfill Supplemental Test was performed after the Sanitary Landfill In Situ Bioremediation Optimization Test (Reference 10.1 and 10.2). The Optimization Test was performed to validate the remediation technology selected for use to remediate two contaminant plumes (a trichloroethylene [TCE] plume and a vinyl chloride [VC] plume) at the Sanitary Landfill located in B-Area. The contaminant plumes emanate from the refuse placed in the landfill and consist of a TCE plume located near the southern edge of the landfill and a VC plume located near the western edge of the landfill. An evaluation of the various remediation technologies was performed and an in situ bioremediation system was selected as the preferred remediation technology. The recommended full-scale system requires two horizontal wells placed along the southern and western edges of the landfill. The southern horizontal well is required to inject air, methane, nitrogen and phosphate into the unconfined aquifer to intercept the contaminants and stimulate the indigenous microorganisms thus remediating the TCE plume. The western horizontal well is required to presently inject air alone into the unconfined aquifer to intercept the contaminants and remediate the VC plume. (The recommended remediation system design contains the ability to inject all constituents into either well, thus providing the ability to address any possible future changes in either of the plumes.

The Optimization Test validated the selected remediation technique of injecting air, methane and nutrients into the saturated zone within the TCE plume and air alone into the VC plume; and identified that full time (24 hours a day) injection was not required. The Sanitary Landfill Supplemental Test was implemented in an effort to determine acceptable injection and noninjection periods necessary to efficiently and cost effectively remediate the contaminants of concern while providing assurances that the contaminants were properly eliminated. A supplemental test plan was generated and carried out after completion of the Optimization Test. The supplemental test was performed on the TCE plume only because the remediation of this plume would require injection of methane and nutrients in addition to air and thus drive the design and operational requirements of the entire system. (The injection of air alone, into the VC plume, does not require the same design and operational considerations associated with the injection of methane.) The results of the test were analyzed by Camp Dresser and McKee to ensure an unbiased interpretation of the data. Camp Dresser and McKee (CDM) has reviewed the data collected at the Savannah River Site's Sanitary Landfill (Westinghouse Savannah River Company, Aiken, South Carolina) during the months of June through September, 1996 and assisted in producing this report.

The Savannah River Site contains a sanitary landfill that historically received paints, thinners, solvents, and disposable batteries over a period of 20-plus years. Leachates, in part consisting of chlorinated solvents, were detected in groundwater samples during an evaluation that occurred from 1984 through 1993. Subsequently, a remedial test system (Figure 1) was designed and installed within each contaminate plume to validate the use of in situ biodegradation of chlorinated solvents as the method of choice. The system consists of three sparge wells (AIW-1, AIW-2 \& AIW-3), a gas extraction well (ASW), and 14 nested monitoring locations within each plume. Each nested monitoring location within the TCE plume has two mini-wells (VZP-1S, 
VZP-2S, etc.), in the unsaturated soils (shallow $=10$ feet below ground surface [bgs]; deep $=16$ feet bgs) and two mini-wells (SZP-1S, SZP-1D, SZP-2S, etc.) in the saturated soils (shallow = 30-40 feet bgs; deep $=45-55$ feet bgs). In the sparge wells, a mixture of air, methane, and gaseous nutrients (nitrous oxide and triethyl phosphate) were injected to stimulate methanotrophs to biodegrade chlorinated solvents like TCE and cis-dichloroethylene (c-DCE) via cometabolism.

The overall objective of this investigation was to distinguish the difference between biodegradation and volatilization of chlorinated solvents in the designed system. In achieving this goal, two separate tests were conducted. The purpose of each experiment was:

1. To establish baseline conditions in which organic contaminants within the TCE plume are potentially stripped from the groundwater and transferred into the vadose zone during sparging; and to decipher the influence of the sparge system on the various monitoring locations.

2. To quantify chlorinated solvent biodegradation of the TCE plume produced by the injection system.

The first test involved injecting air at approximately 5 SCFM (Standard Cubic Foot per Minute) and helium at approximately $1 \%$ to $4 \%$ into each of the sparge wells for a period of approximately 24 hours and regularly monitoring oxygen, carbon dioxide, helium, and organic contaminants in the soil gas and dissolved oxygen and organic contaminants in the groundwater. This test was the control experiment.

The second experiment lasted a week. During this test air, methane, nutrients, and helium were injected for approximately 8 hours a day followed by 16 hours of no injection (for six consecutive days). The injection consisted of a mixture of approximately 5 SCFM of air into each injection well ( 15 SCFM total into the test site), blended with $4 \%$ methane $(\mathrm{CH} 4), 0.07 \%$ Nitrous Oxide ( $\mathrm{N}_{2} \mathrm{O}$ ), $0.007 \%$ to $0.01 \%$ Phosphate (in the form of Triethyl Phosphate, TEP $\left.\left(\mathrm{C}_{2} \mathrm{H}_{5} \mathrm{O}\right)_{3} \mathrm{PO}\right)$ and $1.0 \%$ to $3.0 \%$ helium (He) as a tracer. Sampling for the second experiment focused upon selected monitoring locations (aided by the results of the first experiment).

Results of these tests showed that the unconfined aquifer readily supports oxygen transfer, the subsurface conditions are conducive for aerobic biodegradation mechanisms and air stripping of the groundwater contaminants into the vadose zone did not occur. Pulsed operation of the injection system was successful and can be utilized for the full-scale system operation. An analysis of the capabilities of the full-scale remediation system was performed and an initial start up operating range was selected which the full-scale system could adequately support. The recommended initial start up injection cycle for the remediation system should range between: a daily ( $8 \mathrm{hr}$ ) injection period of air mixed with $4 \%$ methane, $0.07 \%$ nitrous Oxide, and $0.007 \%$ TEP once a week every other week for four (4) injection cycles; to a campaign of an $8 \mathrm{hr}$ injection period of $1 \%$ methane, $0.07 \%$ nitrous Oxide, and $0.007 \%$ TEP every other day for 4 injection periods followed by a non injection period of one week repeated for 4 cycles. . This range is recommended to ensure that the information obtained via the vertical injection wells of the test is appropriately applied to the horizontal wells proposed for the full-scale remediation system. Sampling during this introductory operational period will: ensure that the remediation 
system is functioning properly; enable the further refinement of the operating parameters; and determine the radius of influence for the injection wells. It is highly likely that fewer injections at lower nutrient concentrations will be the final operating mode for the groundwater remediation system. 


\section{Sanitary Landfill Supplemental Test}

Environmental conditions at the Savannah River Sanitary Landfill In Situ Bioremediation Optimization Test Site are favorable for aerobic microorganisms, including methanotrophs. The dissolved oxygen in the groundwater is above $1 \mathrm{mg} / \mathrm{L}$, the Vadose zone oxygen concentration is at air saturation ( $21 \%$ oxygen), and the $\mathrm{pH}$ of the groundwater is between 6 and 8 . Previous experiments enabled the Sanitary Landfill Supplemental Test to be focused upon the sampling of four nested monitoring wells $(2,4,7$, and 13$)$ within the TCE plume. These wells were selected because they were subject to consistent influences by the sparging system.

The Sanitary Landfill Supplemental Test injected a mixture of gases into the test site (air, methane, nutrient, and helium) for a continuous seven (7) day period. The injections were performed for approximately 8 hours daily followed by a non-injection period of 16 hours. Extensive sampling was performed during the entire supplemental test campaign to determine the response time of the indigenous microbial community to the injection campaign.

\section{Dissolved Oxygen, Redox Potential, and $\mathrm{pH}$ Objective(s):}

Measurements of dissolved oxygen (DO), oxidation-reduction (redox) potential, and $\mathrm{pH}$ were continuously recorded at SZP-2S throughout the second experiment to record the influence of the pulsed sparging and ensure an environment that is conducive for aerobic, cometabolic degradation of TCE and/or c-DCE. SZP-2S was selected for this continuous monitoring because it is further down gradient than all other monitoring locations (i.e. will unlikely impact groundwater at other monitoring locations) and it is located at an equal radial distance from air injection wells (AIW) 2 and 3 . Figures 2 through 4 graphically depict the impact sparging had on the dissolved oxygen, oxidation reduction potential, and $\mathrm{pH}$, respectively, during the course of the experiment. Dissolved oxygen concentrations greater than $1 \mathrm{mg} / \mathrm{L}$ (aerobic environment) are desirable because oxygen is required in the cometabolic process in which methane is consumed by microorganisms that also fortuitously degrade TCE and c-DCE (cometabolism). The redox potential is directly correlated to DO such that, as oxygen concentrations increase, the redox potential should also increase. Most microorganisms are generally in a more favorable environment and have greater activities when the $\mathrm{pH}$ is in the range of 6 to 8 standard units.

\section{Results:}

A. Background dissolved oxygen concentrations were initially about $1 \mathrm{mg} / \mathrm{L}$.

B. During the injection phases, DO concentrations consistently increased to approximately $11 \mathrm{mg} / \mathrm{L}$.

C. When the injection system was off, DO concentrations quickly decreased to concentrations that were slightly greater than the DO level during the previous system off period.

D. Over the length of the experiment, the DO concentration, as measured during "off" times, asymptotically approached $5 \mathrm{mg} / \mathrm{L}$.

E. Background oxidation reduction potential is approximately $350 \mathrm{mV}$.

F. Redox potential decreased during pulsed system operations which contradicts the general relationship with dissolved oxygen. Presently an explanation for these phenomena has 
not been determined. Investigation into this anomaly is continuing. However, the general direction of the Redox Potential throughout the test did follow an upward trend.

G. Redox potential, as measured during "off" times gradually increased to approximately $400 \mathrm{mV}$ during the week of testing.

$\mathrm{H}$. Background $\mathrm{pH}$ was approximately 6 , and

I. $\mathrm{pH}$ increased approximately 1.3 standard units during pulse injections and then quickly returned to background levels during "off" times.

\section{Conclusions:}

Air saturated water at sea level and at a temperature range between 20 and $25^{\circ} \mathrm{C}$ (the temperature range of the groundwater) has a dissolved oxygen concentration of approximately $8 \mathrm{mg} / \mathrm{L}$. During periods of pulse injection, the DO increased to approximately $11 \mathrm{mg} / \mathrm{L}$. The sharp increase in DO to concentrations greater than air saturation is a result of supersaturation of water during sparge pulses. The subsequent decrease in DO concentrations (immediately following injection system shut down) is caused by degassing and is not representative of oxygen utilization by microbial populations. The increase of DO observed during the down (injection off) times of system operation, over the test period, are a better representation of air sparging effects on the DO concentration in the groundwater. Since DO concentrations were consistently above $1 \mathrm{mg} / \mathrm{L}$, the groundwater in the test system would be conducive for aerobic biodegradation mechanisms.

The cause of decreased redox potential measurements and increased $\mathrm{pH}$ during injection phases is uncertain. It is possible that the supersaturated groundwater may have caused misleading results during these periods. However, the gradual increase of redox potential during the week of testing was likely due to the increase DO concentrations that were observed.

The $\mathrm{pH}$ of the groundwater environment is within the range in which microbial populations generally flourish.

\section{Gas Transport into the Vadose Zone (Experiment 1) Objective(s):}

In both the first and second experiments, helium was used as a conservative tracer gas. The first experiment primarily focused upon (1) identifying monitoring locations that were significantly impacted by the sparge system, and (2) quantifying potential background oxygen utilization rates and potential organic contaminant mass transfer from the groundwater to the vadose zone. Organic contaminant mass transfer issues are addressed in Section 6.

In the first experiment, the sparge system (air and helium) was operated for a period of 28 hours. Gas samples were frequently collected during system operation and also once daily for the three days following sparging. Helium concentration percentages in selected wells $(2,4,7$, and 13$)$ are shown in Figures 5 through 8, respectively. These vadose zone well points are graphically displayed because they are also wells that were selected for analysis in the second methane experiment. 


\section{Results:}

A. In all vadose zone wells, the deep sample locations were influenced by the air sparging faster than the shallow ones and have higher helium concentration percentages.

B. The different well locations were impacted in varying degrees.

C. Of the four selected monitoring wells $(2,4,7$, and 13$)$, wells 4 and 7 were influenced the fastest and to the greatest extent.

D. Generally, after sparging terminated, the helium concentrations in the deep wells decreased and those in the shallow wells increased.

\section{Conclusions:}

The rapid influence of sparging on wells 4 and 7, as compared to wells 2 and 13, indicates that preferential pathways for the sparged gas were likely created in the soils to the north of AIW-2 (in the area of wells 4 and 7). The increase of helium concentration in the shallow wells and concomitant decrease in the deep wells after system termination is a function of mass transfer. Which is driven by the concentration gradients induced during the injection campaign and continues until the gradient is depleted. All four well locations were selected for sampling analysis in the second experiment because they encompassed the range of influence generated by the sparging system.

\section{Gas Transport into the Vadose Zone (Experiment 2)}

\section{Objective(s):}

Helium was similarly injected into the sparge wells in the second experiment to act as a conservative tracer to methane and oxygen and to further identify the wells that were more influenced by the sparging. Methane was injected as part of the system operations. Figures 9 and 10 depict concentration percentage ratios of methane to helium for each monitoring well sampled in both the deep and shallow locations. Comparisons for each well can be made against the baseline conditions established in the air injection well.

\section{Results:}

A. In the deep vadose zone wells, increased concentration percentages of helium and methane were detected in VZP-4 and VZP-13 faster than at other wells.

B. The order of influence by the sparge system in the shallow wells was VZP-4S, VZP-7S, VZP-2S, and then VZP-13S.

C. Methane and helium did not appear at all shallow well locations until at least the third pulse.

D. There is a general, initial increase of methane.

E. The methane/helium ratios in the shallow vadose zone points are consistently less than the ratios in the deep locations, for each respective well.

F. Apparent methane consumption was detected in VZP-2D, 4D, 13D, 4S, and 13S which further supports the fact that the indigenous microbial community was stimulated.

\section{Conclusions:}

Figures 9 and 10 conclusively indicate that all sampled monitoring locations in the vadose zone were influenced by methane, helium, air and nutrient sparging. As anticipated, the deep vadose locations were impacted before the shallow points because the deep vadose zone piezometers are 
located closer to the injection wells than the shallow vadose zone piezometers. The time difference between the deep and shallow zones is representative of the different travel lengths from the injection point to the sample points and the concentration gradient driven gas transport within the unsaturated soils. The second experiment confirmed a preferential pathway to VZP4D (4-deep) and VZP-7D (7-deep). The existence of preferential pathways for the full-scale system is less likely because of the increased depth of the injection well.

\section{Gas Analyses Normalized to Average AIW Concentrations (Experiment 2) Objective(s):}

Gas samples from each of the three air injection wells (AIWs) were analyzed frequently for methane, oxygen, and helium concentrations. Since each AIW has the same source, the major gas analysis results were averaged to represent the sparge input into the test system over time. These averaged results were also used to normalize the major gas analyses at each of the vadose zone monitoring well locations. Results for each sampled point are graphically represented in Figures 11 through 18 for wells VZP-2, 4, 7, and 13; shallow and deep. The objective of this section is to further demonstrate potential oxygen and/or methane utilization in addition to Section 5 .

\section{Results:}

A. The unsaturated soils within the vicinity of the sampled monitoring wells are not oxygen limited. The soils are all at, or near, air saturation ( 21 to $22 \%$ oxygen).

B. The data show a later influence of the sparge system when compared to the results of Section 3, although to a lesser degree than on the shallow well points. This can be explained by the fact that the injection phase of Section 3 was continuous for 24 hours thus providing a sustained driving force. Whereas the injection phase for this section was pulsed for only eight hours a day which does not provide the same driving force.

C. The normalized methane data in the deep well points, although occasionally scattered, closely mimic the normalized helium data in the early stages (first three pulses) of the test experiment. In the later days of the experiment (last three pulses) the normalized methane concentrations are generally less than the normalized helium concentrations, and may suggest an increase in methane utilization.

D. In all shallow vadose zone well points, the shape of the normalized methane data curve is similar to the normalized helium data curve, but the methane concentrations are consistently lower than the helium concentrations.

Conclusions:

Figures 11 through 18 again indicate that methane gas is being consumed. The deep well data within the first three days of testing show that methane and helium traveled at nearly the same rate. This would be expected since a large mass of methane and helium was injected, the two gases have water solubility limits that are similar $\left(3.5 \mathrm{~mL} / 100 \mathrm{ml} \mathrm{H}_{2} 0\right.$ and $1.0 \mathrm{~mL} / 100 \mathrm{ml} \mathrm{H}_{2} 0$, respectively) and it is assumed that the two gases have similar (minimal) sorptive properties. After the third pulse, the two normalized data sets begin to deviate. Furthermore, the normalized helium data are always lower than the normalized methane data in the shallow wells. The 
difference between the two is caused by a microbial utilization of the methane. During the first three pulses, a microbial population capable of utilizing methane was adapting to the methanerich environment. After this lag time, the methanotrophs began to consume the methane for microbial maintenance and possibly for growth.

\section{Methanotrophs (Experiment 2)}

\section{Objective(s):}

Bacterial counts for total (AODCs - Acridine Orange Direct Counts) and methanotrophic microorganism populations (DFAs - Direct Fluorescent Antibodies and MPNs Most Probable Numbers) were conducted at three selected shallow wells in the saturated zone (wells 2,9, and 14). The objective for performing microbial counts was to verify a methanotrophic population increase that would correlate with methane utilization. Figures 19 through 23 show the results of these counts.

\section{Results:}
A. The total bacterial counts as indicated by AODCs (Figure 19) did not indicate a change in the total number of bacteria.
B. Methanotrophic bacterial counts as indicated by DFAs (Figure 20) indicated a slight increase in the number of methanotrophs.
C. The methanotrophic bacterial counts as indicated by MPNs and FAs (Figures 21 through 23) were not significantly different.
D. As the methane injections progressed a shift in population densities was indicated by the MPN results (Figures 21 through 23).

\section{Conclusions:}

The MPN and FA methanotroph data from the Sanitary Landfill groundwater samples were found to be not significantly different. Data for each of three select wells sampled daily during an 8 day testing period is plotted in Figures 19 through 23. In Figure 19 the AODC counts indicated no change in the microbial population during the test period. Figure 20 indicated a slight change in methanotrophs over the test period when using the Direct Fluorescent Antibodies cultured for methanotrophs. In Figure 21 the initial counts from the FA's show no methanotrophs whereas the MPN's have substantial counts. Halfway through the sampling period though, the populations seem to coincide, indicating a possible population shift. It appears that the methanotrophs indicated by the MPN's are of a type for which we currently have no antibody, thus no FA counts were possible. However, as the injection of methane progressed, the FA targeted methanotrophs increased in population. The assumption is that the methanotrophs that corresponded with the FA's were selected in the environment and over time increased in number. In Figure 22 the variation in the results does not seem to have affected the statistical correlation of the two methods as they are still not significantly different. In Figure 23 the differences are proportional between the two methods. This difference is not unusual, and was even expected, when comparing an indirect method (MPNs) to a direct one (DFAs). 


\section{Organic Contaminants in the Vadose Zone (Experiment 2) \\ Objective(s):}

Gas samples from both shallow and deep monitoring locations in the vadose zone for wells 2,4 , 7 , and 13 were regularly collected in Tedlar $\circledast$ bags and analyzed for organic contaminants. The objective of the analyses for PCE, TCE, and DCE was to detect potential degradation and/or to account for concentration changes. The detection limits for PCE, TCE, and DCE were $10 . \mu \mathrm{g} / \mathrm{L}$, $10 \mu \mathrm{g} / \mathrm{L}$, and $80 \mu \mathrm{g} / \mathrm{L}$, respectively. The results of the analyses are in Figures 24 through 31 .

\section{Results:}

A. PCE and TCE concentrations in 4S, 7S, 7D, 13S, and 13D increased during the test period. However, the apparent increases are due to increased concentrations in one data set $(9 / 10 / 96)$, which may be due to sampling or analytical error.

B. With the exception of the 9/7/96 data point for VZP-13D, cis-DCE concentrations are below or near the detection limit.

\section{Conclusions:}

Statistically, it is difficult to suggest that the increased TCE and PCE concentrations, as indicated by the analytical data, is caused by mass transfers from the groundwater to the vadose zone. If the data are representative of gas sparging effects, then it is likely that TCE and PCE were volatilized.

\section{Organic Contaminants in the Saturated Zone (Experiment 1)}

Objective(s):

During the initial experiment in which only air and helium were injected into the sparging wells, chlorinated contaminant analyses were completed on a number of wells. For simplicity, only graphs of wells 2, 4, 7, and 13 (shallow and deep) are presented in Figures 32 through 39 . The primary objective was to investigate potential PCE, TCE, and/or DCE volatilization. In addition, potential microbial utilization of TCE and DCE under these controlled conditions was investigated. Results for PCE can be used for comparison because the aerobic environment is not favorable for dechlorination and PCE cannot be aerobically biodegraded.

\section{Results:}

A. In wells 4,7 , and 13, DCE and TCE concentration trends closely resemble the PCE concentration trends.

B. In well 2, PCE concentrations are below the detection limit, therefore, a correlation can not be made. DCE concentrations vary in well 2 , but within a relatively small range.

\section{Conclusions:}

The purpose of Experiment 1 was to establish the extent to which PCE, TCE, and DCE were stripped from the groundwater into the vadose zone. Although TCE and DCE concentrations varied within the saturated zone, they did so in a manner that was consistent with PCE levels. PCE cannot be aerobically biodegraded and is more volatile than TCE and DCE. Therefore, it is 
likely that the fluctuating concentrations are caused by analytical error and that the amount of TCE and DCE stripped into the vadose zone was insignificant.

\section{Organic Contaminants in the Saturated Zone (Experiment 2)}

Objective(s):

The first experiment established that TCE and DCE were probably not stripped from the groundwater into the vadose zone. The objective of the second experiment, with sparging of air, methane, nitrous oxide, and triethyl phosphate, was to detect/evaluate/demonstrate TCE and/or DCE microbial degradation through methanotrophic cometabolism. Again, TCE and DCE concentrations can be compared to PCE concentrations because PCE is not aerobically biodegraded by cometabolism. Results for wells $2,4,7$, and 13 (shallow and deep) are graphically displayed in Figures 40 through 48.

Results:

A. For the most part, PCE and TCE concentrations were constant at all sample locations.

B. In all wells, DCE concentrations on the third day of operations increased over the background sampling analyses. Following the third pulse, DCE concentrations decreased over the remainder of the test in all wells.

\section{Conclusions:}

The cause for the initial increased DCE concentrations on the third day of the experiment is unknown. However, following these initial increased concentrations, DCE concentrations consistently decreased over the remainder of the experiment. Constant PCE and TCE concentrations over the length of the experiment suggest that DCE was cometabolically degraded by methanotrophic bacteria, not stripped. In Section 7, it was established that the sparge system had little to no effect upon DCE concentrations within the saturated zone and that DCE was not stripped into the vadose zone.

\section{DCE Concentration Profiles (Experiment 2)}

Objective(s):

Although previous analyses (Sections 7 and 8 ) indicated that no DCE was volatilized from the groundwater to the vadose zone, DCE concentrations from both vadose zone and saturated zone sampling locations were graphed together (Figures 49 through 52). If DCE was stripped from the groundwater to the vadose zone, then decreased DCE concentrations in the groundwater would correspond to increased DCE concentrations in the vadose zone. If this correlation does not exist, then decreased DCE concentrations can be attributed to cometabolic biodegradation. 


\section{Results:}
A. In wells 2,4 , and $7, \mathrm{DCE}$ concentrations in the vadose zone either remained constant or decreased during the time when DCE concentrations in the saturated zone were decreasing.
B. The DCE concentration datum point in VZP-13D on 9/9/96 suggests that DCE concentrations in the vadose zone increased. However, this point is suspect because it does not follow the pattern of the other monitoring wells and it is difficult to conclude that one datum point represents a trend.

\section{Conclusions:}

The cis-DCE concentration profiles in wells 2, 4, and 7 suggest that DCE did not have a mass transfer from the groundwater into the vadose zone. Therefore, it is likely that the decreased DCE concentrations in the groundwater are due to cometabolic biodegradation by methanotrophic microorganisms. Results in well 13 are less conclusive. DCE concentrations in the shallow vadose zone sampling location remained below detection limits. The single datum point in VZP-13D after the third methane/air/nutrient/helium pulse shows an increased DCE concentration. This would suggest a mass transfer, but the statistical reliability of this single datum point must be questioned. 


\section{Overall Conclusions}

A preliminary experiment in which only air and helium were sparged into injection wells indicated that PCE, TCE, and DCE were not stripped from the groundwater into the vadose zone. Analytical data collected during this test confirmed the influence upon the selected wells and was used to define the Supplemental Test parameters and data collection points.

Helium, methane, nitrous oxide, and TEP injected in the vadose zone during the Supplemental Test suggested that the indigenous methanotrophic microbial population required three days to adapt to the amended surroundings. After this period, methane was utilized by the microbial population as a food and energy source. Correspondingly, cis-DCE concentrations after the third day began to decrease, a trend that lasted the length of the experiment. Since monitoring well profile data (contaminant concentrations at each depth interval for a nested well) did not indicate a contaminant mass transfer from the groundwater to the vadose zone, it is likely that cis-DCE was biodegraded through methanotrophic cometabolism. Cis-DCE would probably have continued to be degraded preferentially over TCE, due to steric effects, until concentrations became non-detectable, had the test period lasted longer.

Although the duration of the Sanitary Landfill Supplemental Test was not long enough to indicate definite injection and non-injection periods for the operation of the full-scale remediation system, the data does suggest a starting point. Given the results discussed above, an analysis (Ref. 10.4) of the full scale groundwater remediation system capabilities was performed to determine the range of operating conditions the full scale system could support during start-up and initial operations. This analysis indicated that the 560 SCFM (standard cubic foot per minute) compressor, in concert with the 12,000 cubic foot capacity natural gas trailer (both specified for the full-scale system) could adequately support the recommended start up range. This recommended range is between: a daily $(8 \mathrm{hr})$ injection period of air mixed with $4 \%$ methane, $0.07 \%$ nitrous Oxide, and $0.007 \%$ TEP once a week every other week for four (4) injection cycles; to an $8 \mathrm{hr}$ injection period of $1 \%$ methane, $0.07 \%$ nitrous Oxide, and $0.007 \%$ TEP every other day for 4 injection periods followed by a non injection period of one week repeated for 4 cycles. This range of operation supports the generation of data needed to ensure efficient and effective full-scale system operation and can be maintained by the specified fullscale system components. This range of operations will permit the collection of data such as the radius of influence, groundwater flow measurements, and contaminant monitoring, which will assist in determining the length of the non-injection period and will further refine the pulsed injection period, thus providing for the most cost effective system operation. 


\section{References}

10.1 Sanitary Landfill In-Situ Bioremediation Optimization Test Plan (U), Westinghouse Savannah River Company, SWE-ERG-94-0514; Rev. 0, 9/28/94.

10.2 Sanitary Landfill In Situ Bioremediation Optimization Test Final Report (U), Westinghouse Savannah River Company, WSRC-TR-96-0065, Rev. 1, 4/1/96.

10.3 Fluorescent Antibody Application in the Bioremediation of TCE at the Savannah River Site, WSRC-MS-96-0686 Brigmon, R.L. 1996.

10.4 Sanitary Landfill Groundwater Remediation System, Initial Operational Range for Data Collection, Westinghouse Savannah River Site, Calculation No. SRT-EST-97204, Revision 0, Denis J. Altman, 3/20/97. 


\section{FIGURE 1}

TEST SYSTEM LAYOUT

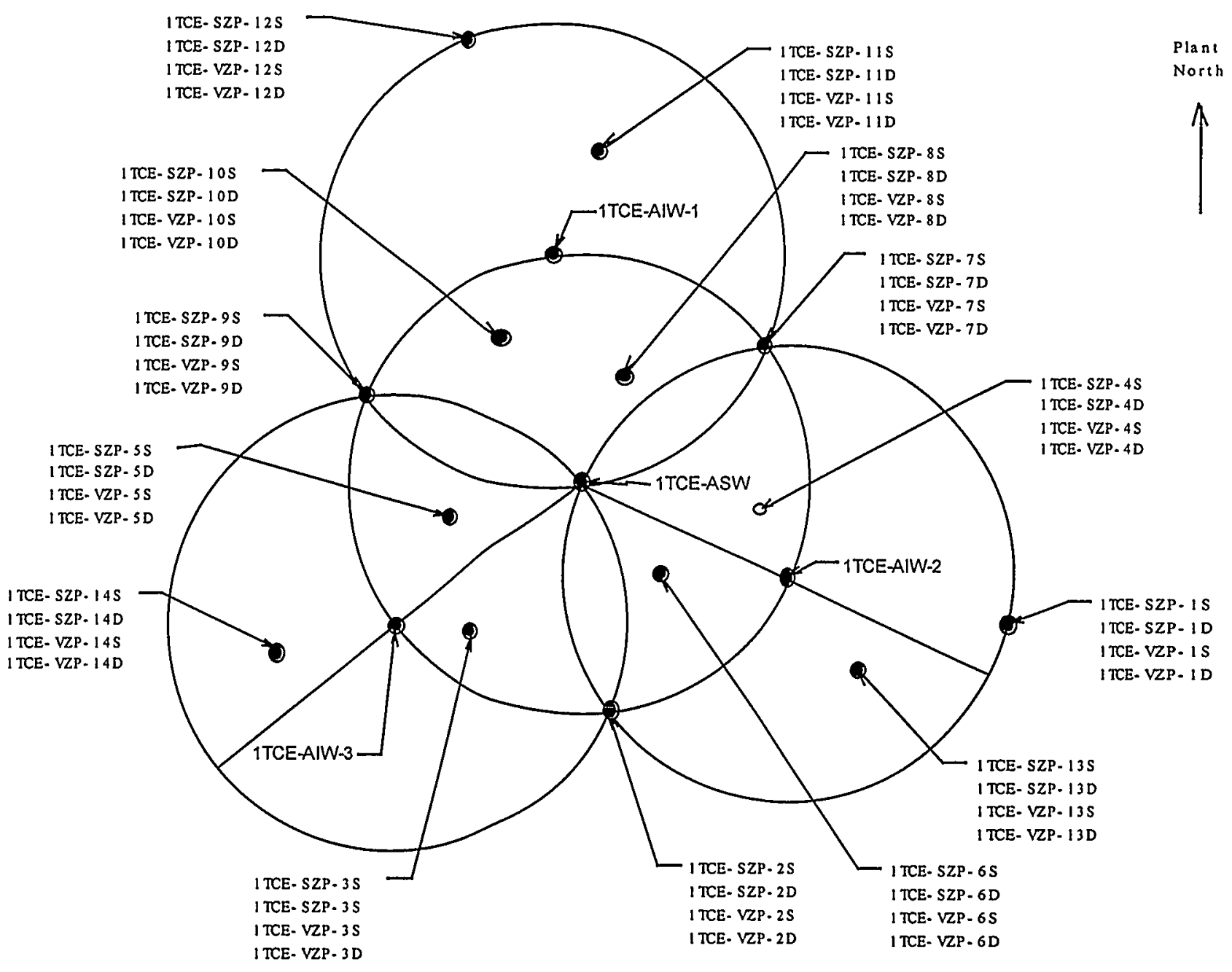




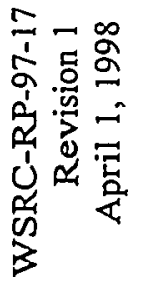

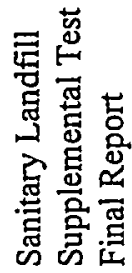

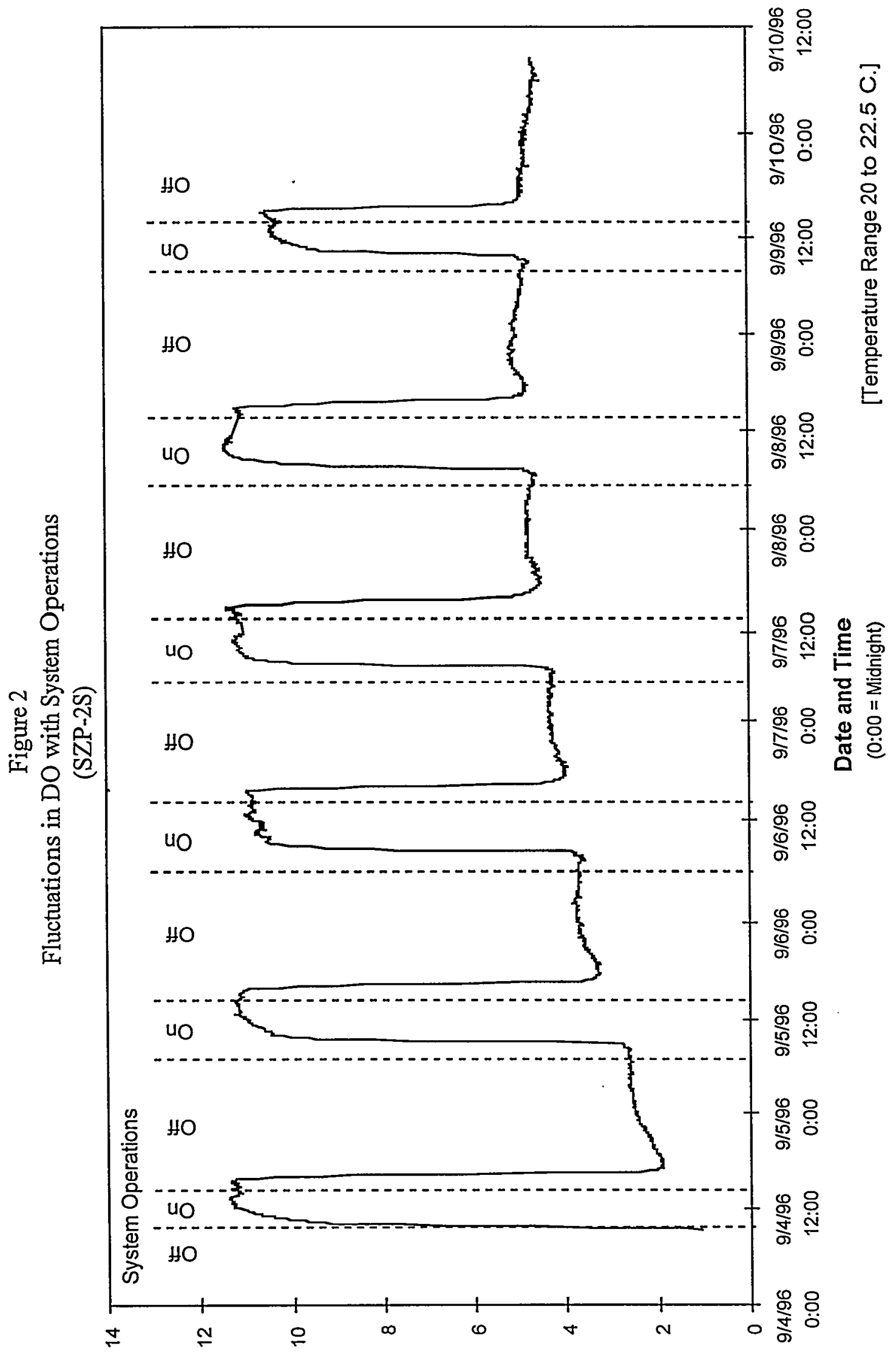




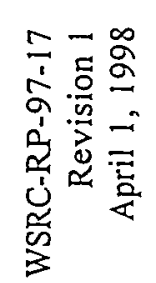

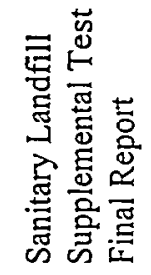

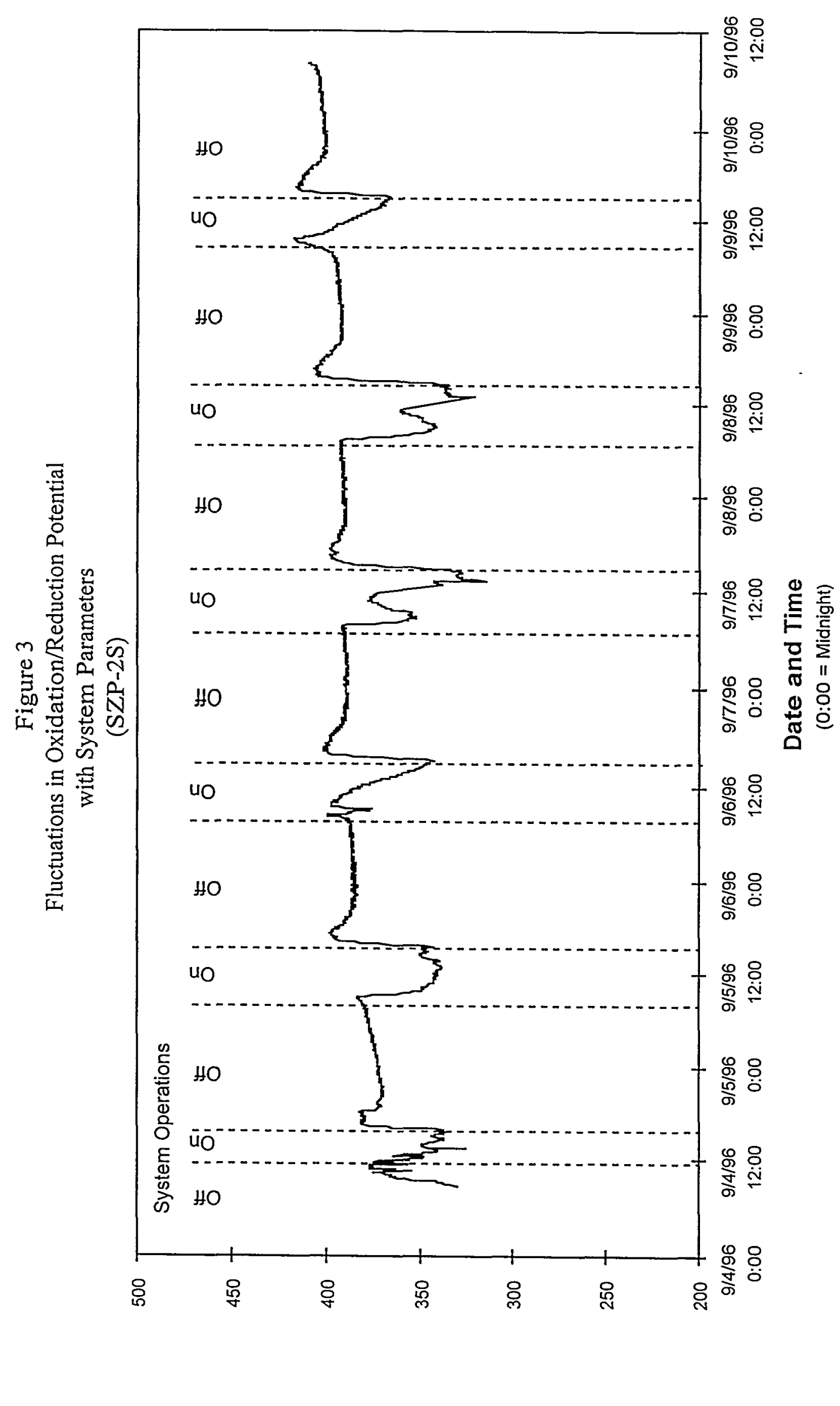


Figure 4

Fluctuations in $\mathrm{pH}$ with System Operations

(SZP-2S)

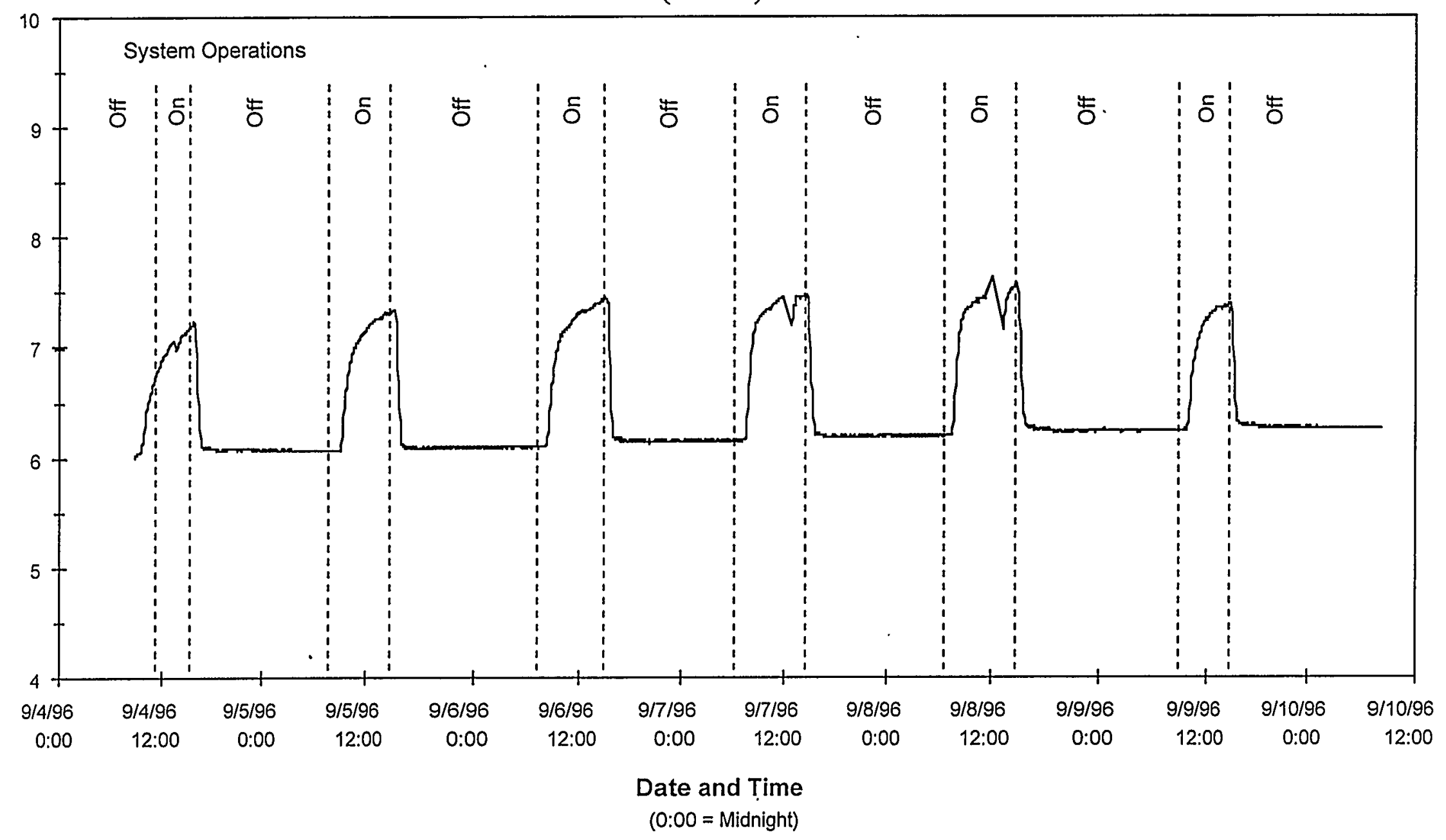


Figure 5

Gas Transport

VZP-2

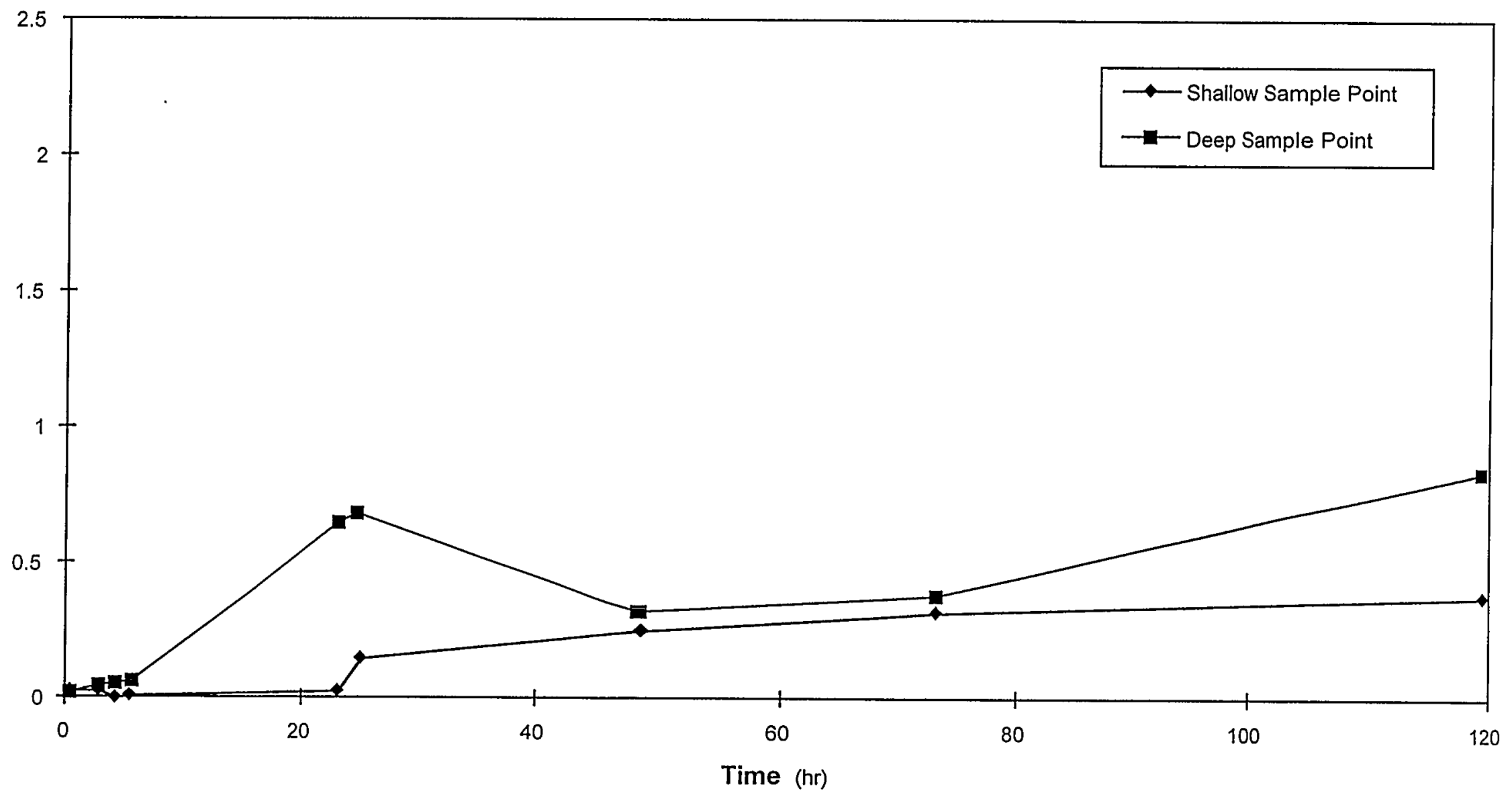


Figure 6

Gas Transport

VZP-4

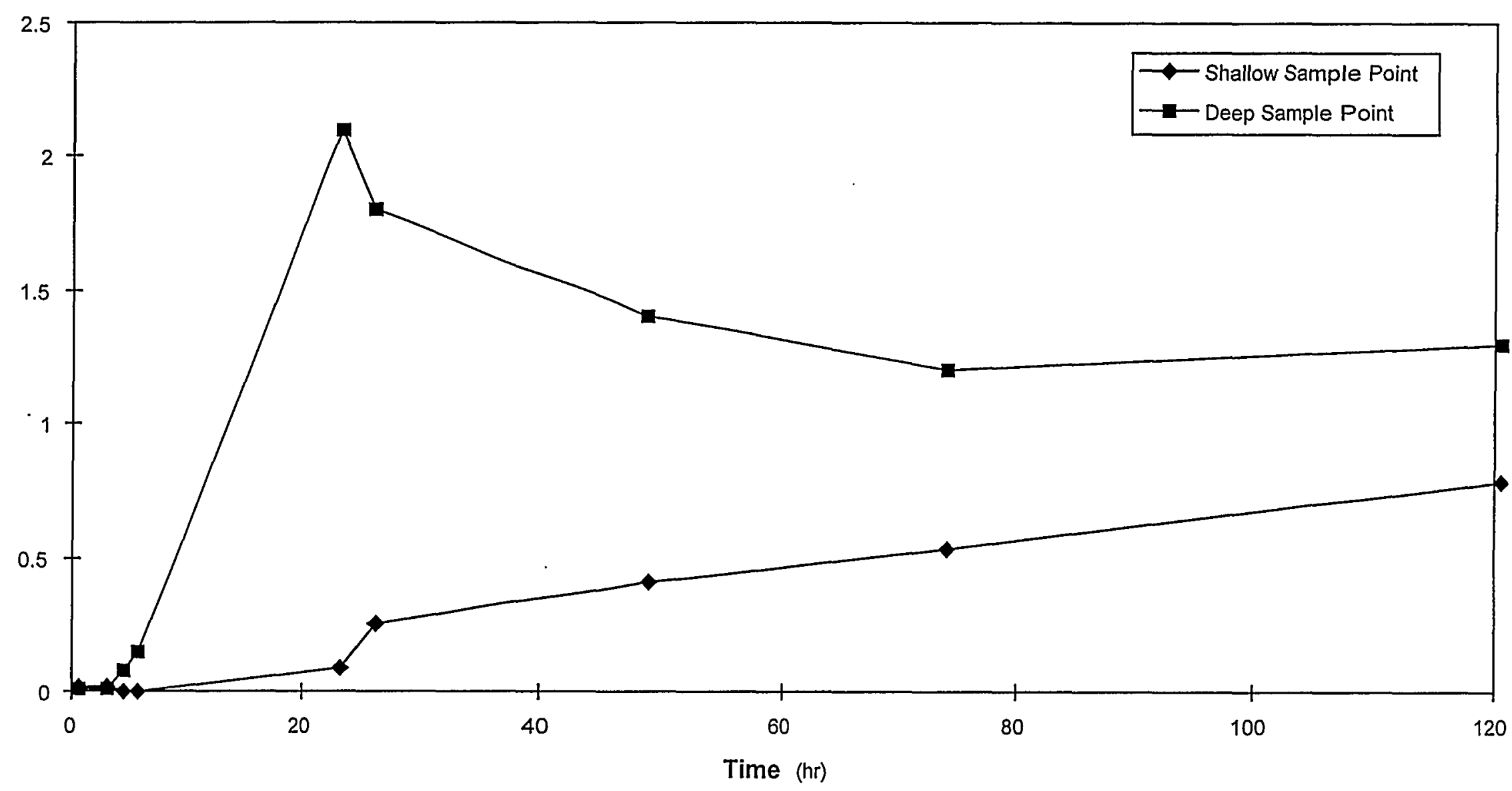


Figure 7

Gas Transport

VZP-7

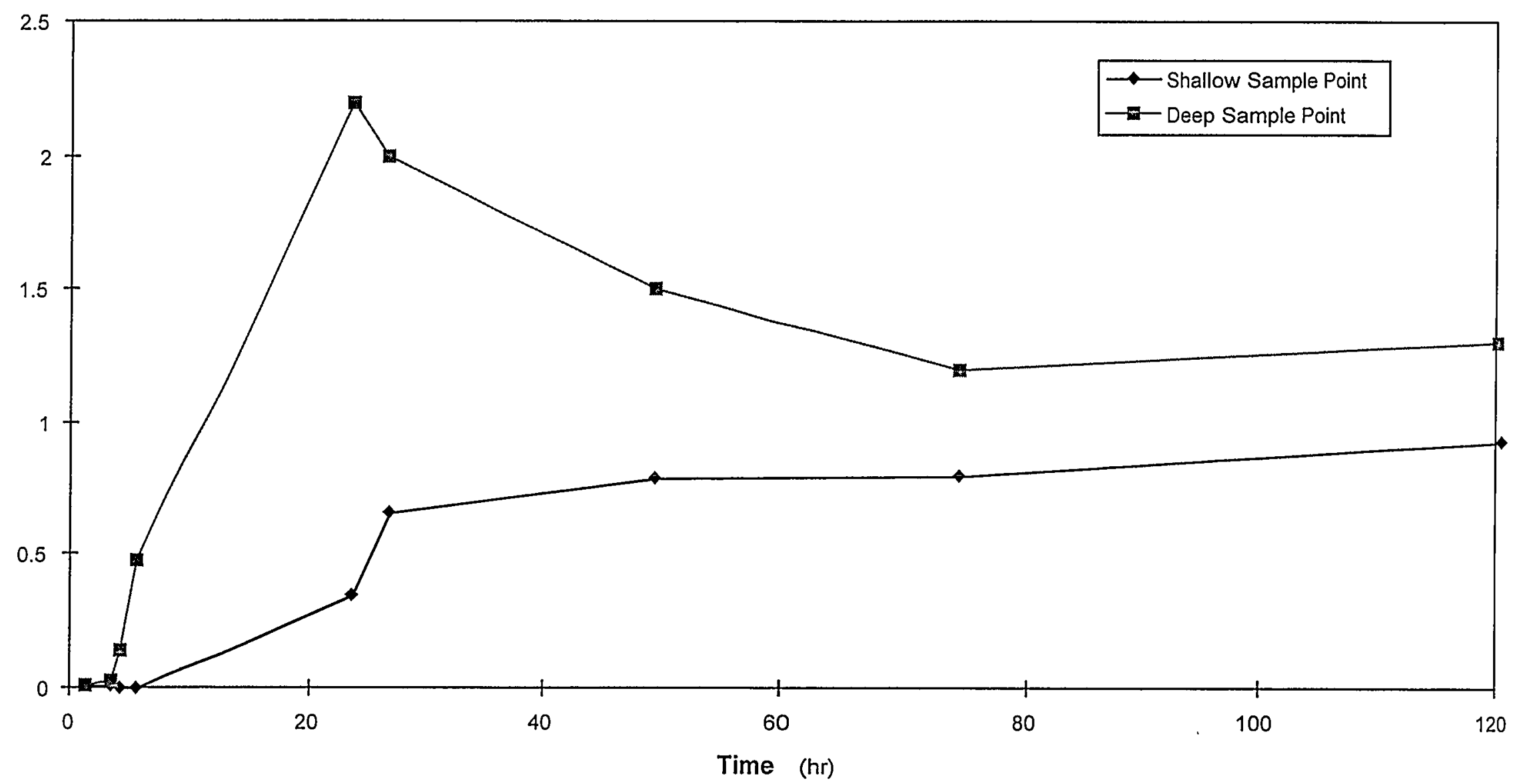


Figure 8

Gas Transport

VZP-13

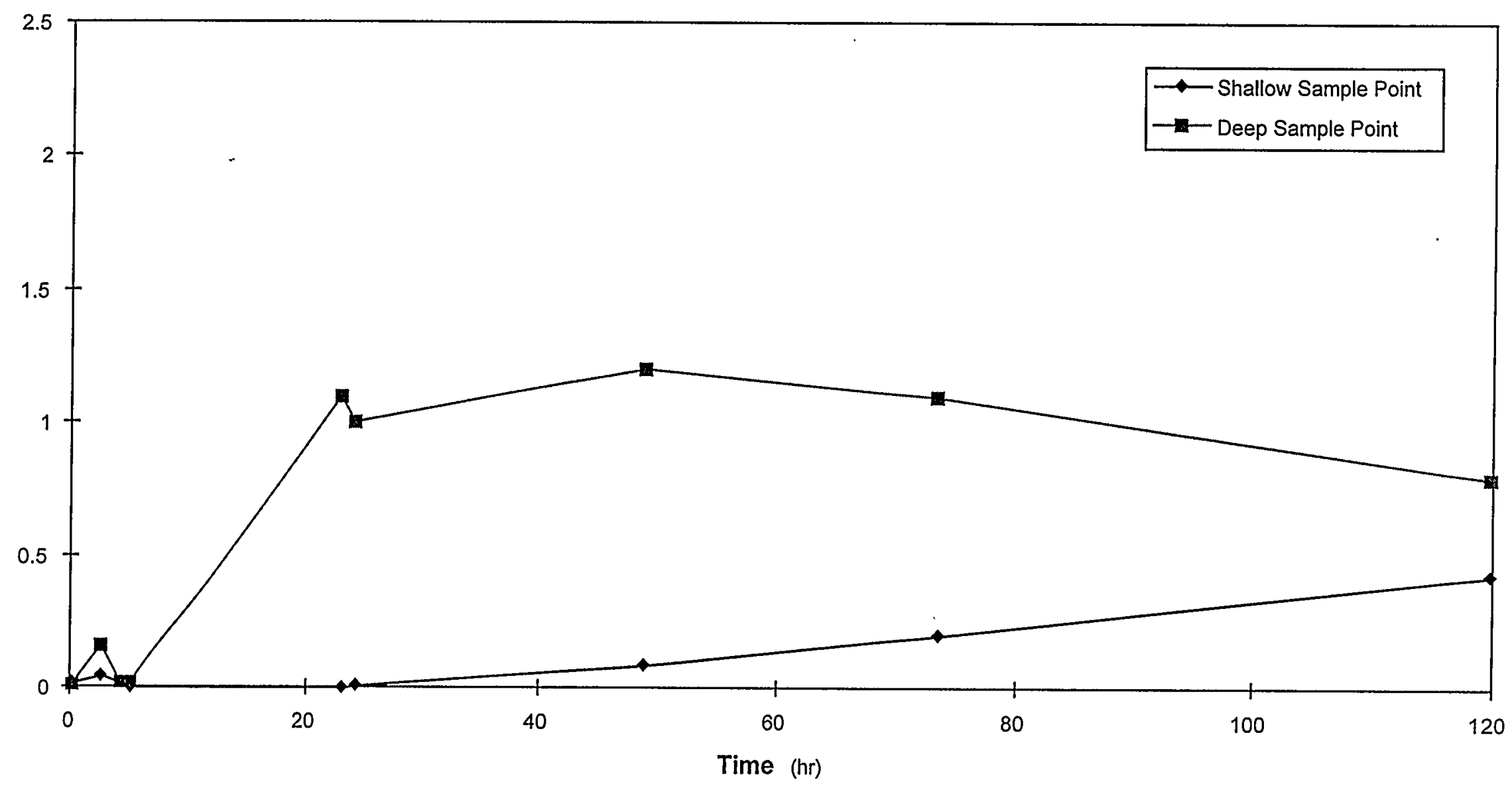



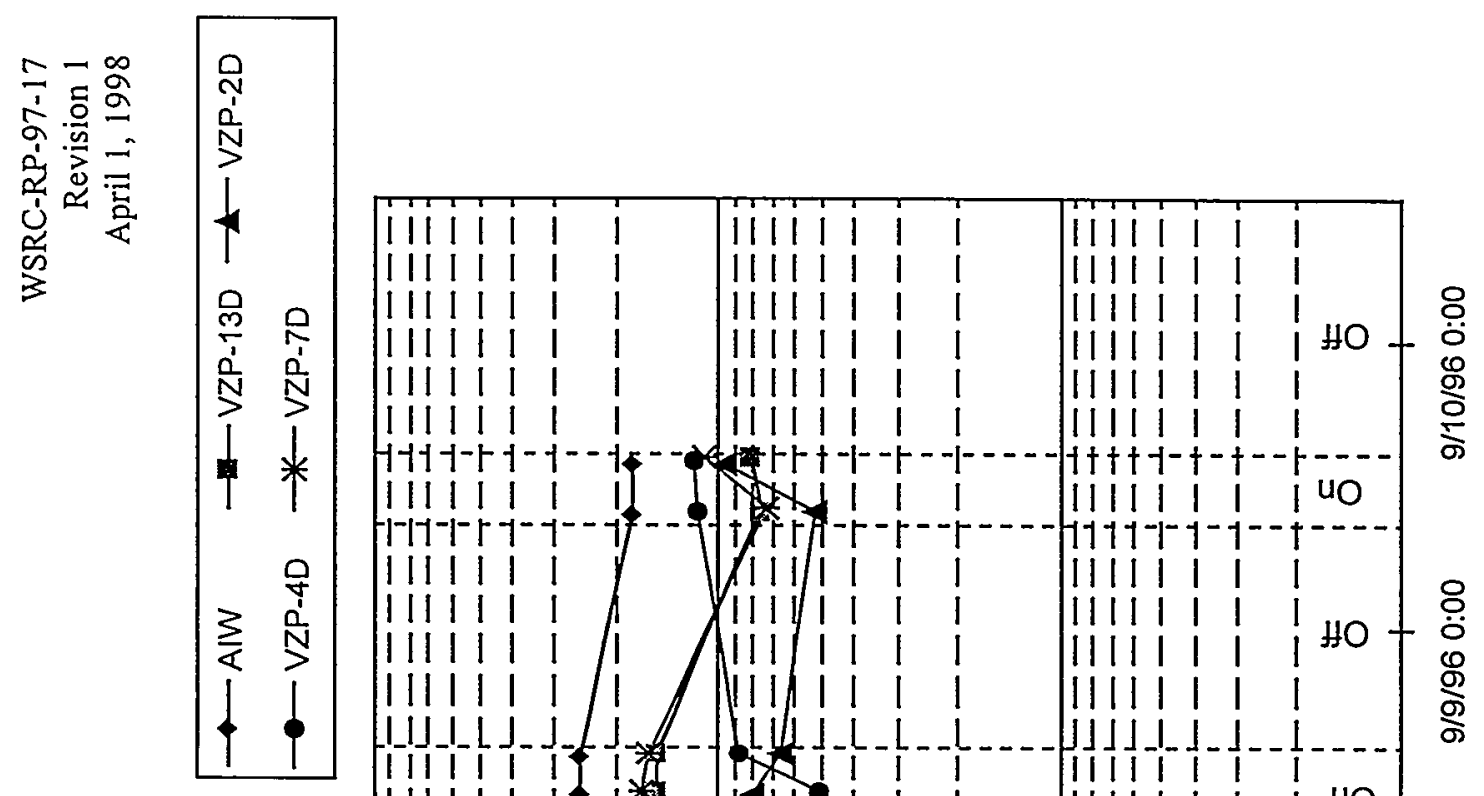

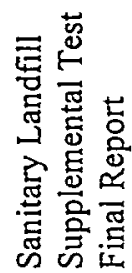

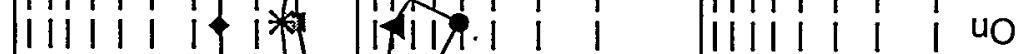

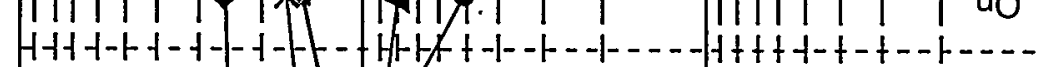

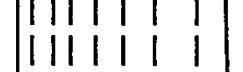

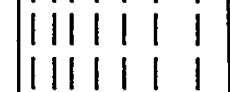

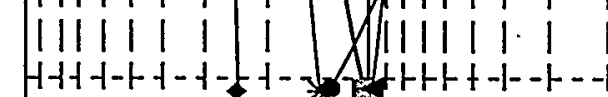

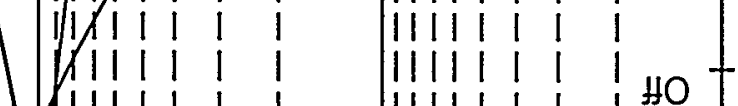

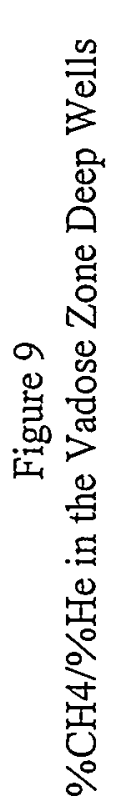
IIIIII

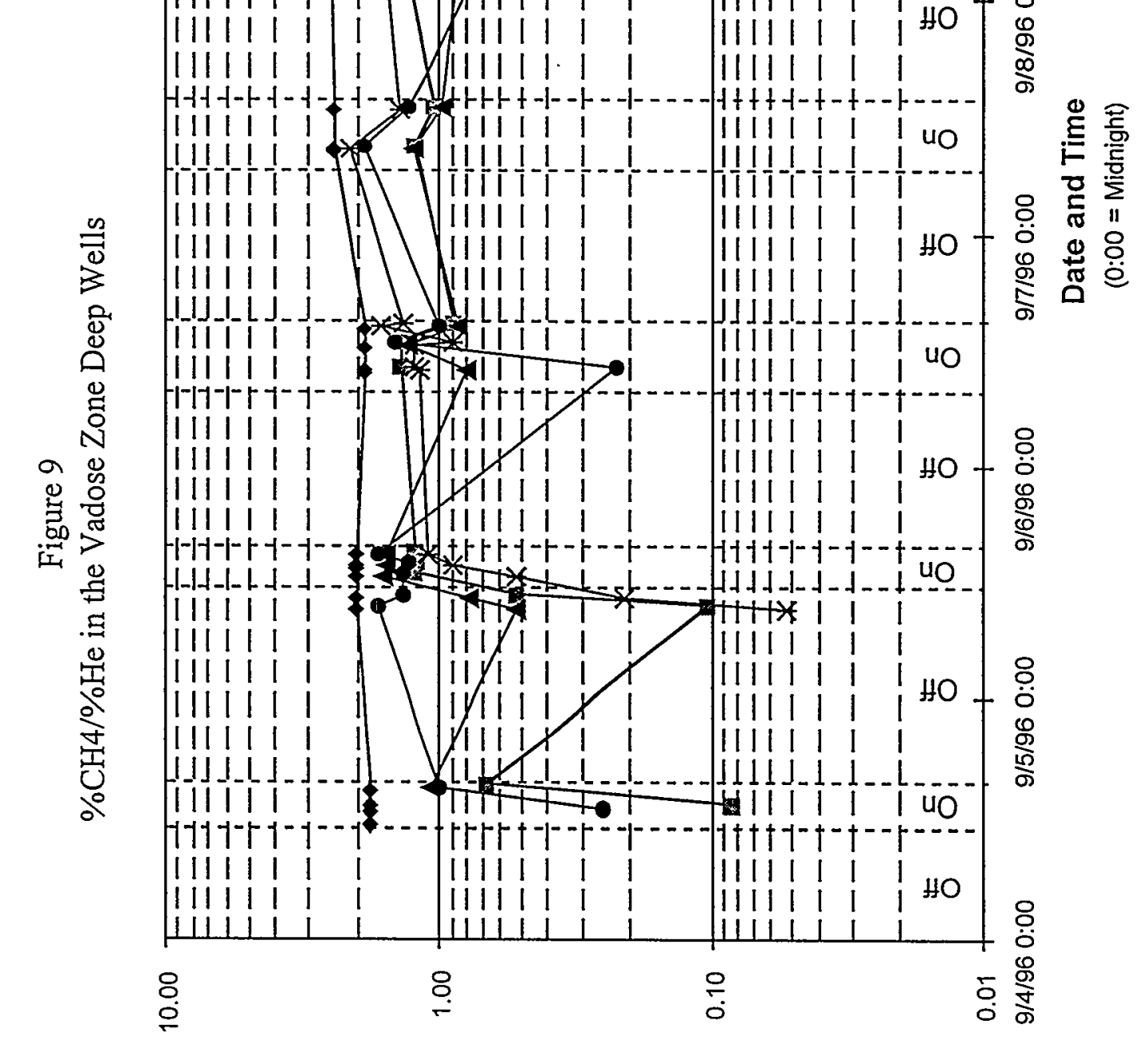




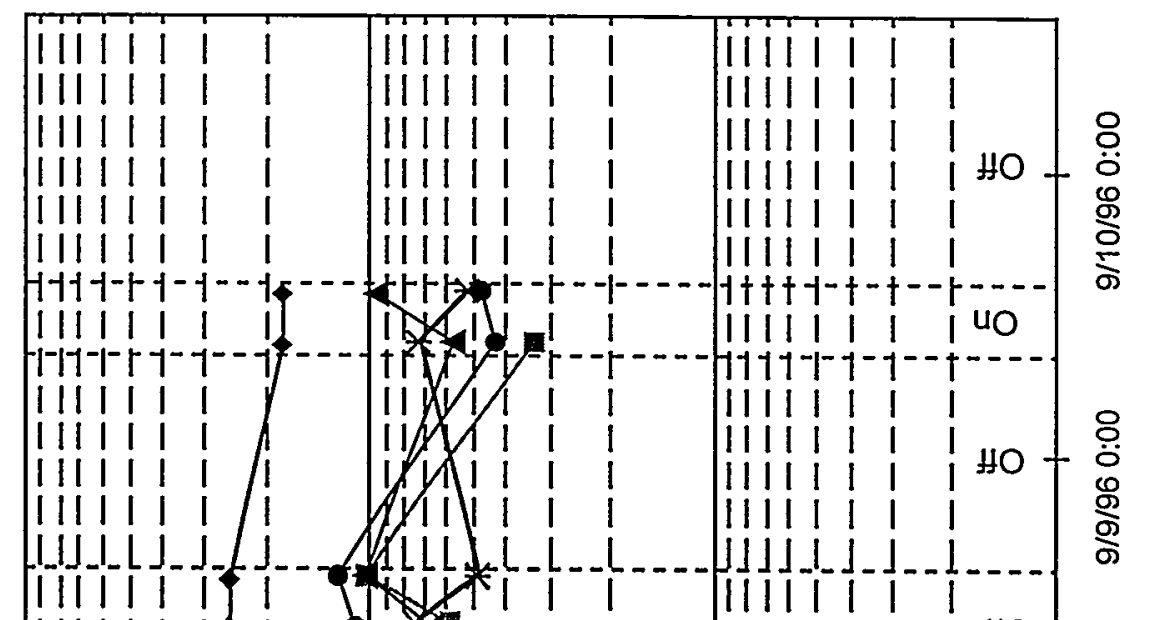

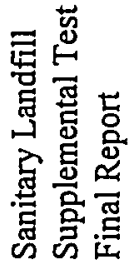
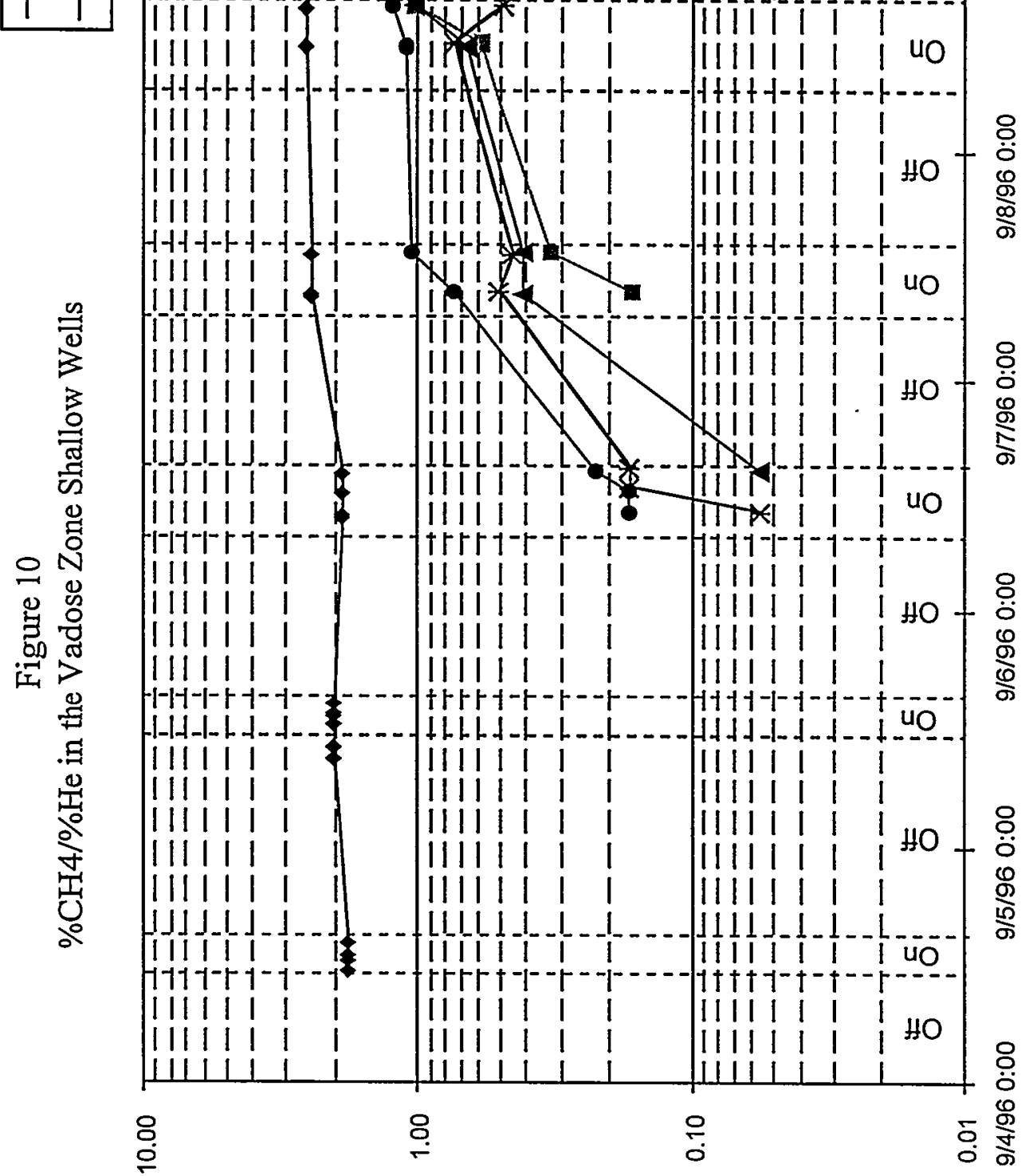


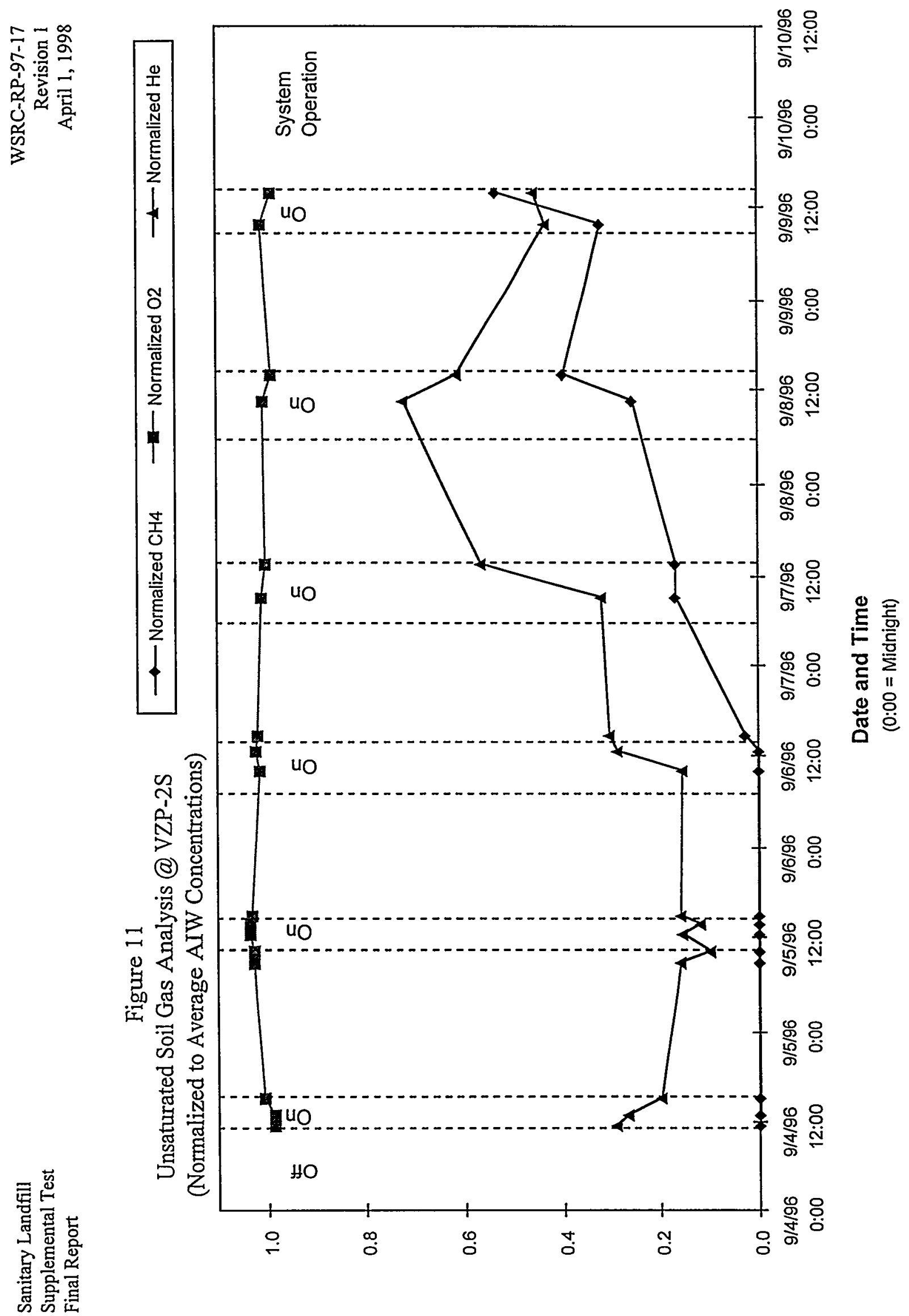


Figure 12

Unsaturated Soil Gas Analysis @ VZP-2D

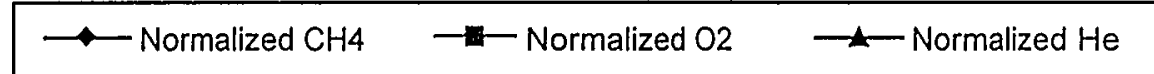

(Normalized to Average AIW Concentrations)

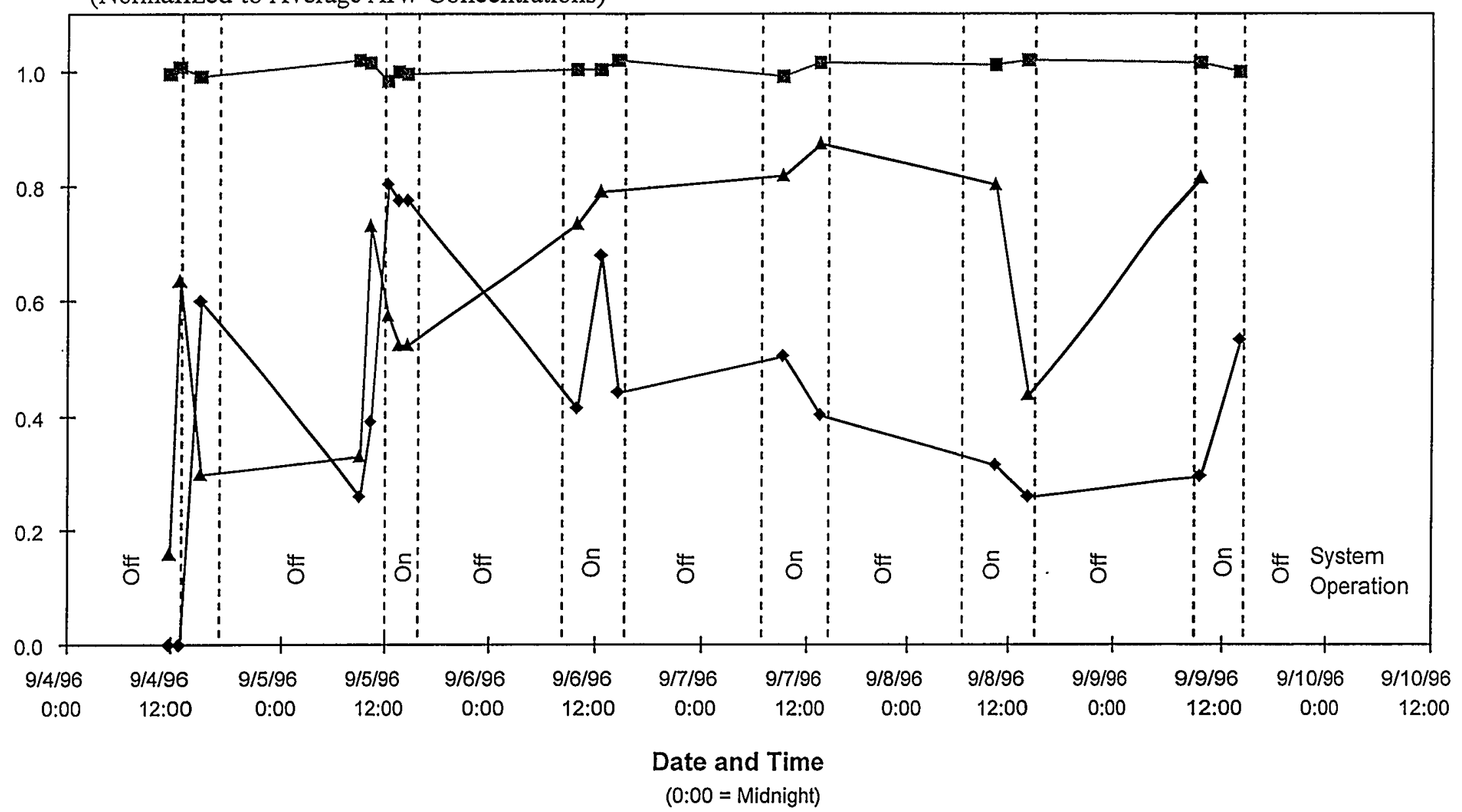


Figure 13

Unsaturated Soil Gas Analysis @ VZP-4S (Normalized to Average AIW COncentrations)

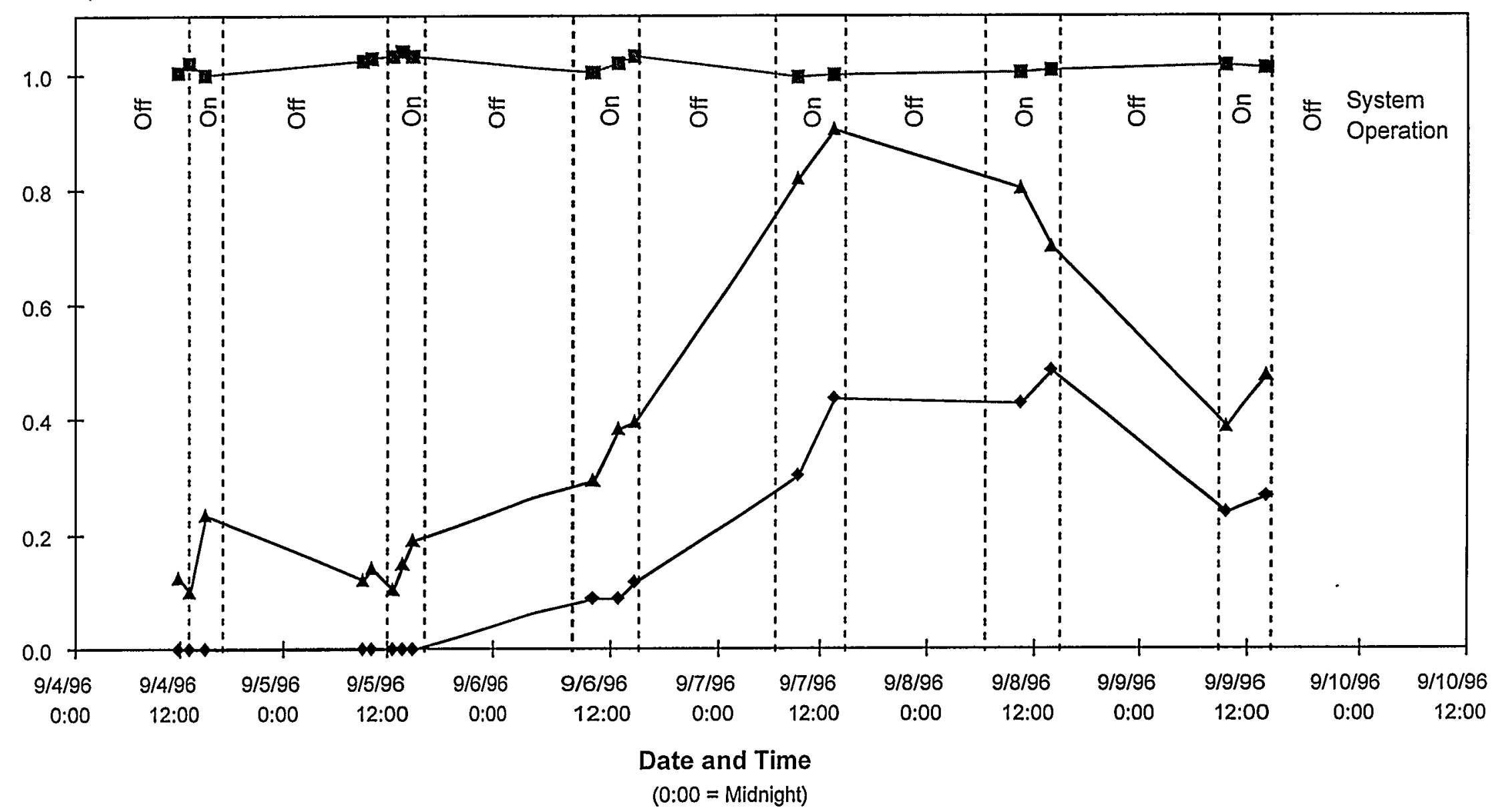




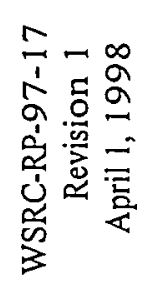

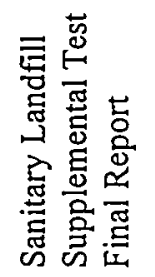

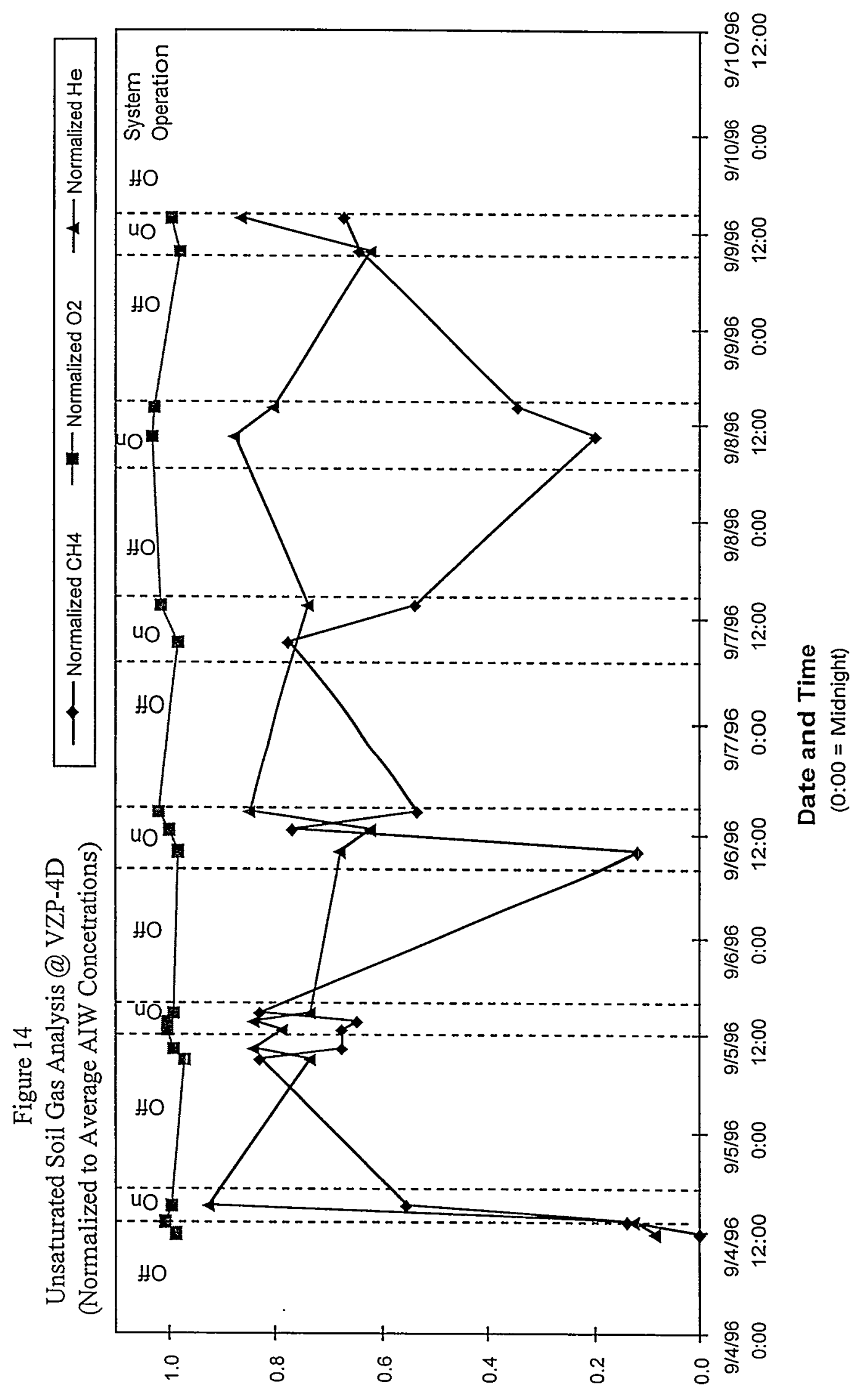


Figure 15

Unsaturated Soil Gas Analysis @ VZP-7S (Normalized to Average AIW Concentrations)

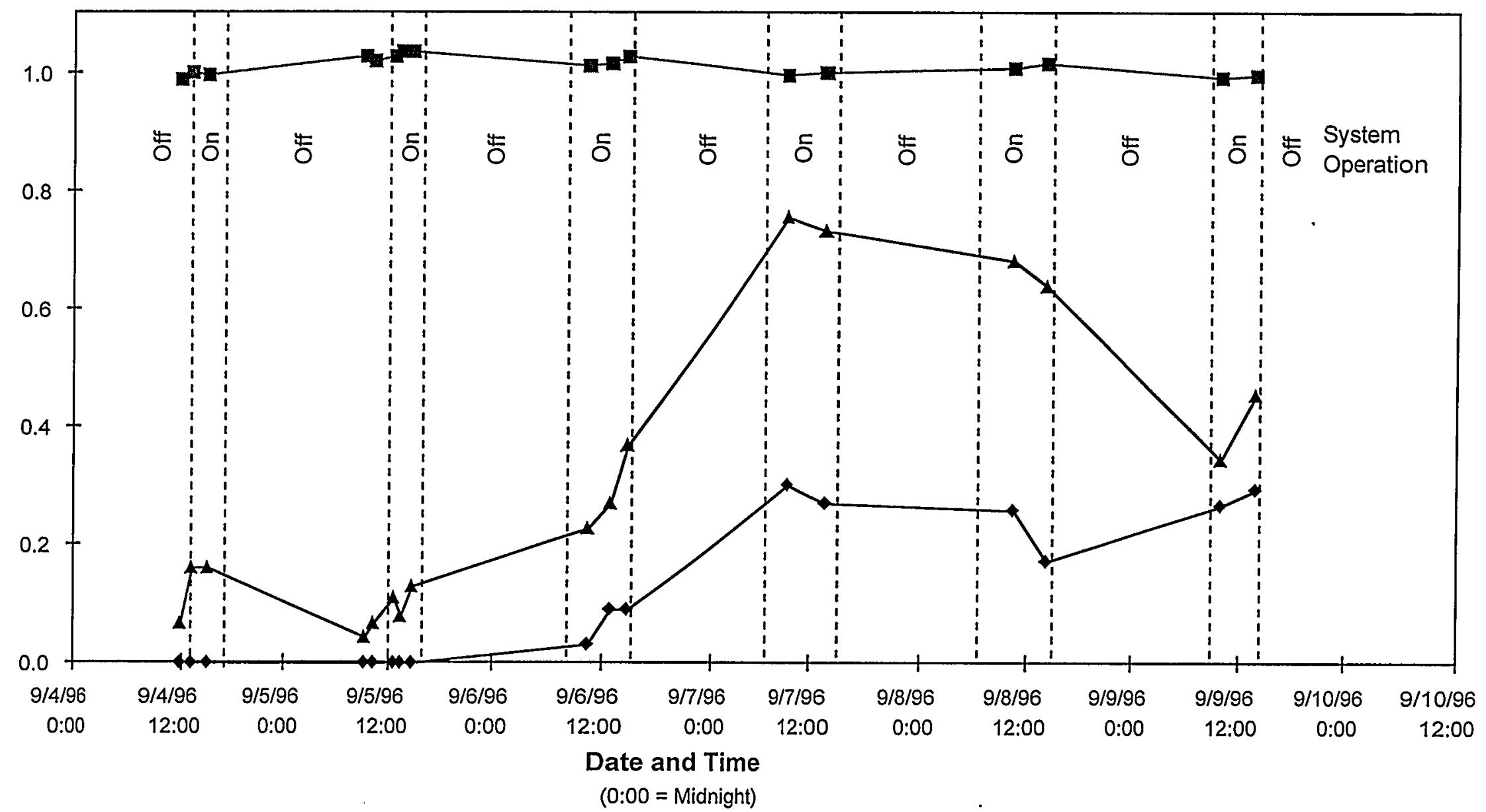



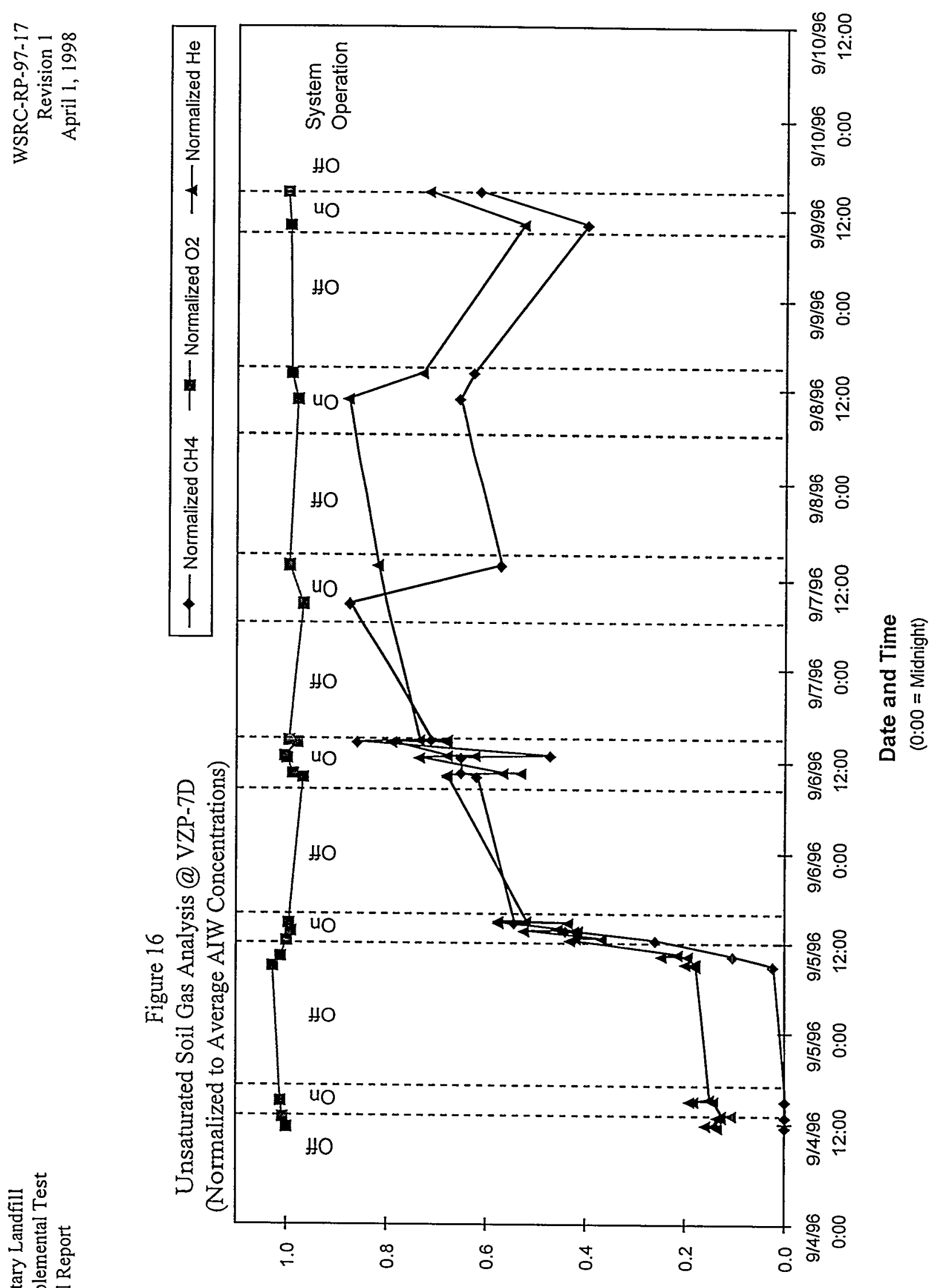

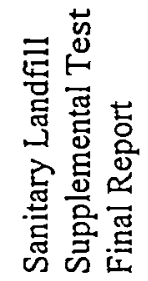


Figure 17

Unsaturated Soil Gas Analysis @ VZP-13S

(Normalized to Average AIW Concentrations)

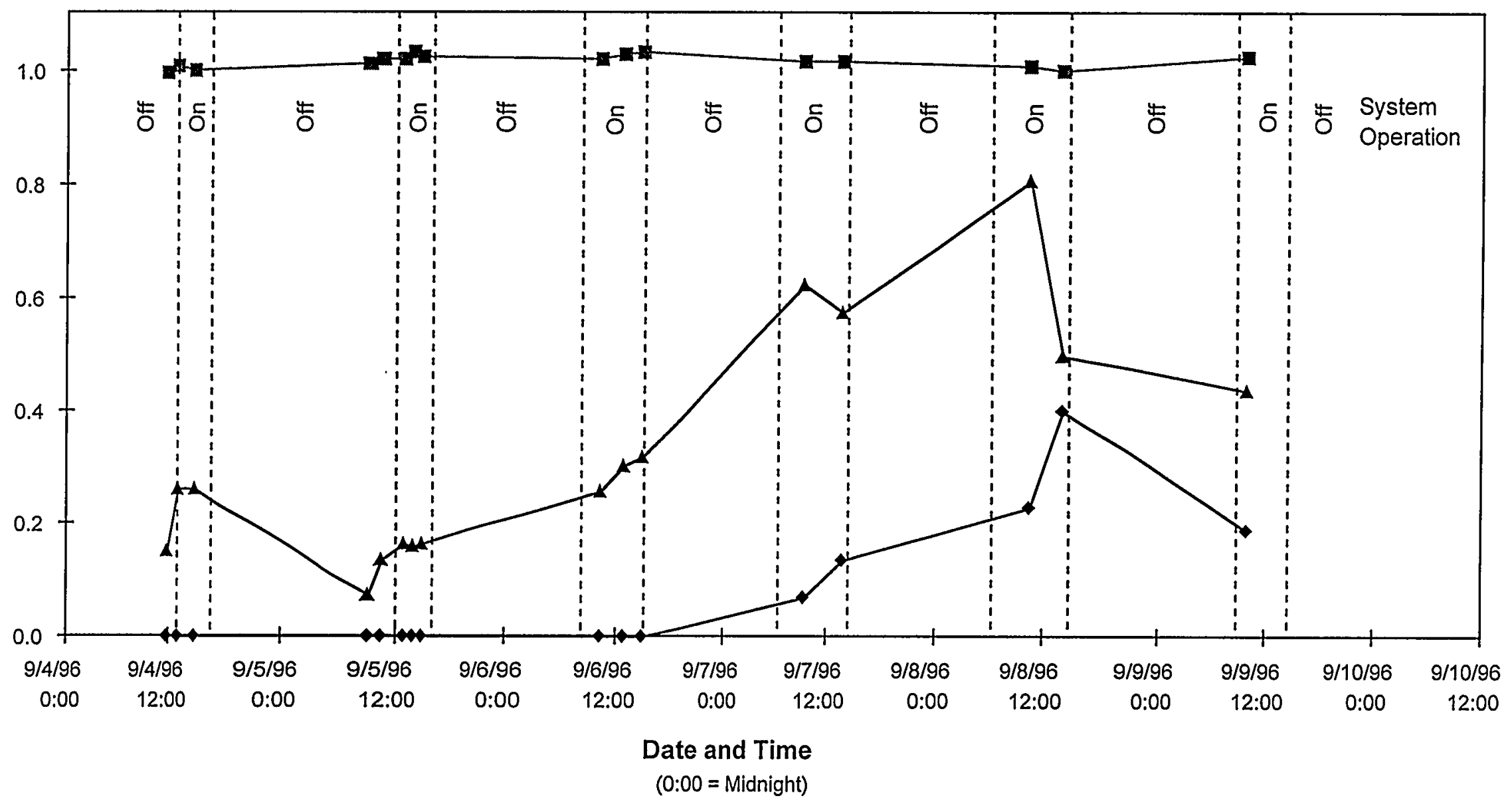



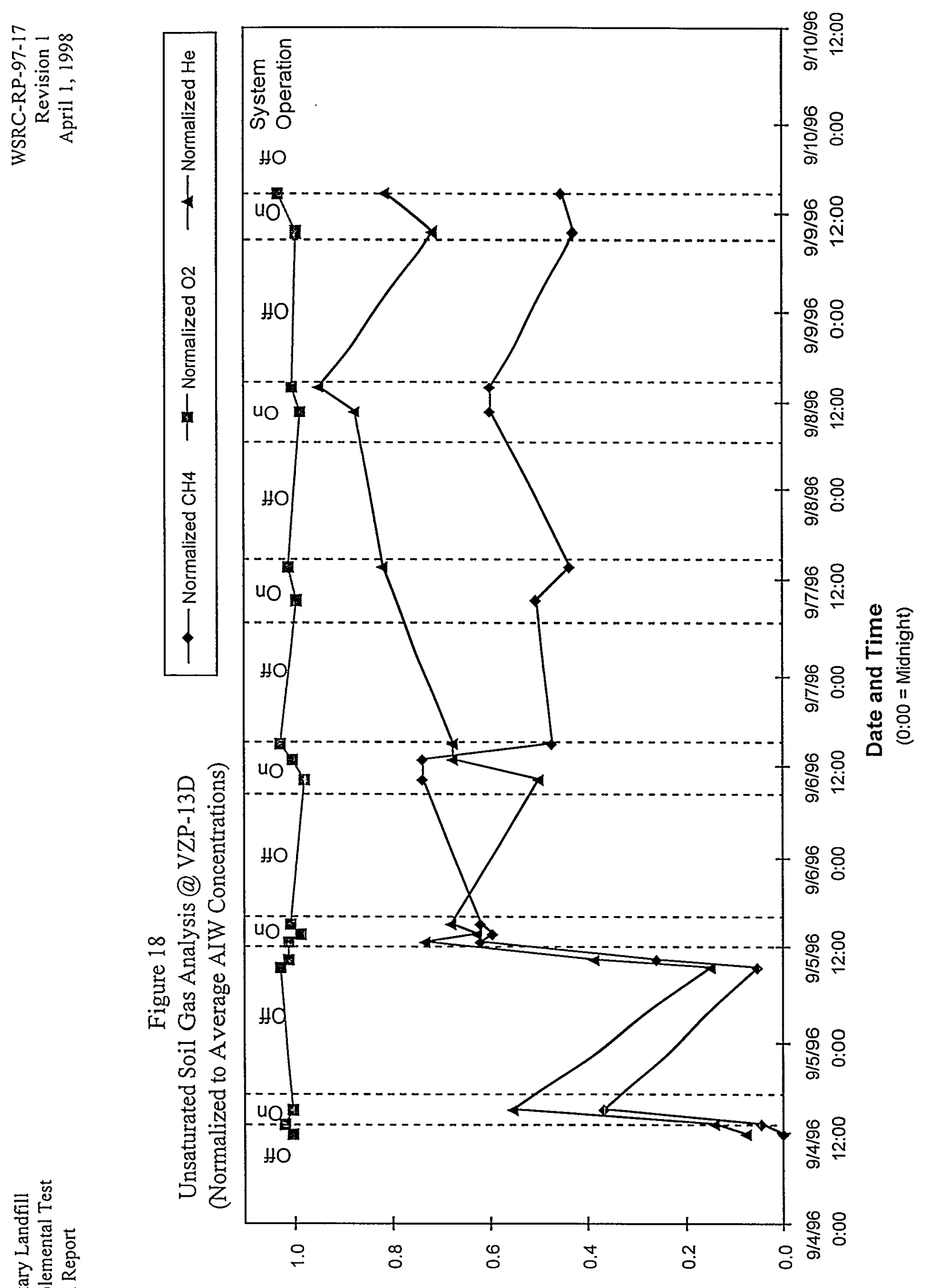

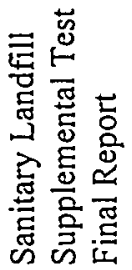


Figure 19

Total Bacterial Counts by ACRIDINE ORANGE DIRECT COUNTS

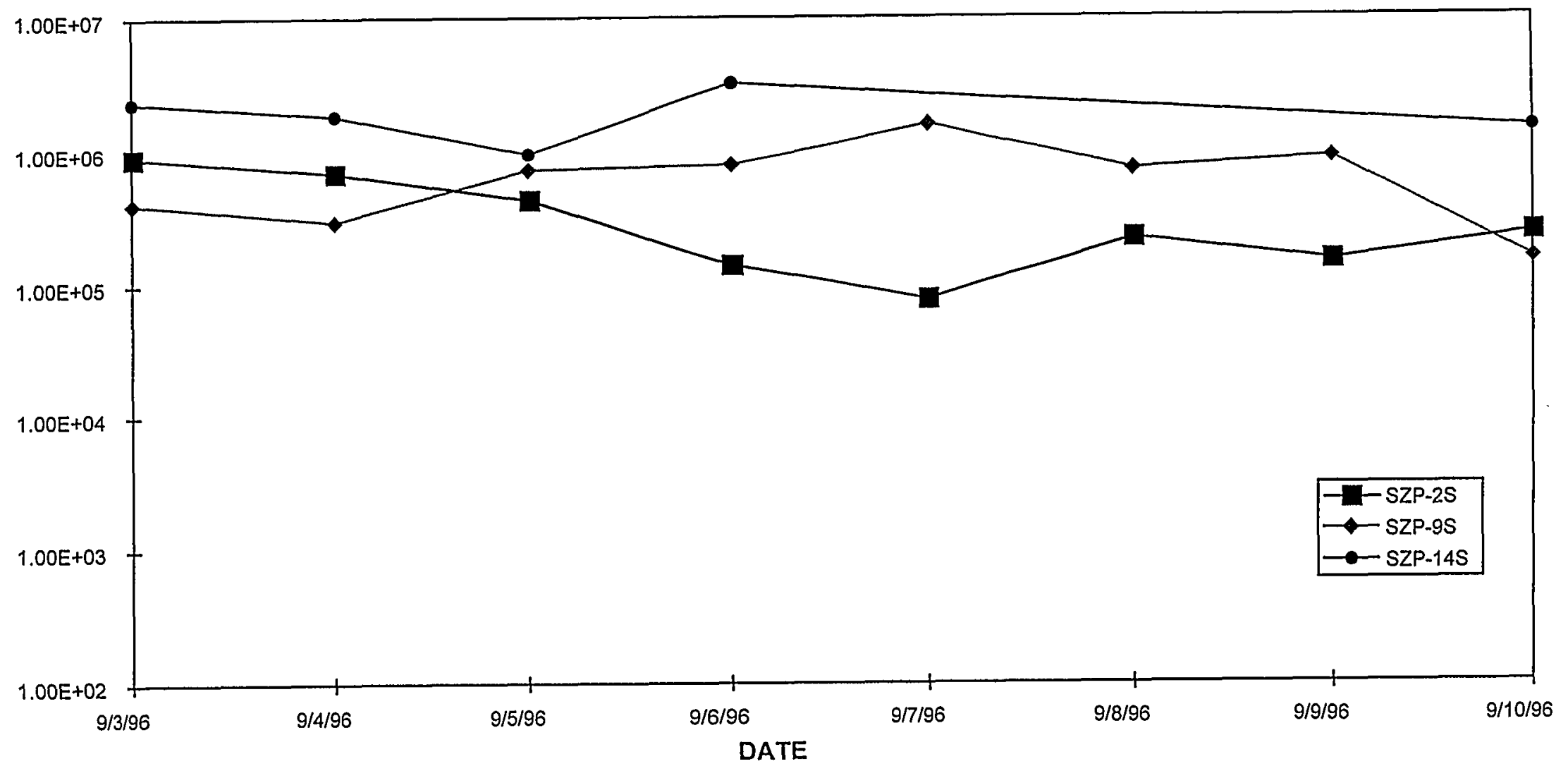


Figure 20

Total Methanotropic Bacterial Counts by METHANOTROPH FA COUNTS

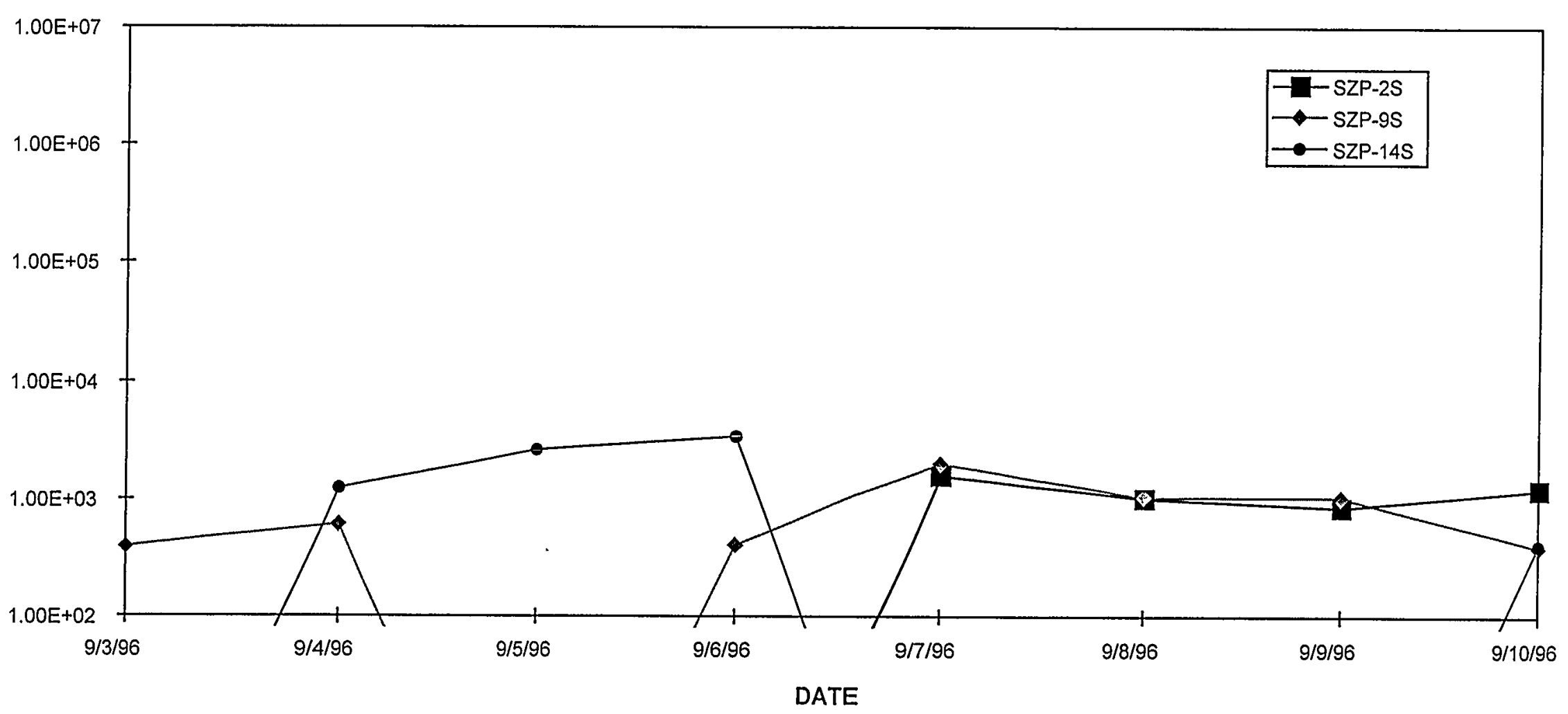



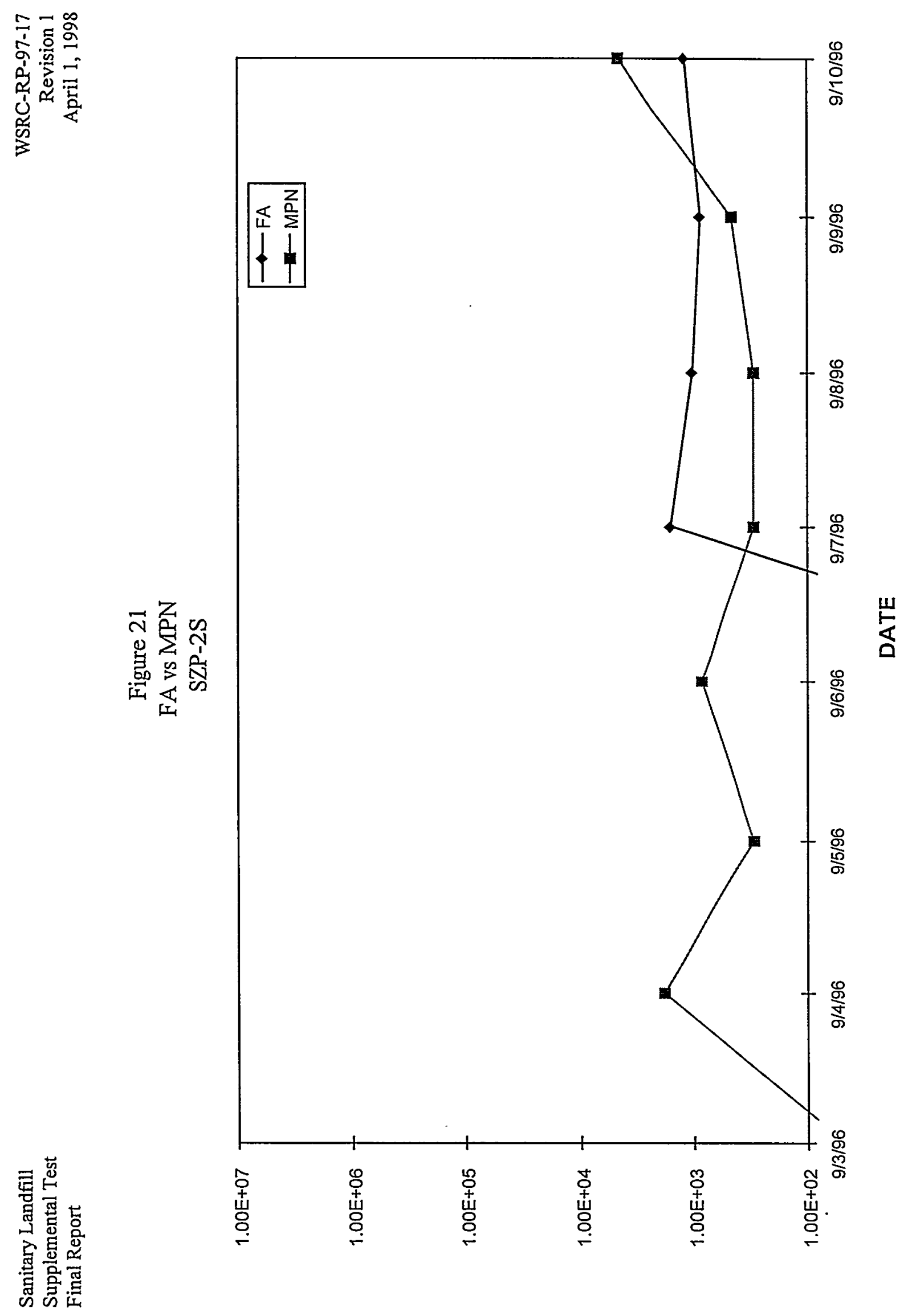

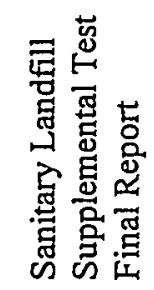


Figure 22

FA vs MPN

SZP-9S

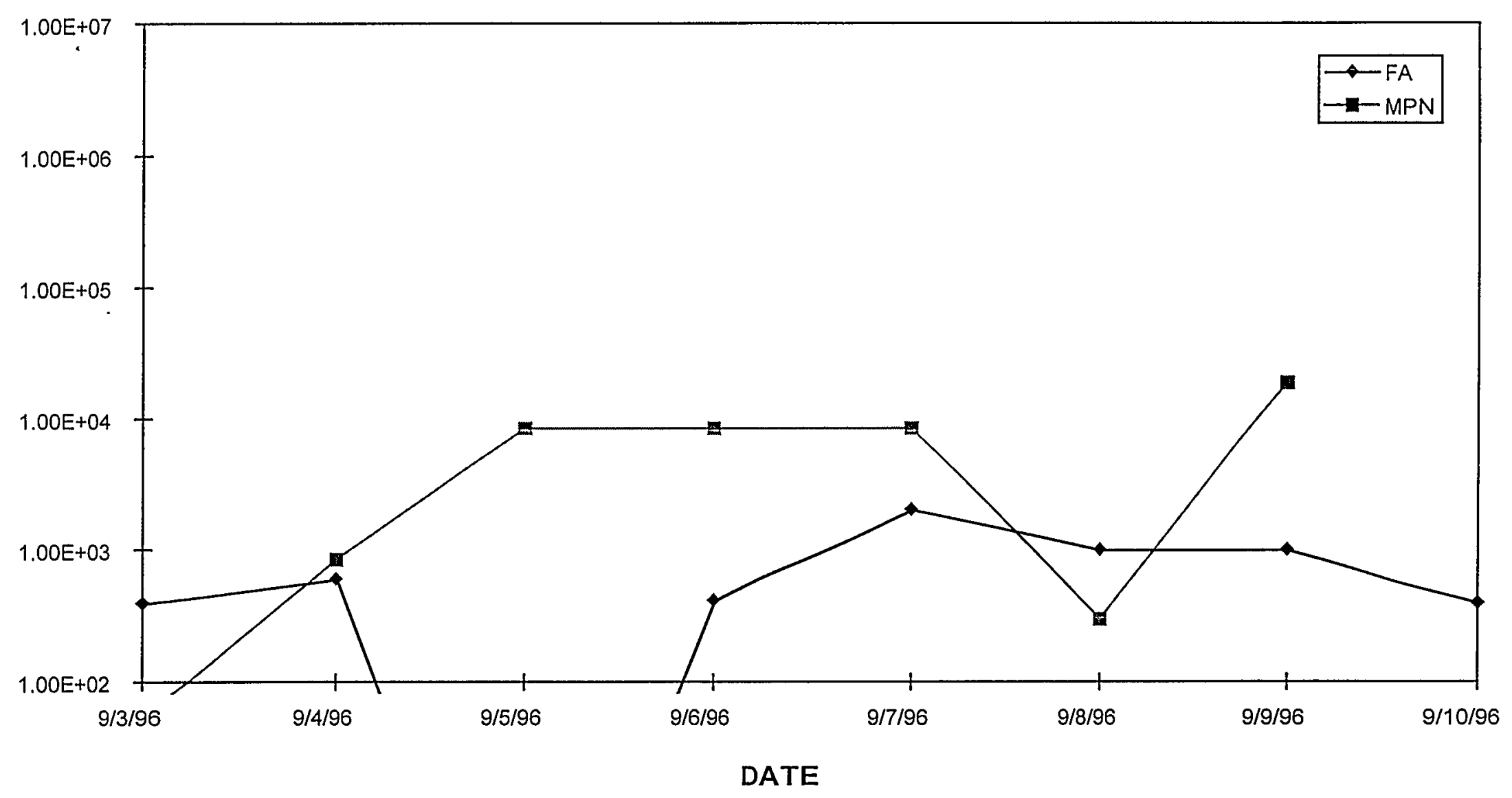


Figure 23

FA vs MPN

SZP-14S

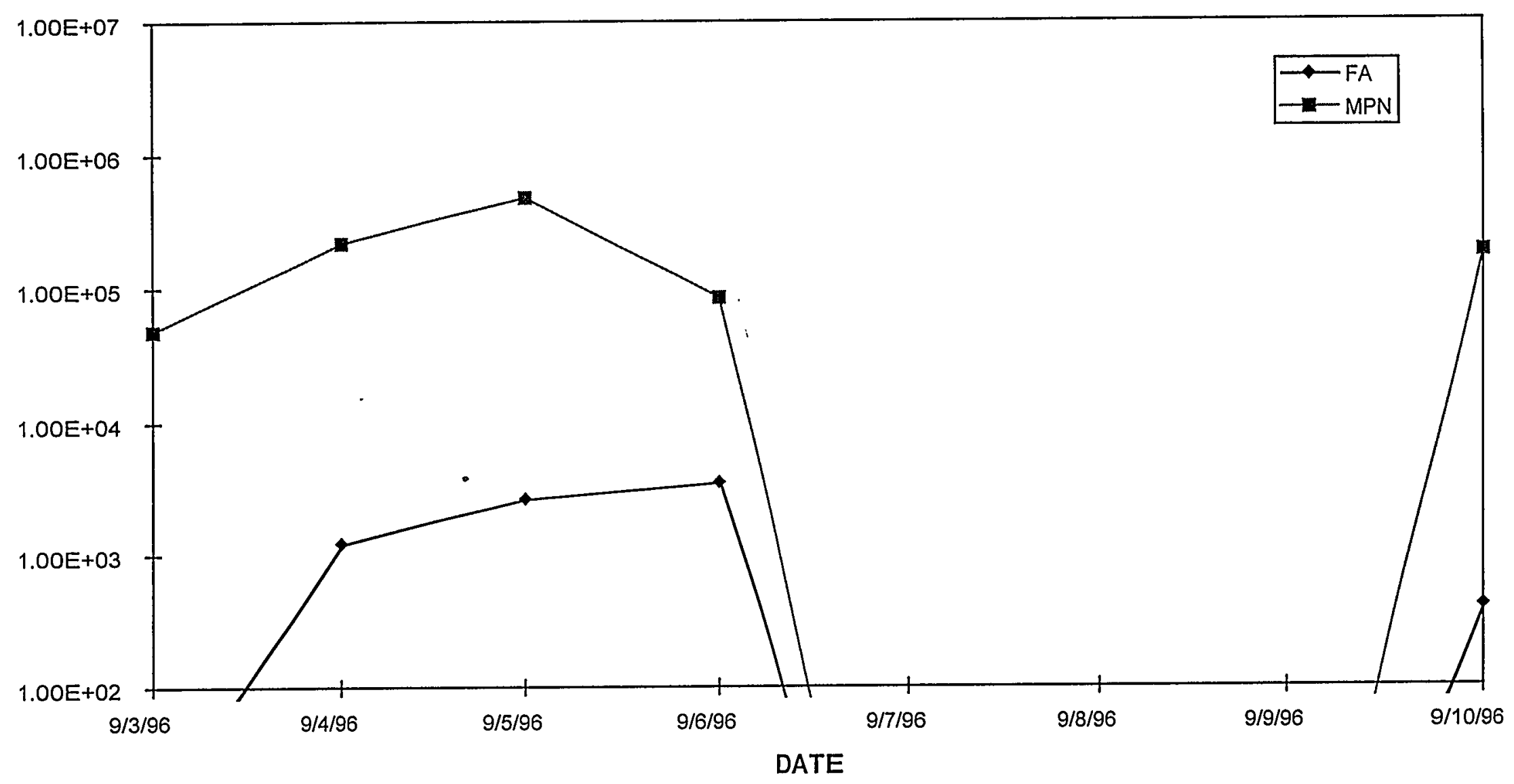


Figure 24

Organic Contaminants

VZP-2S

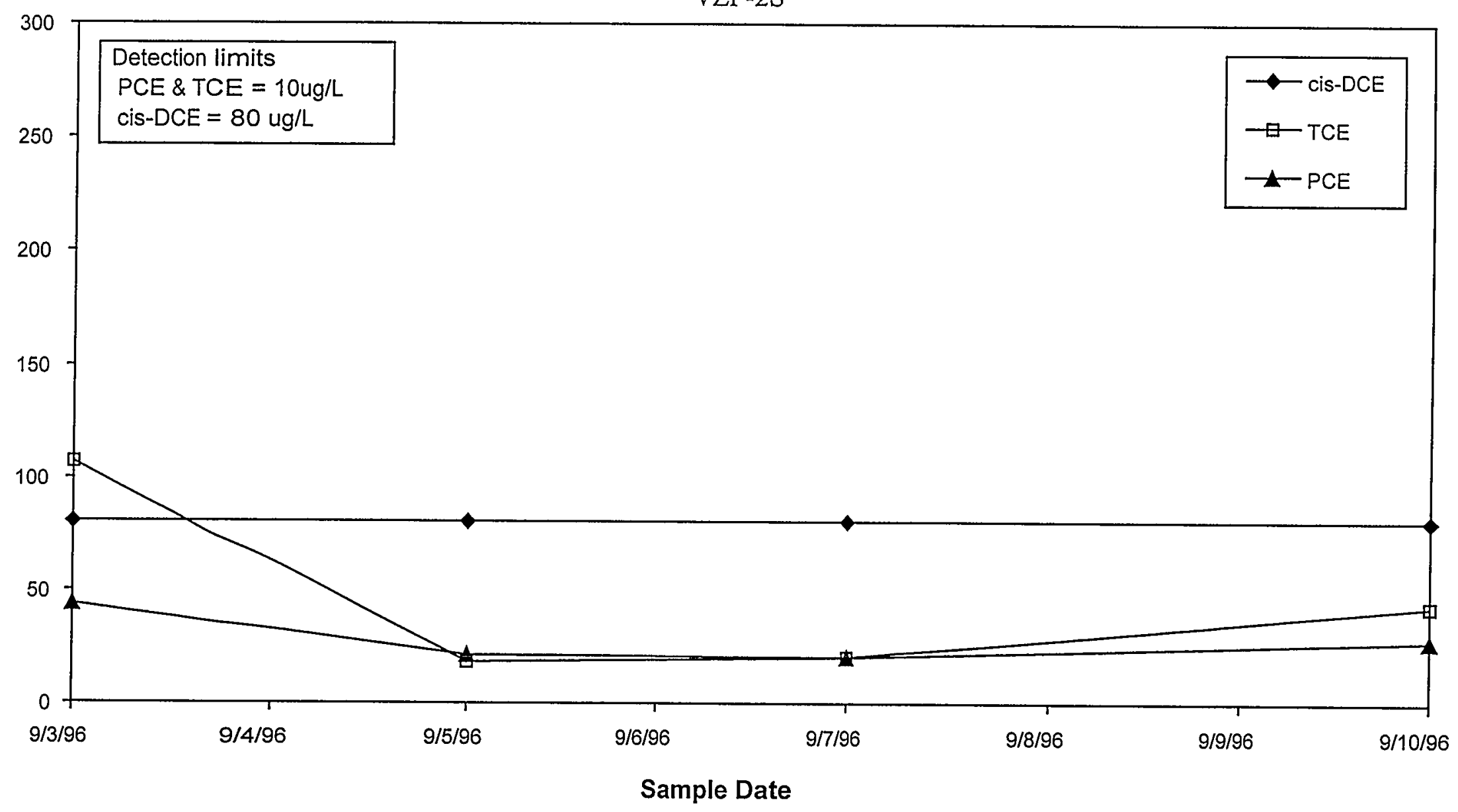


Figure 25

Organic Contaminants

VZP-2D

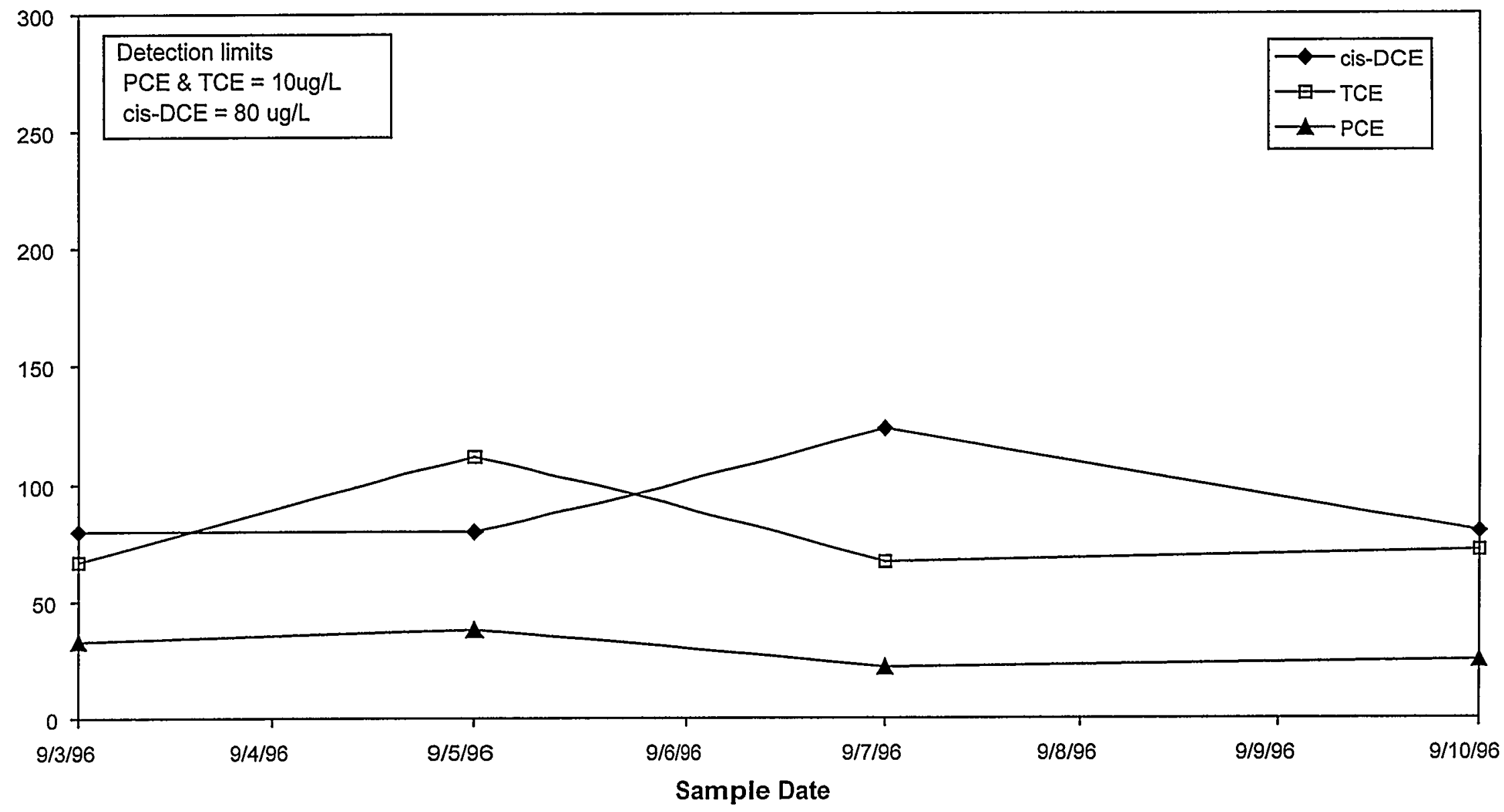


Figure 26

Organic Contaminants

VZP-4S

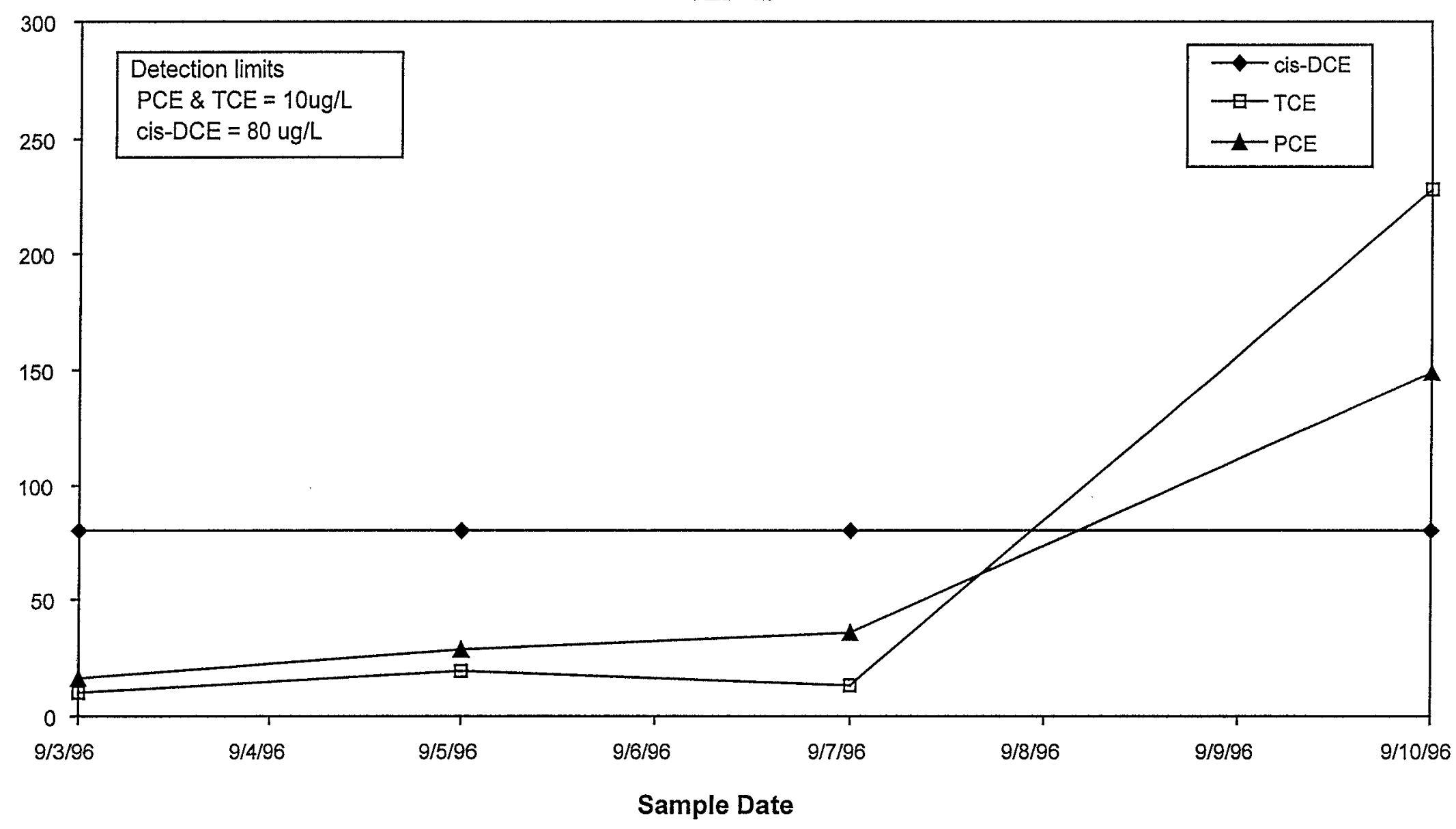


Figure 27

Organic Contaminants

VZP-4D

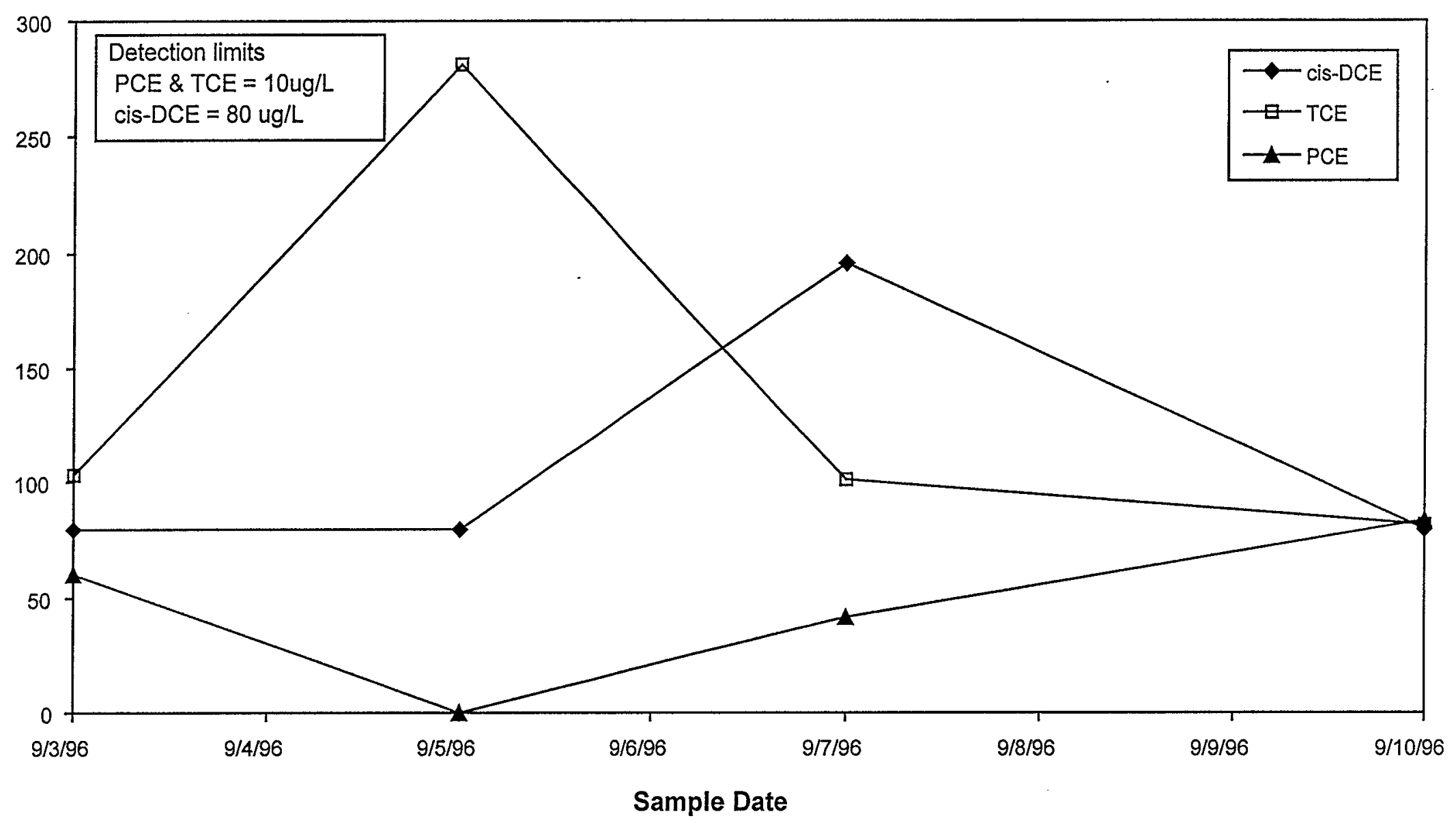


Figure 28

Organic Contaminants

VZP-7S

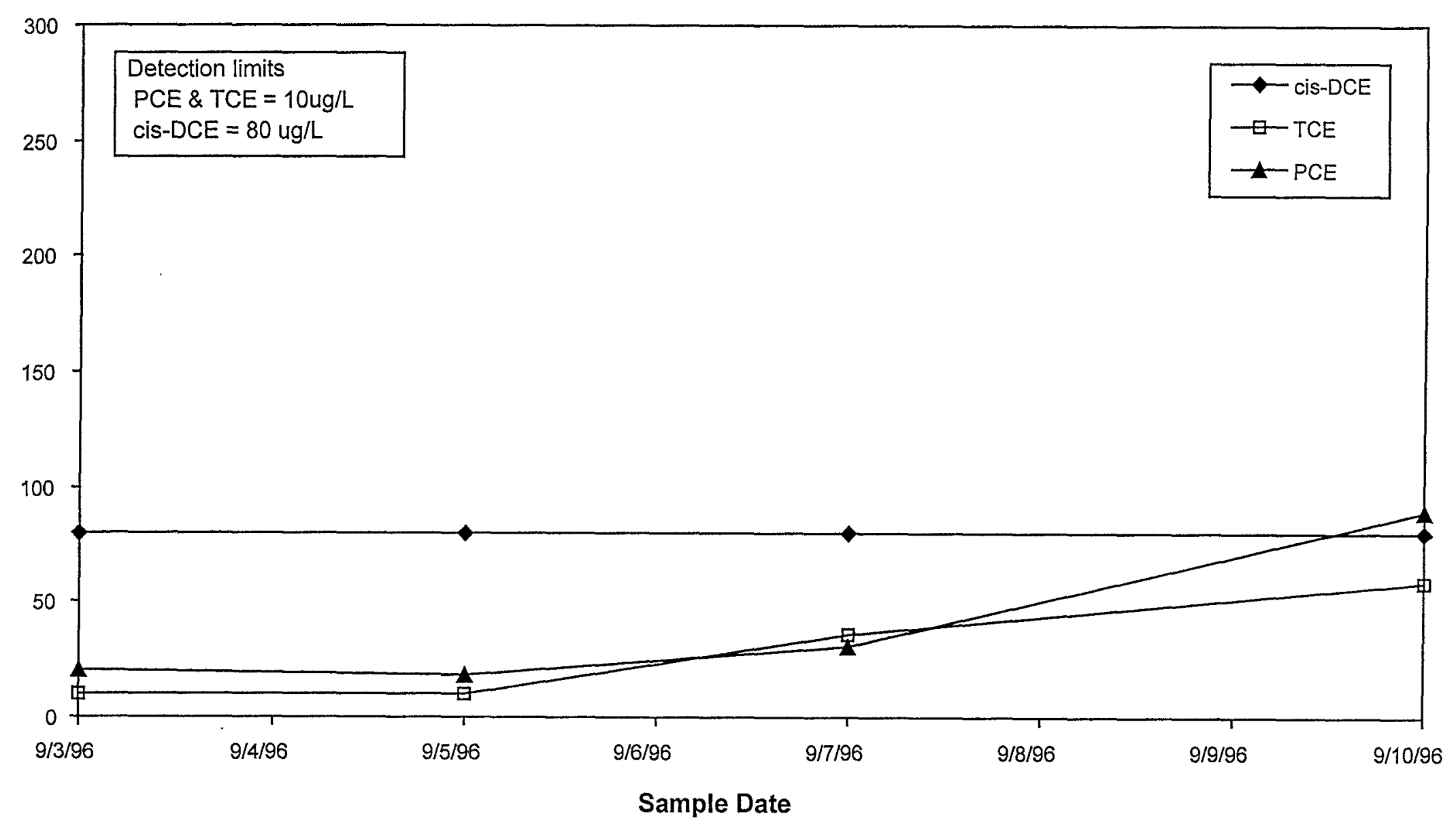


Figure 29

Organic Contaminants

VZP-7D

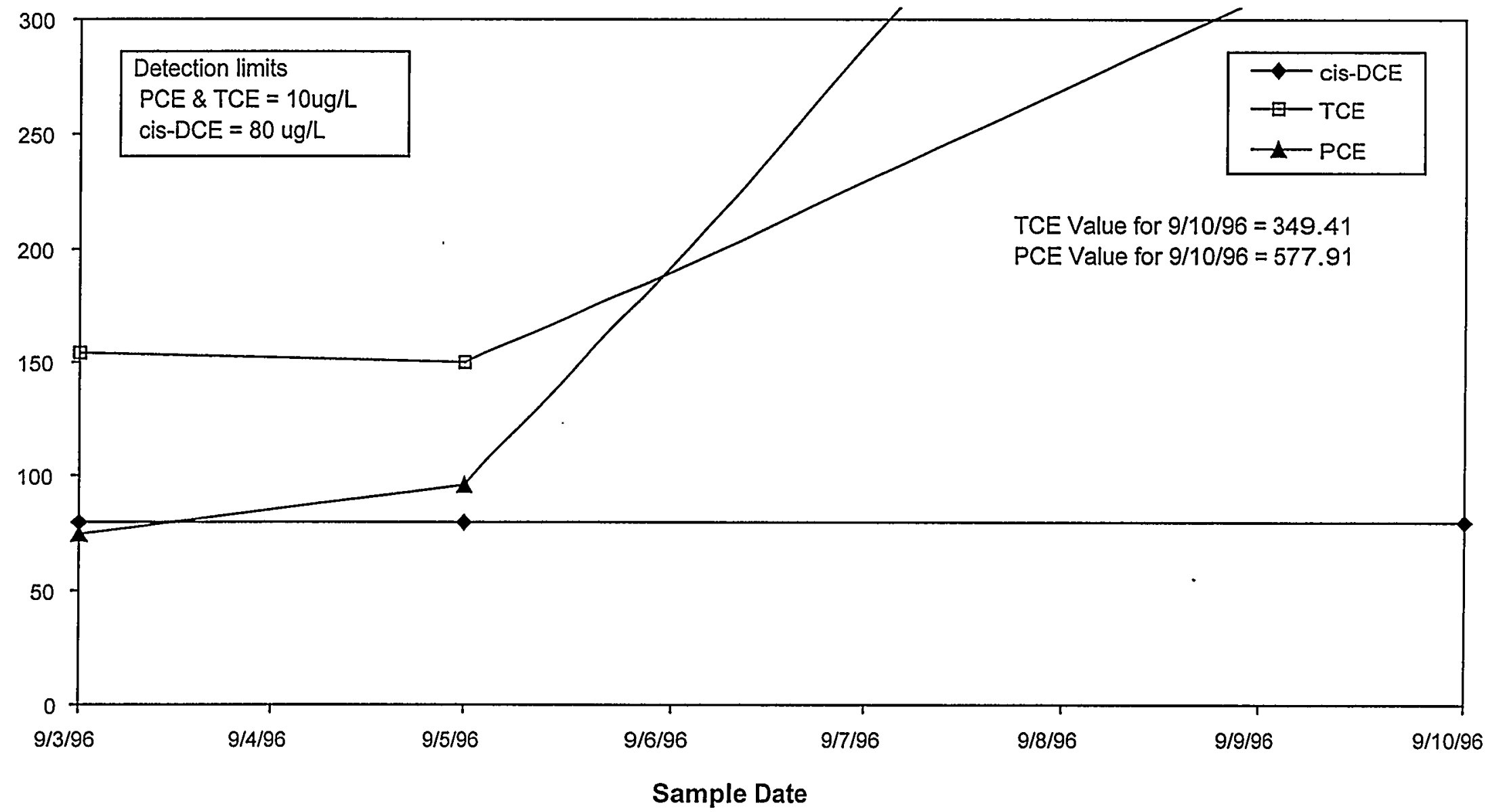


Figure 30

Organic Contaminants

VZP-13S

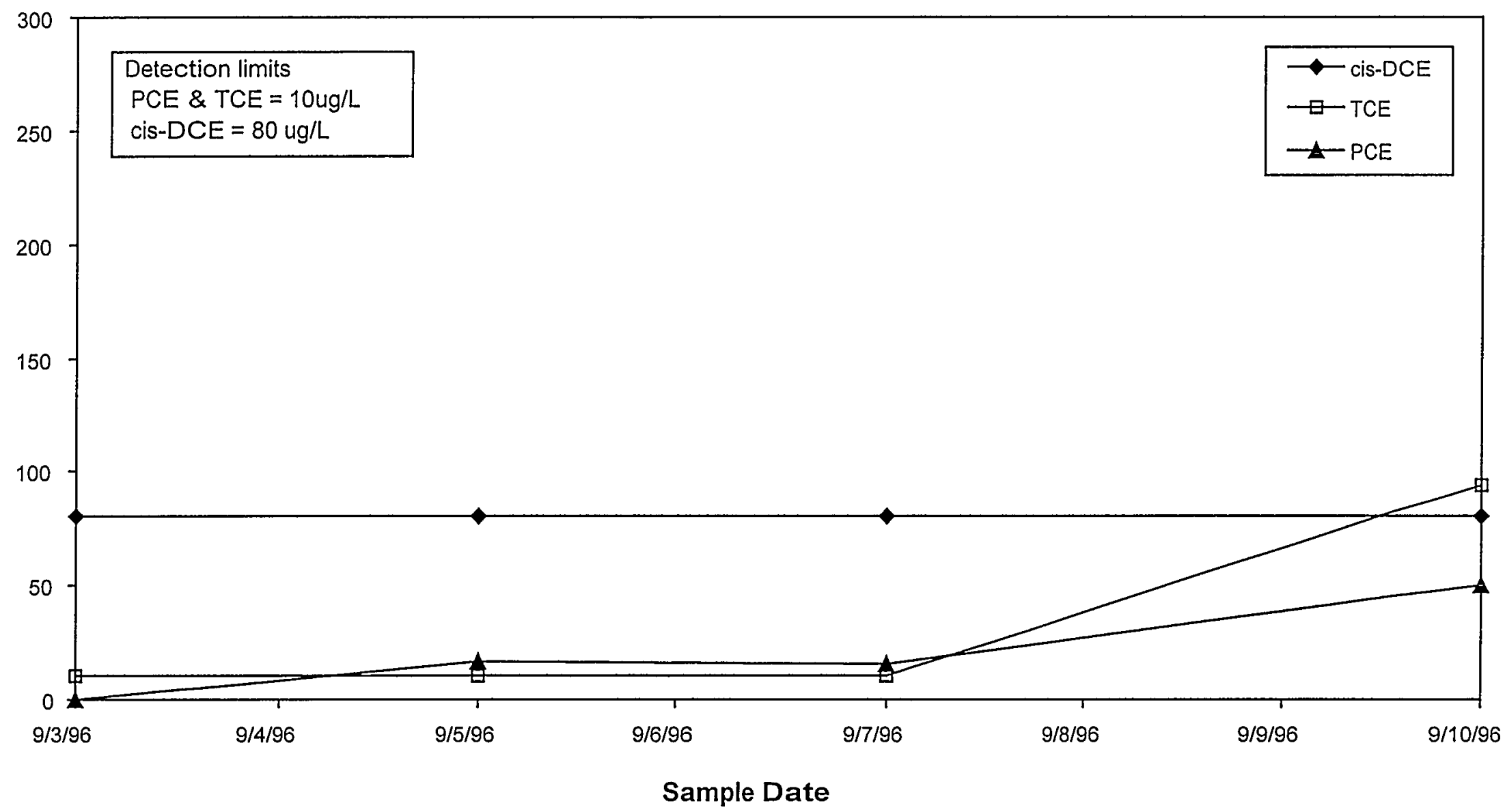


Figure 31

Organic Contaminants

VZP-13D

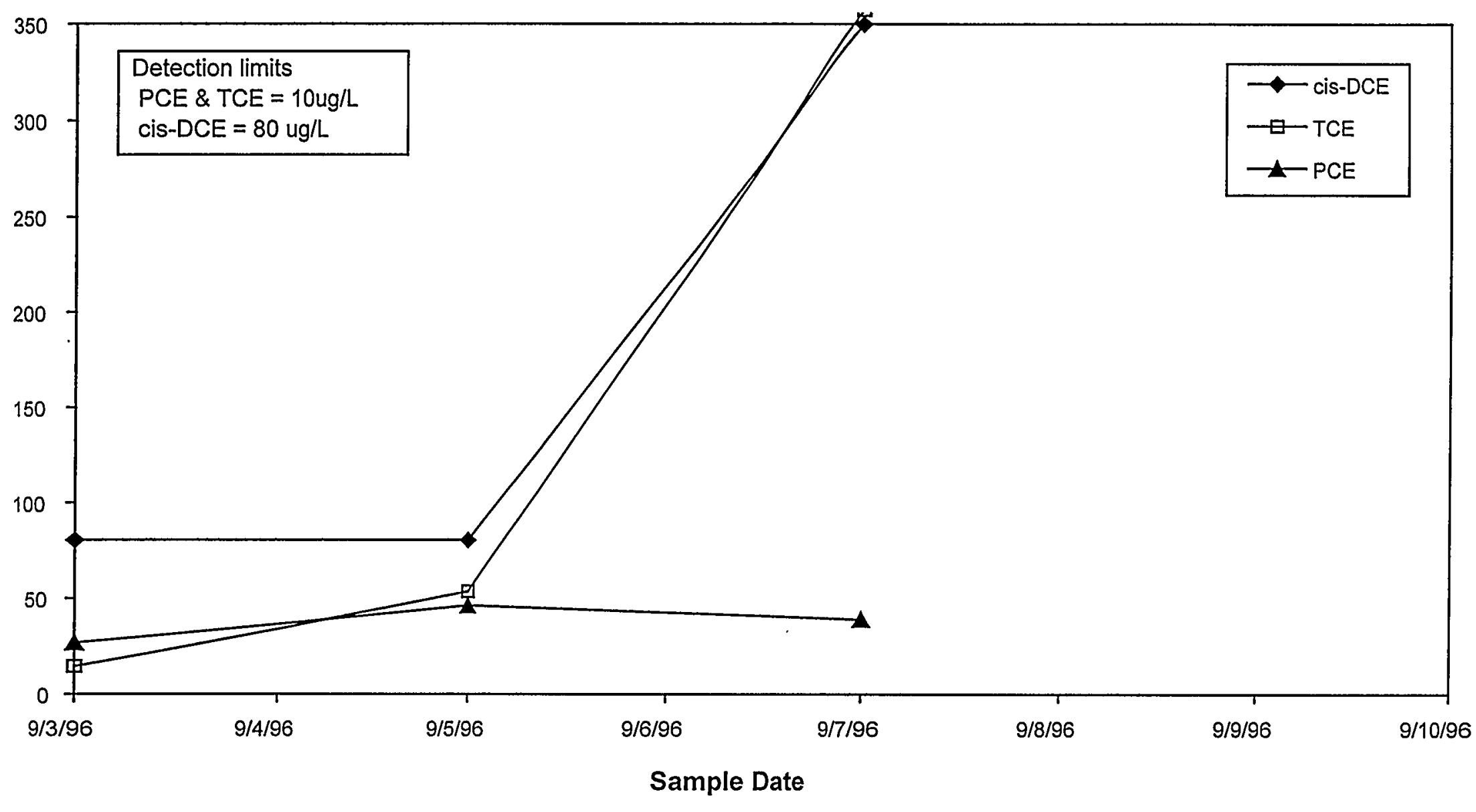


Figure 31

Organic Contaminants

VZP-13D

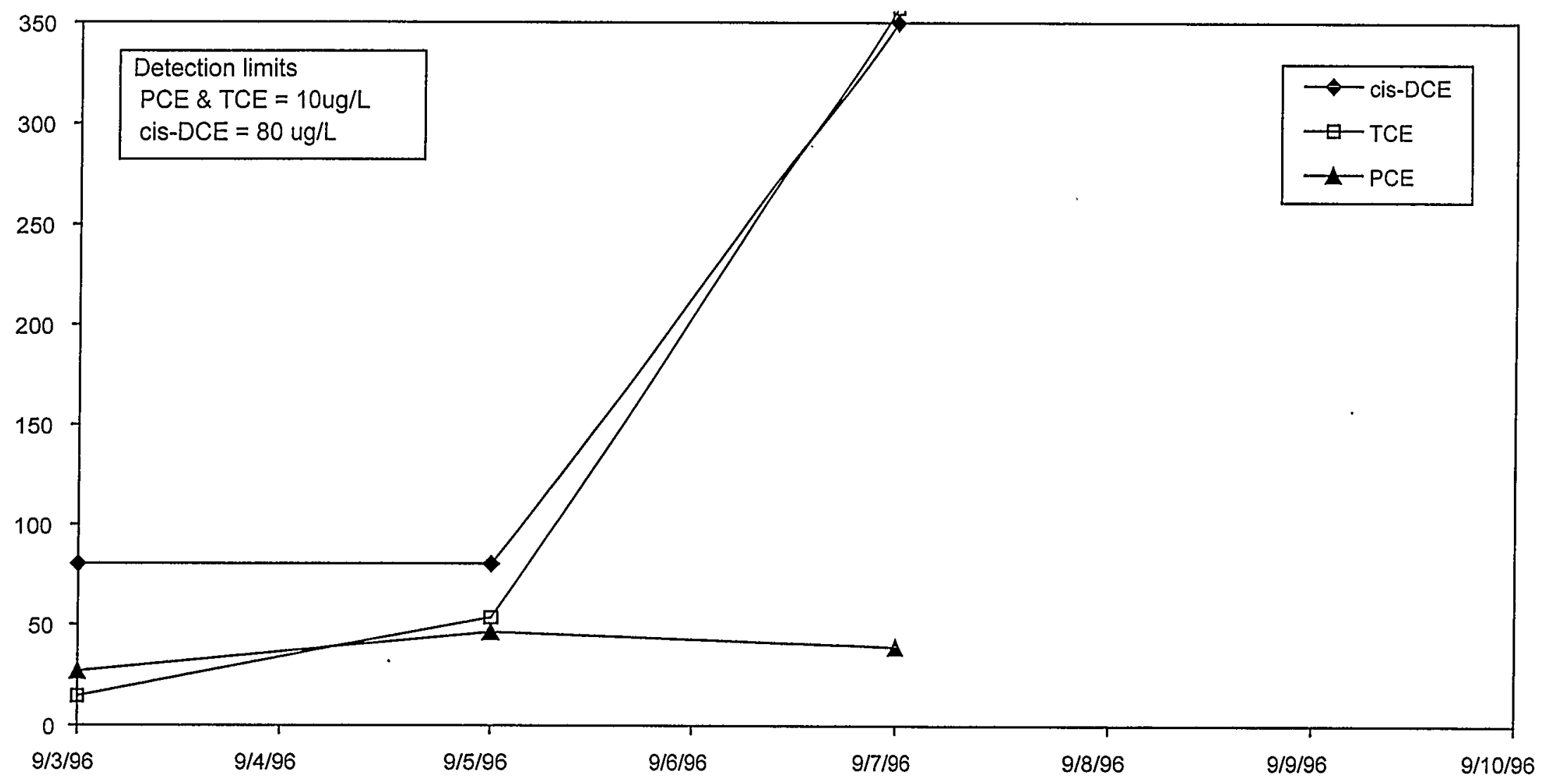

Sample Date 
Figure 33

Organic Contaminants

SZP-2D

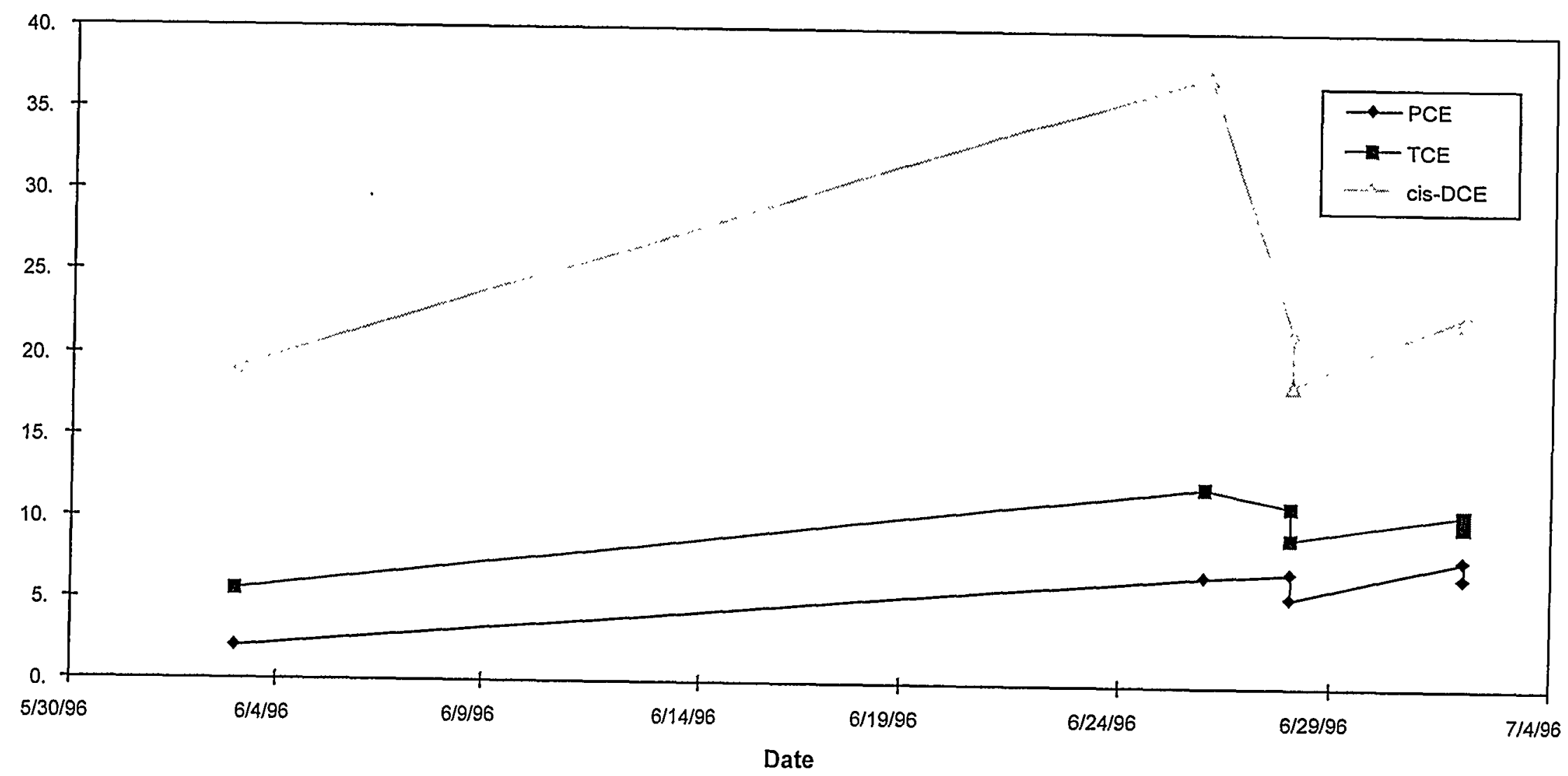


Figure 34

Organic Contaminants

SZP-4S

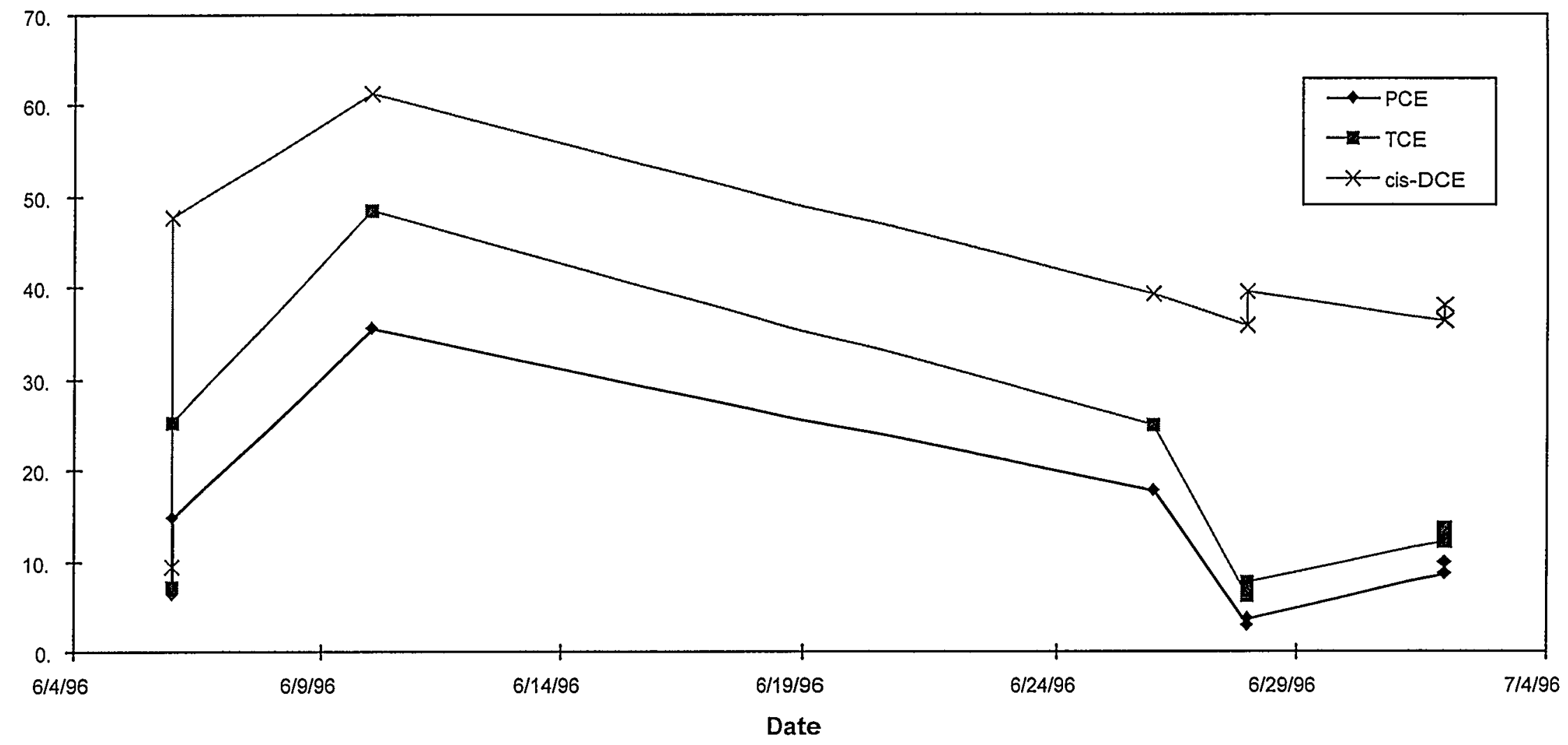




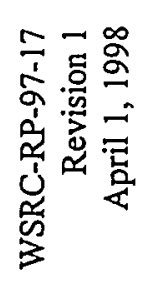

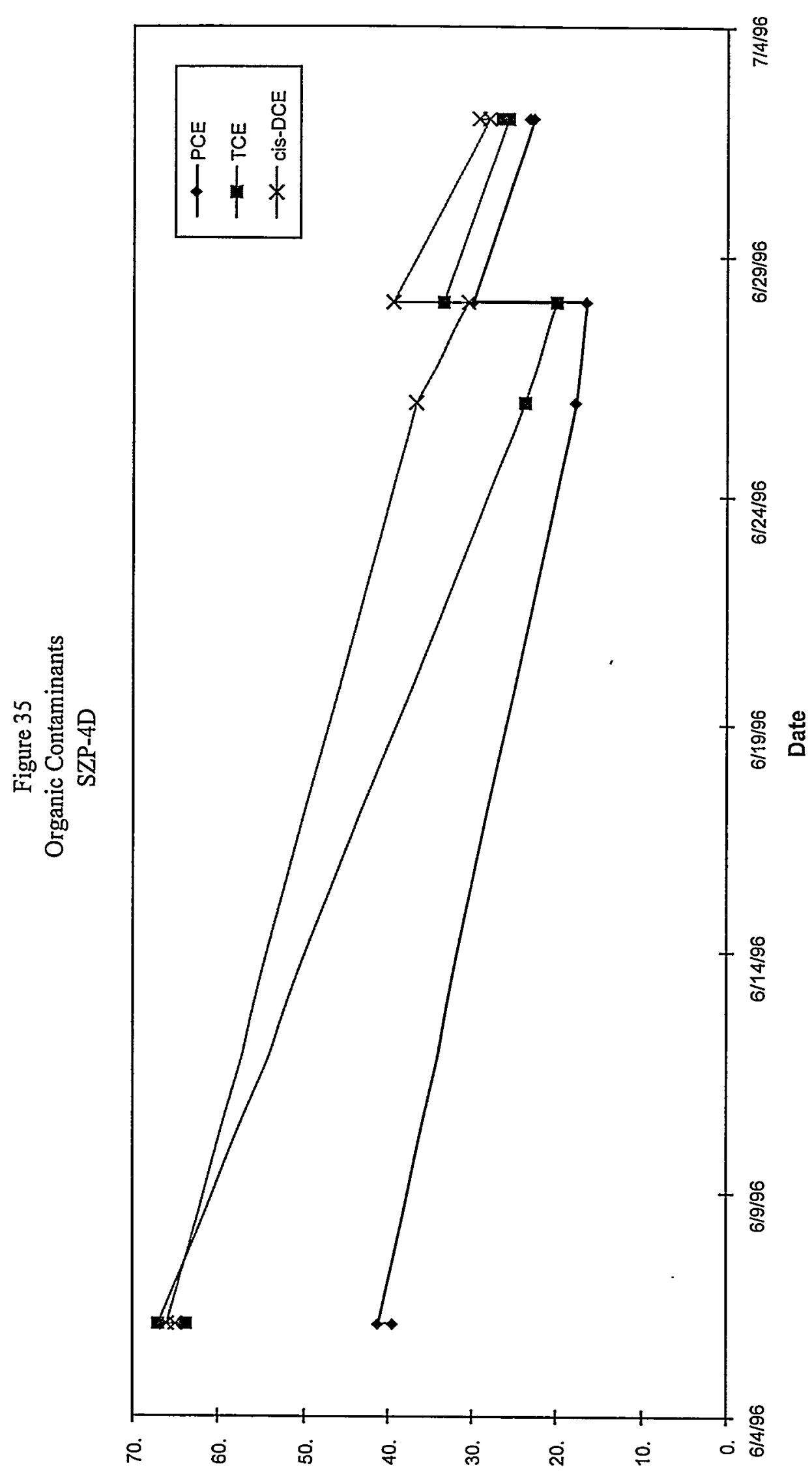

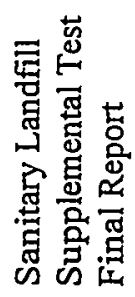


Figure 36

Organic Contaminants

SZP-7S

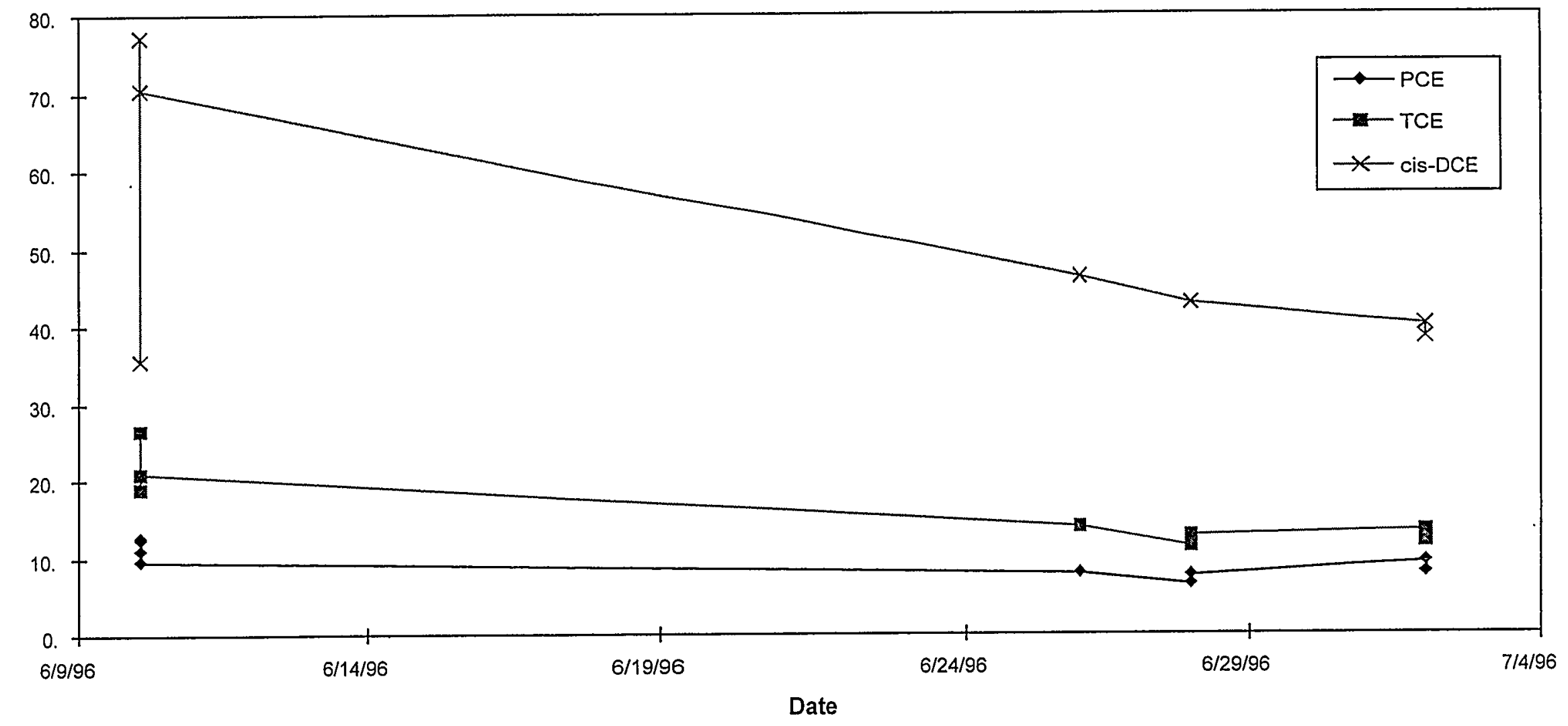


Figure 37

Organic Contaminants

SZP-7D

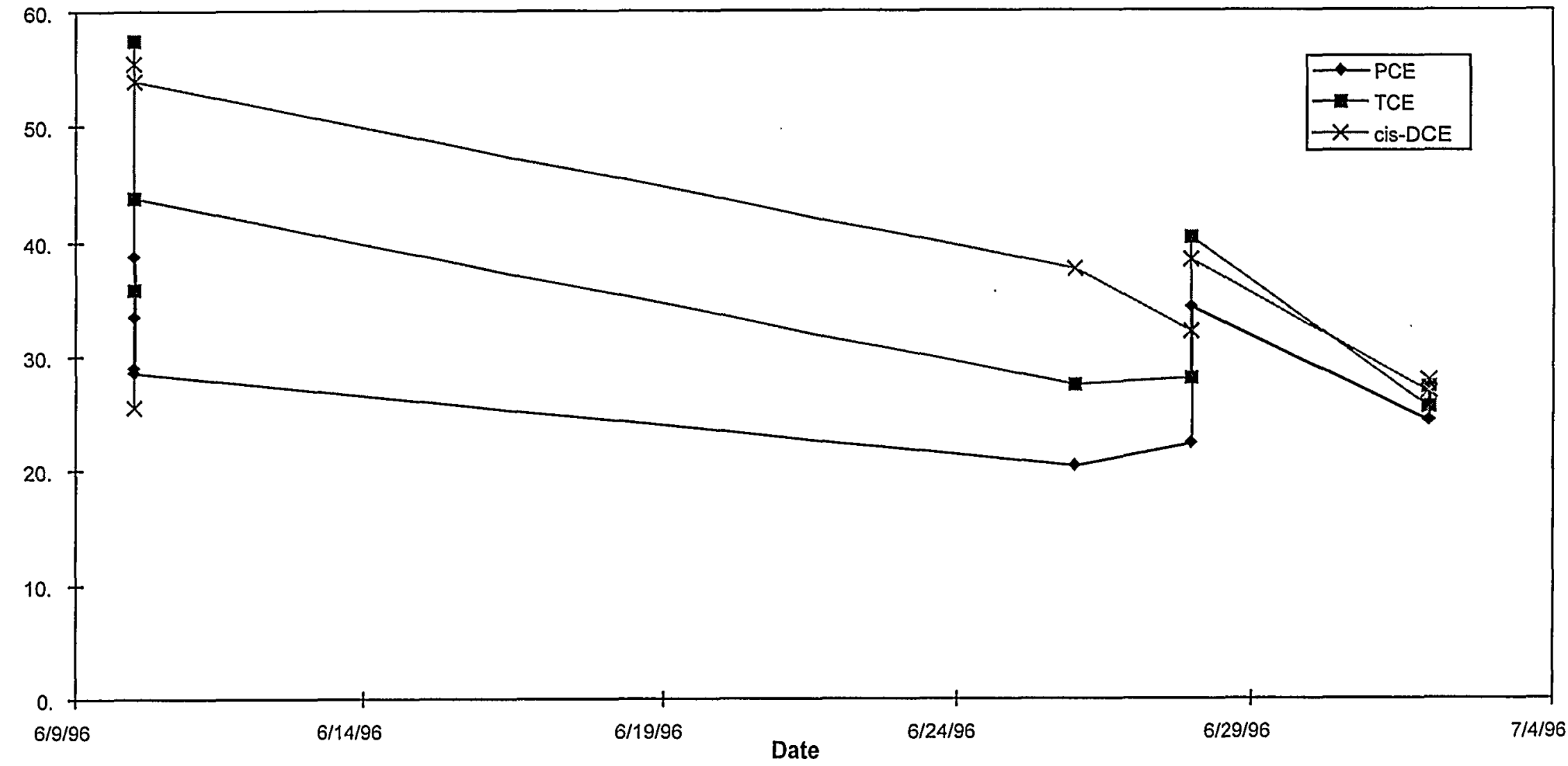


Figure 38

Organic Contaminants

SZP-13S

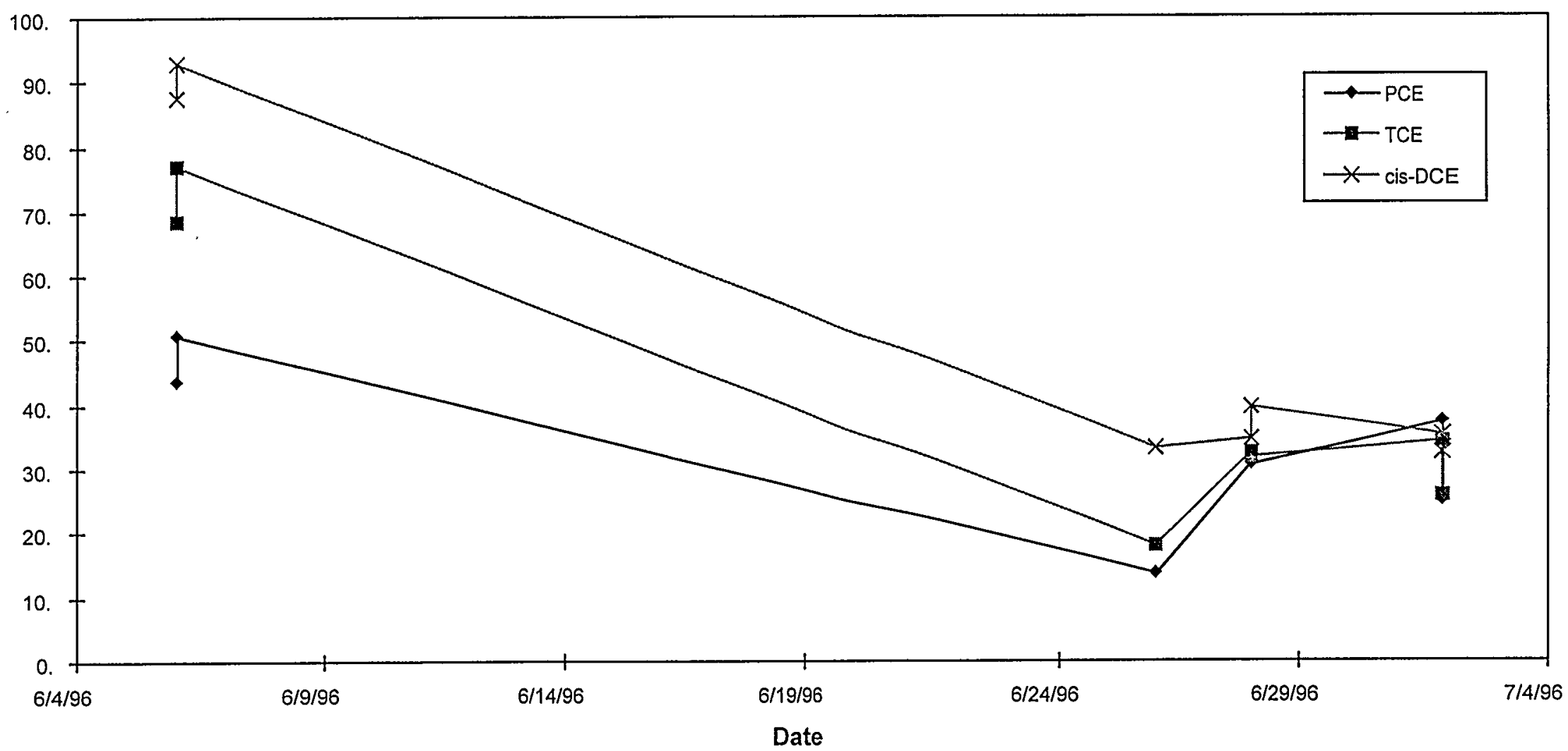


Figure 39

Organic Contaminants

SZP-13D

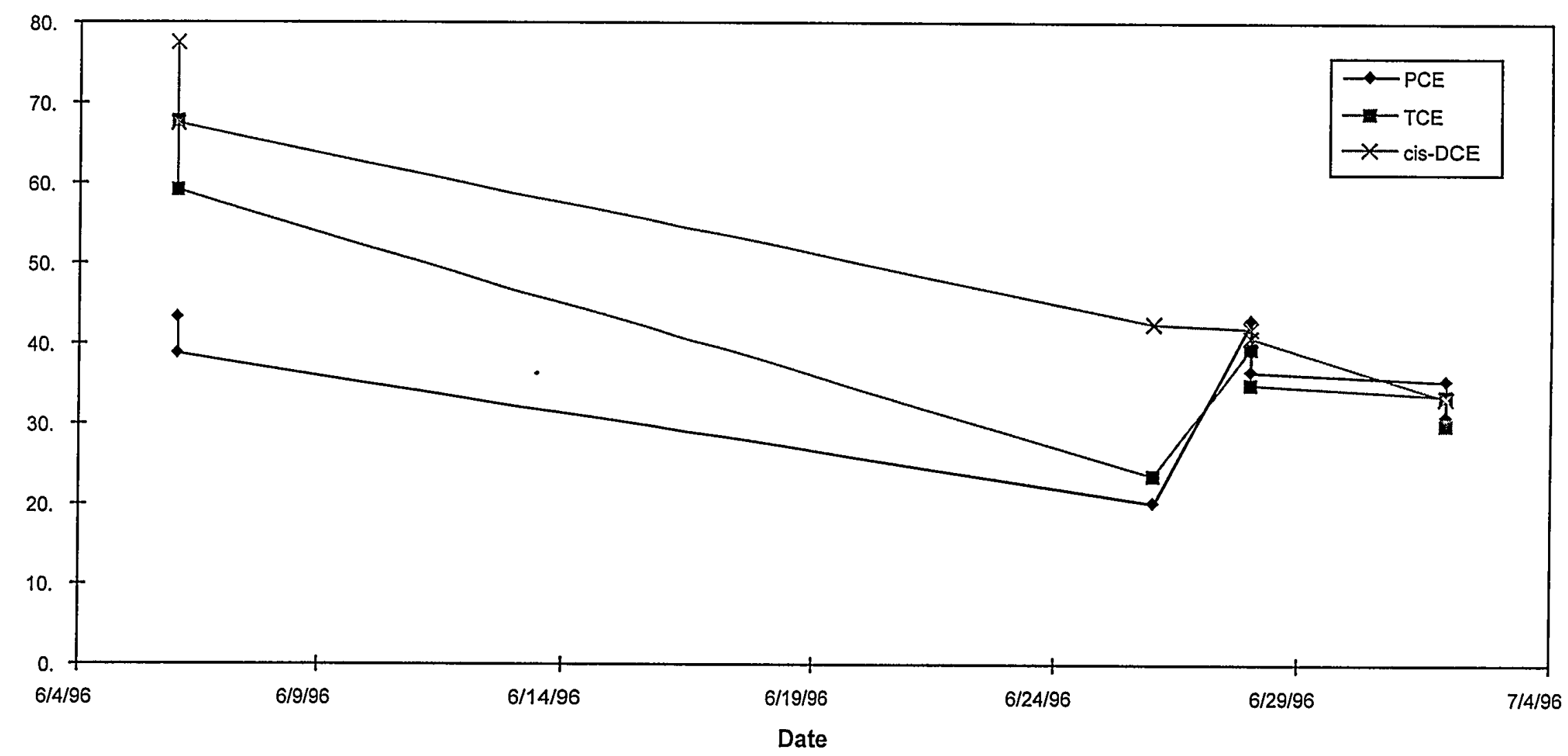


Figure 40

Organic Contaminants

SZP-2S

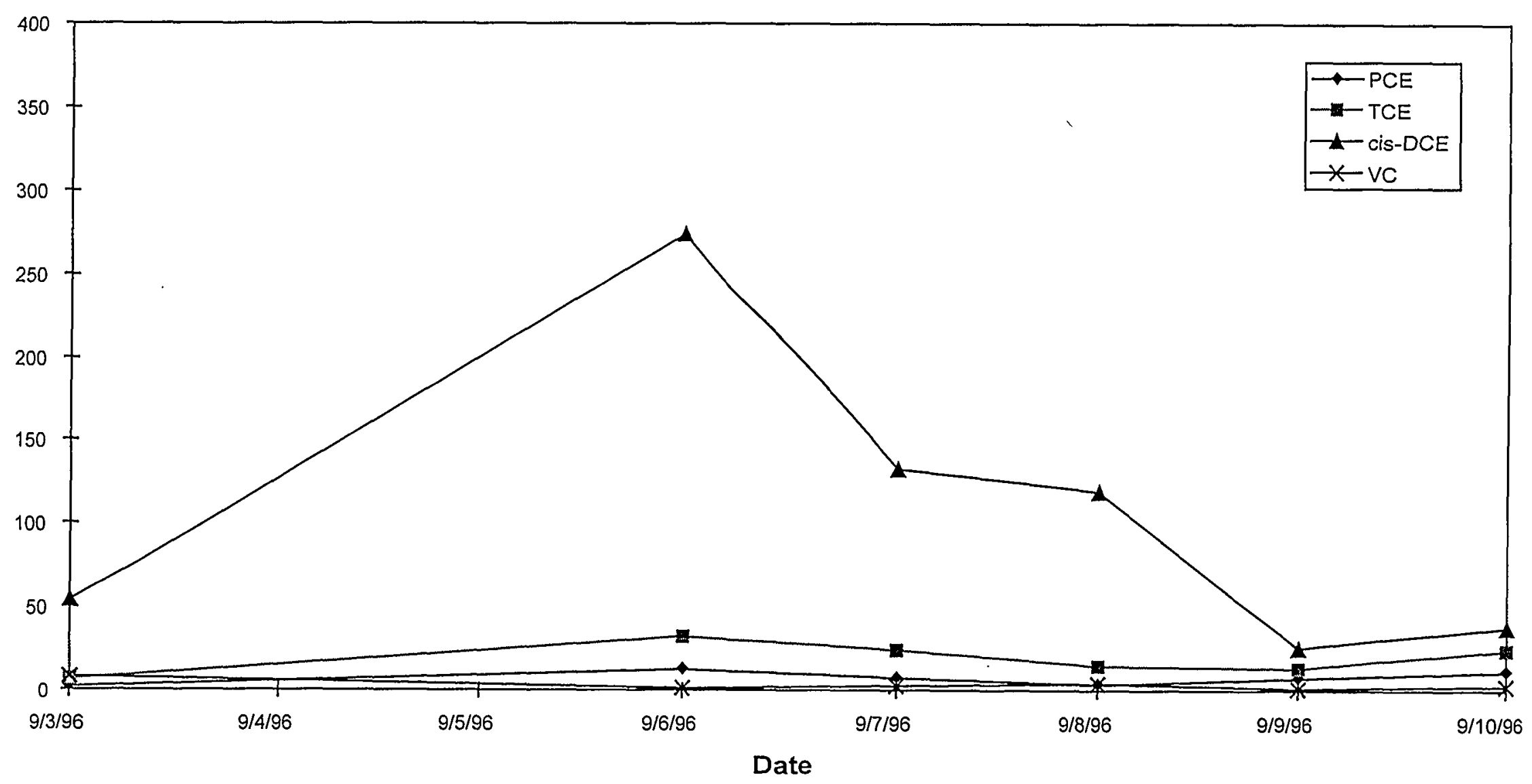


Figure 41

Organic Contaminants

SZP-2D

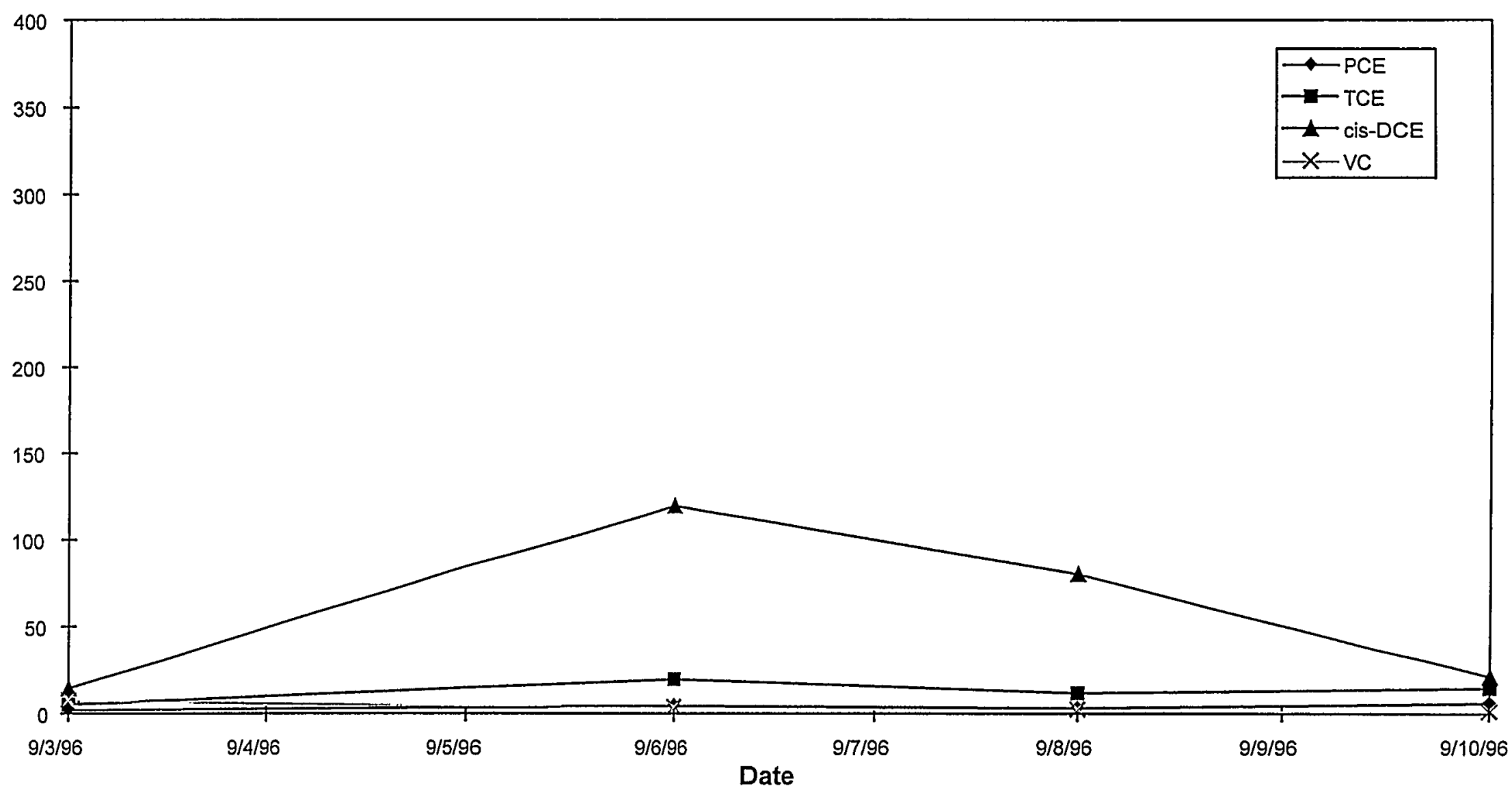


Supplemental Test

Revision 1

Final Report

Figure 42

Organic Contaminants

SZP-4S

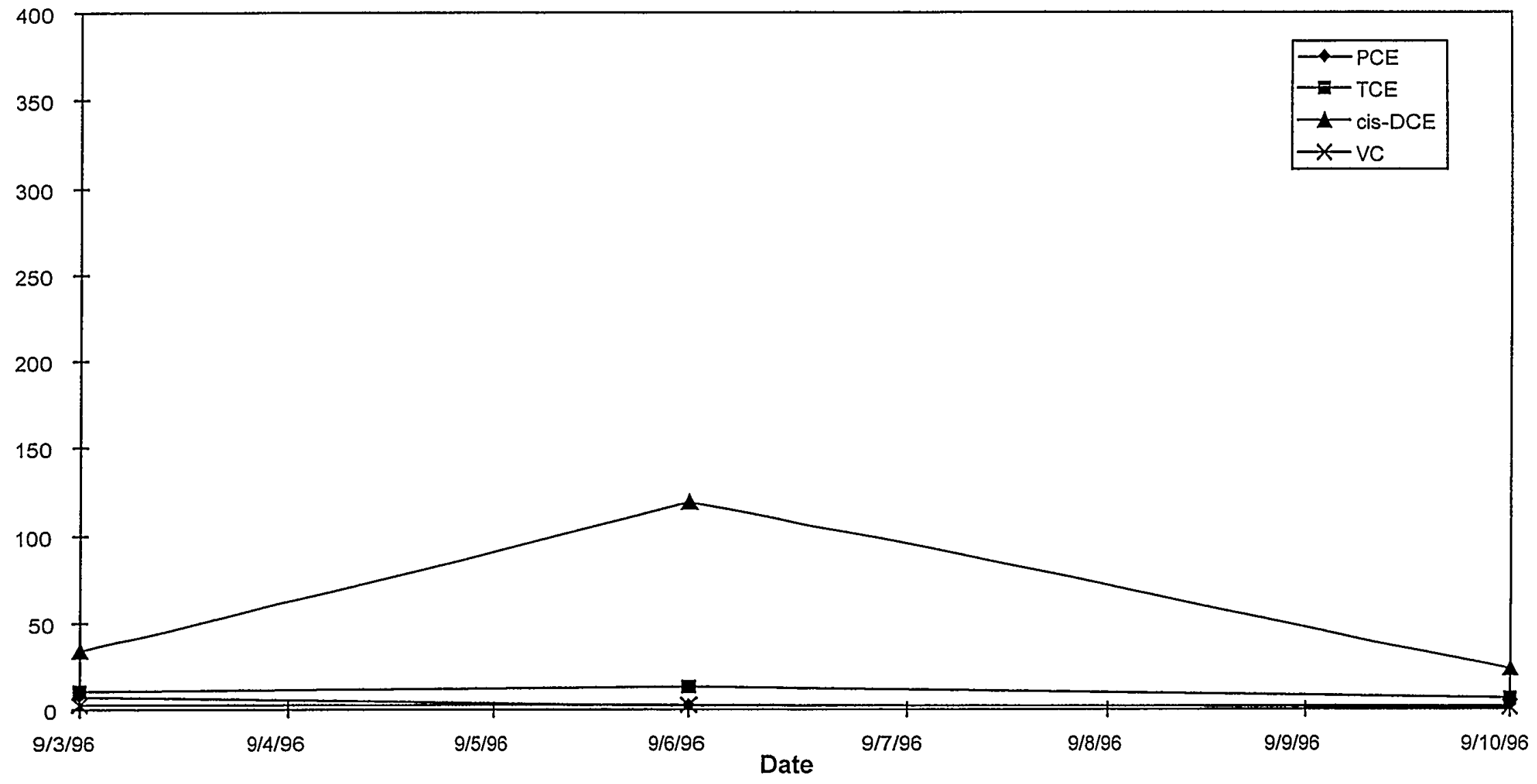


Supplemental Test

Revision 1

Final Report

Figure 43

Organic Contaminants

SZP-4D

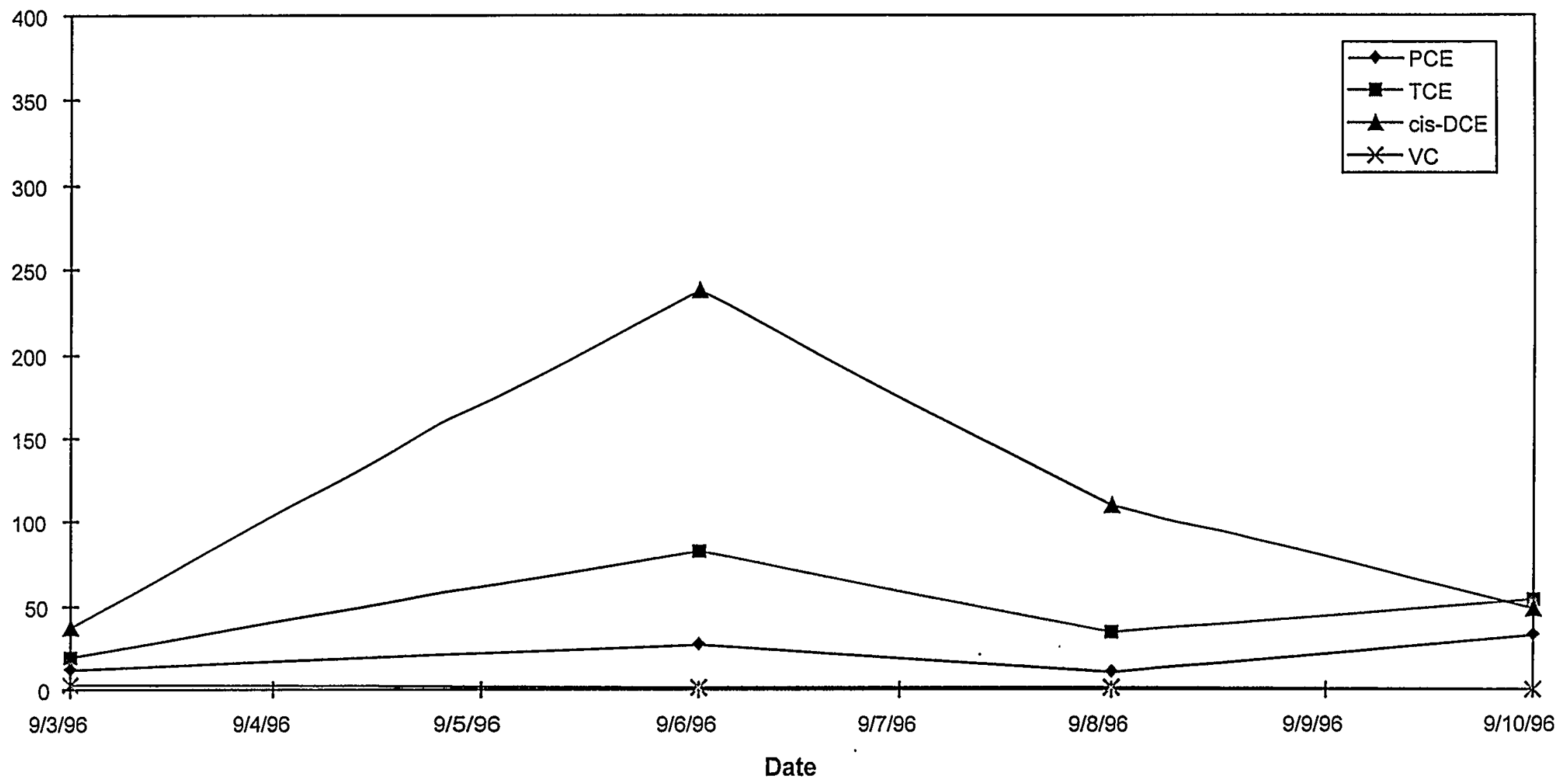


Figure 44

Organic Contaminants

SZP-7S

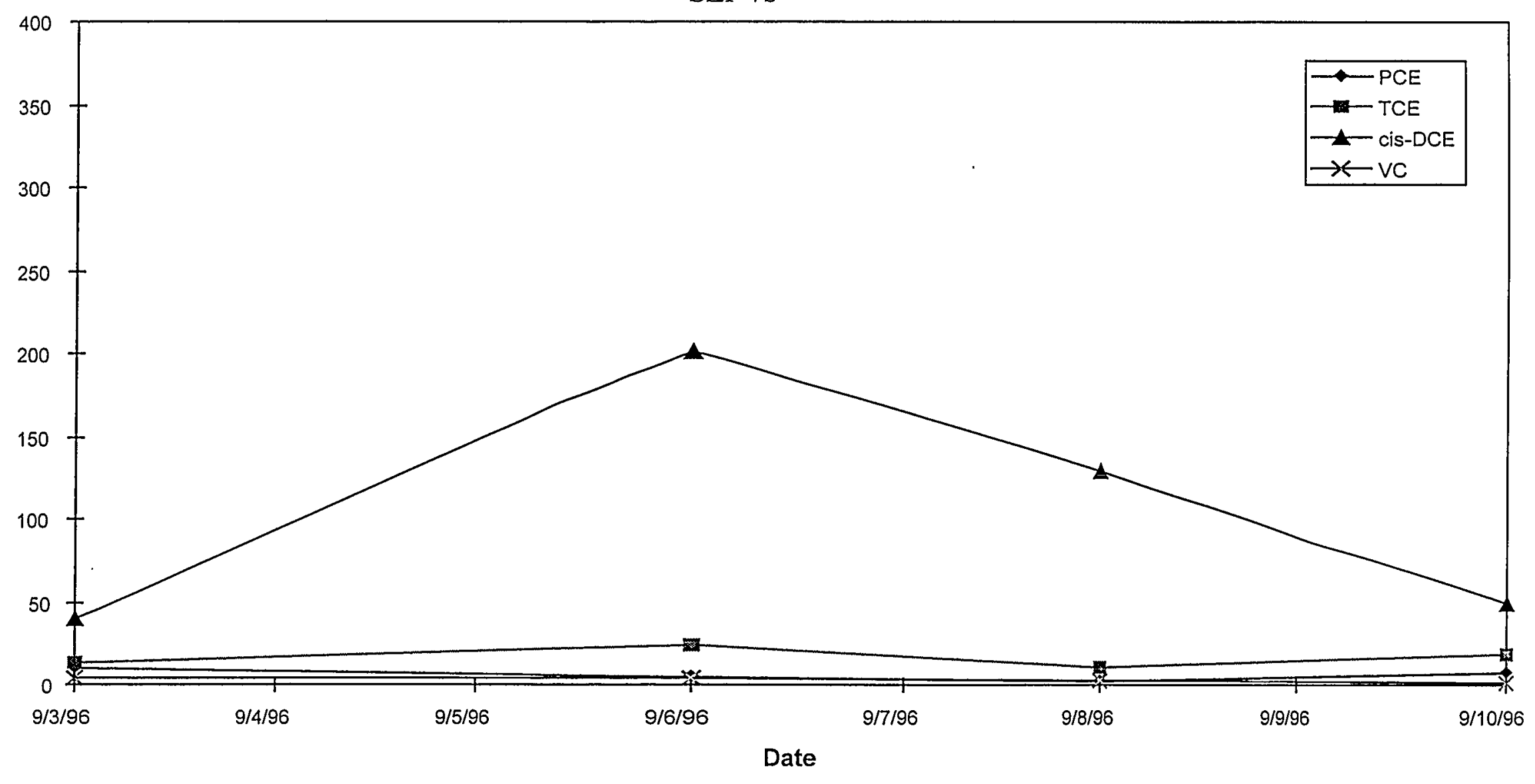


Supplemental Test

Revision 1

Final Report

Figure 45

Organic Contaminants

SZP-7D

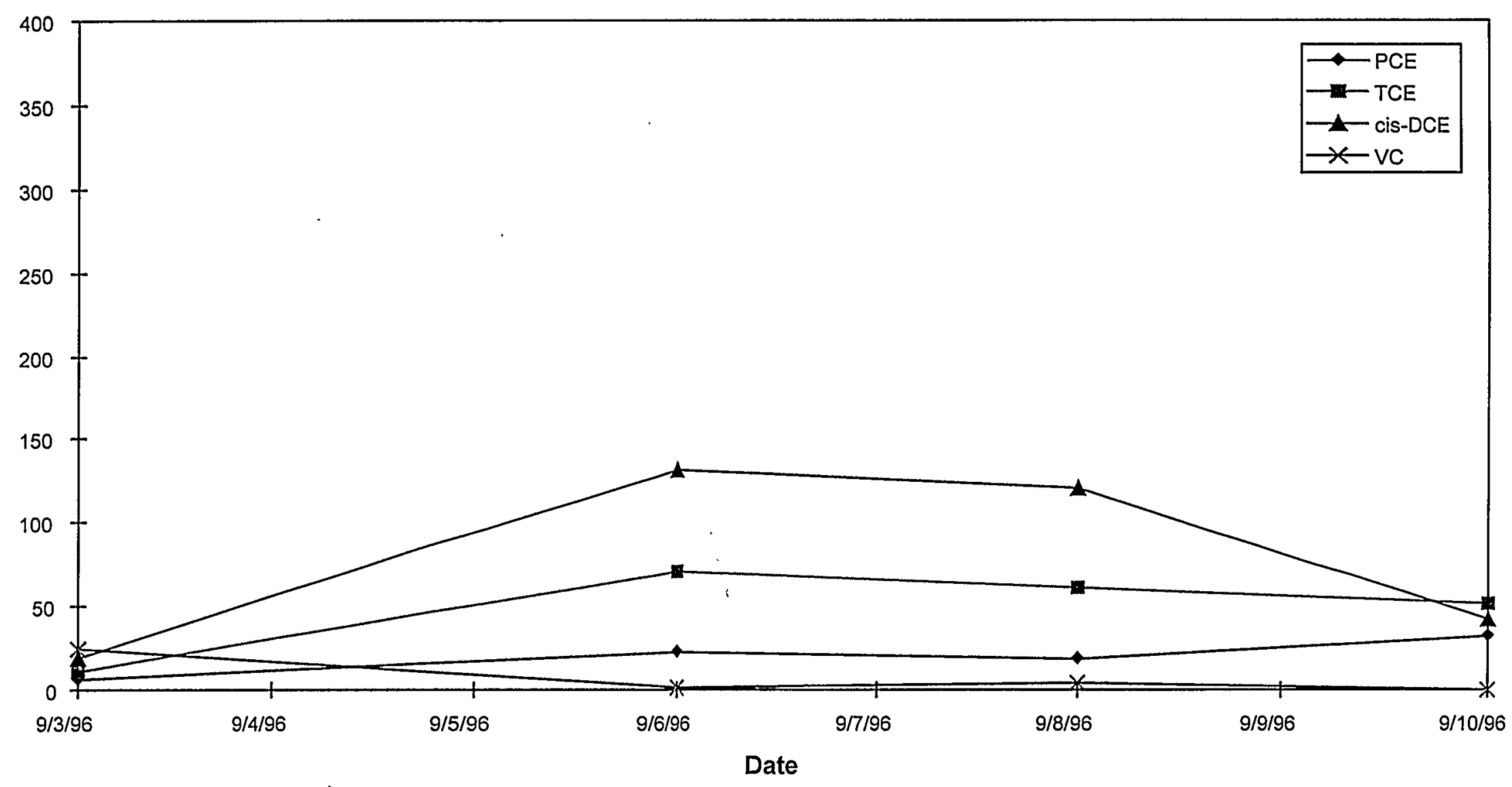


Figure 46

Organic Contaminants

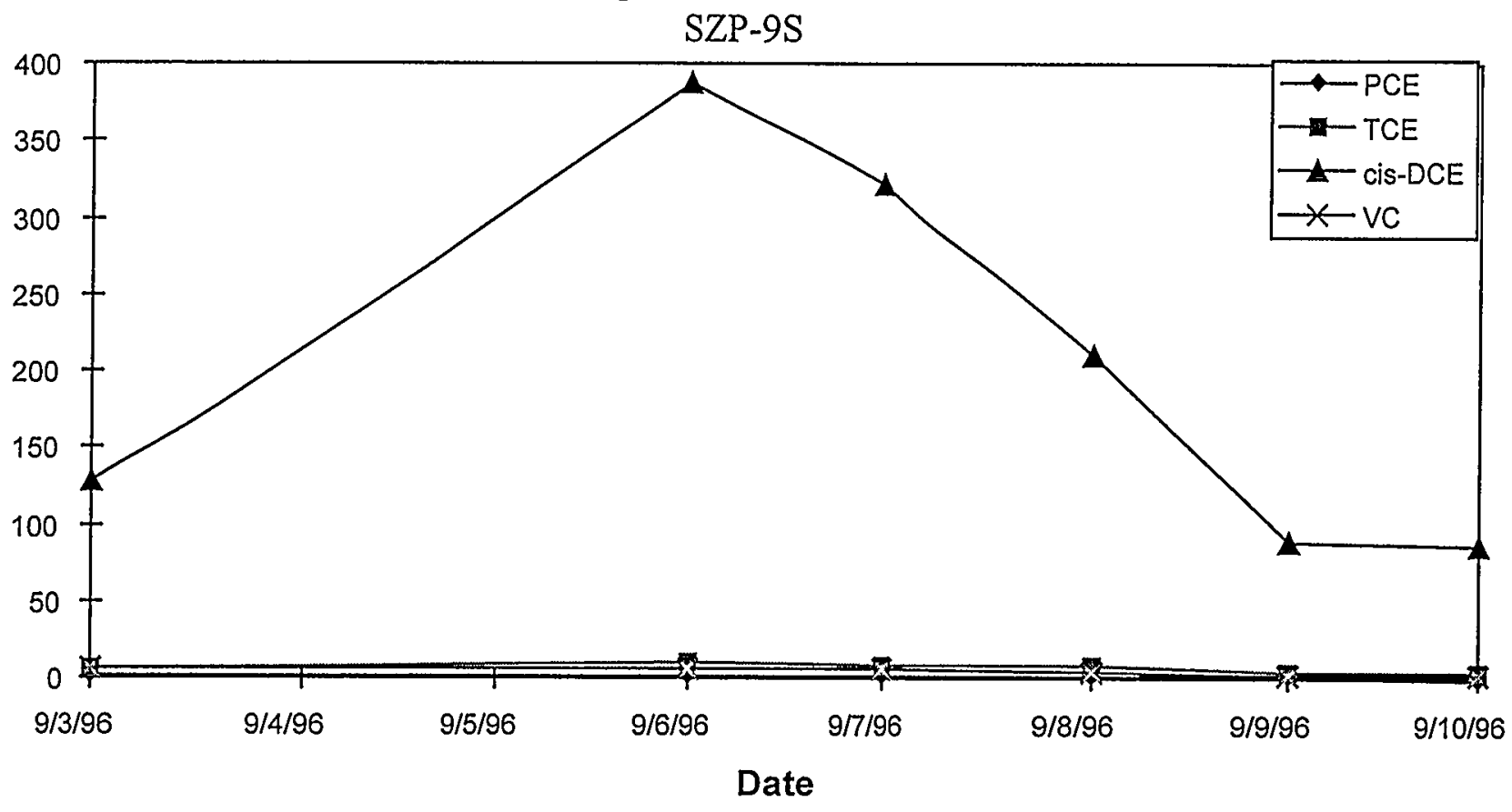


Figure 47

Organic Contaminants

SZP-13S

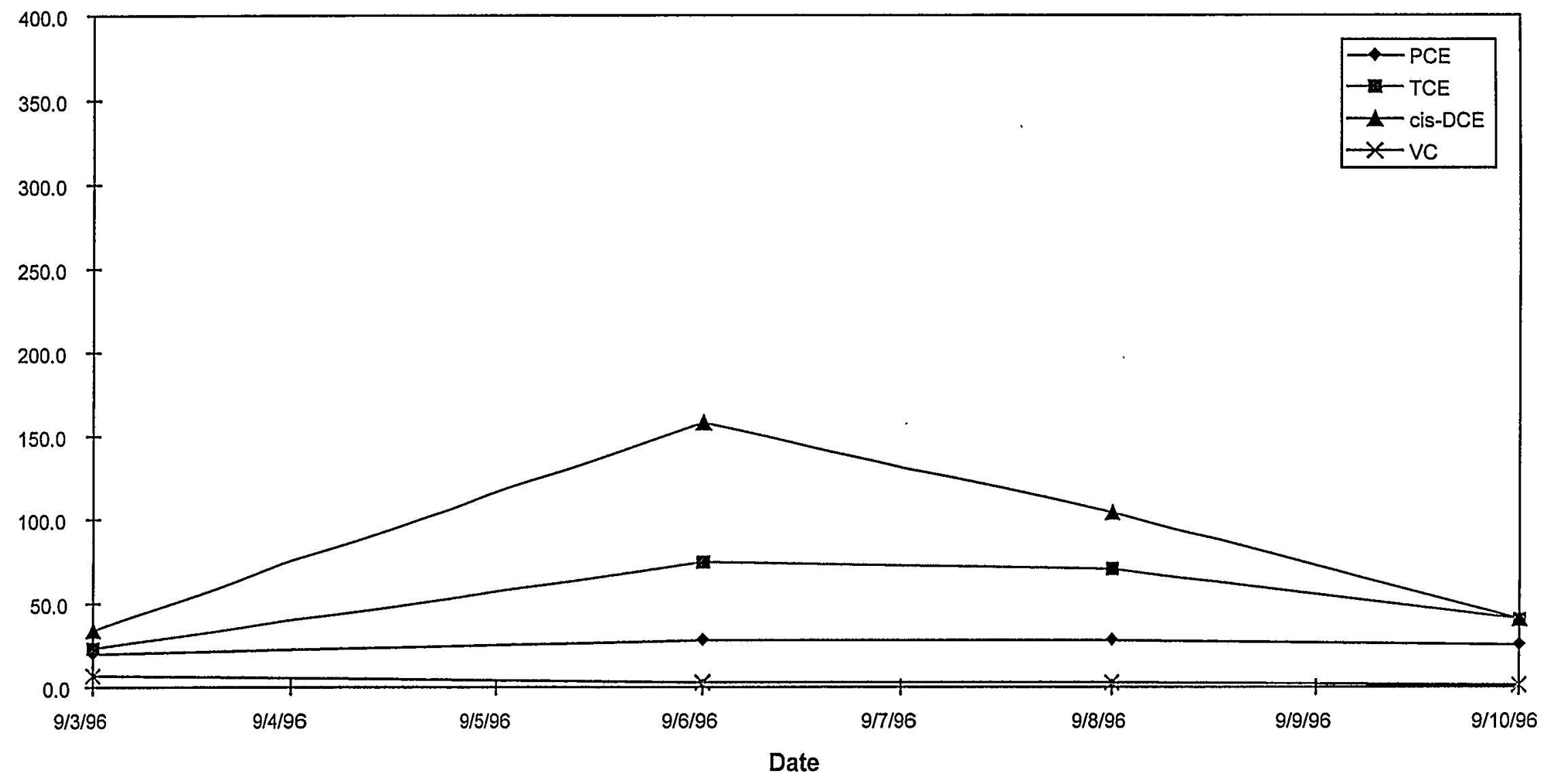


Figure 48

Organic Contaminants

SZP-13D

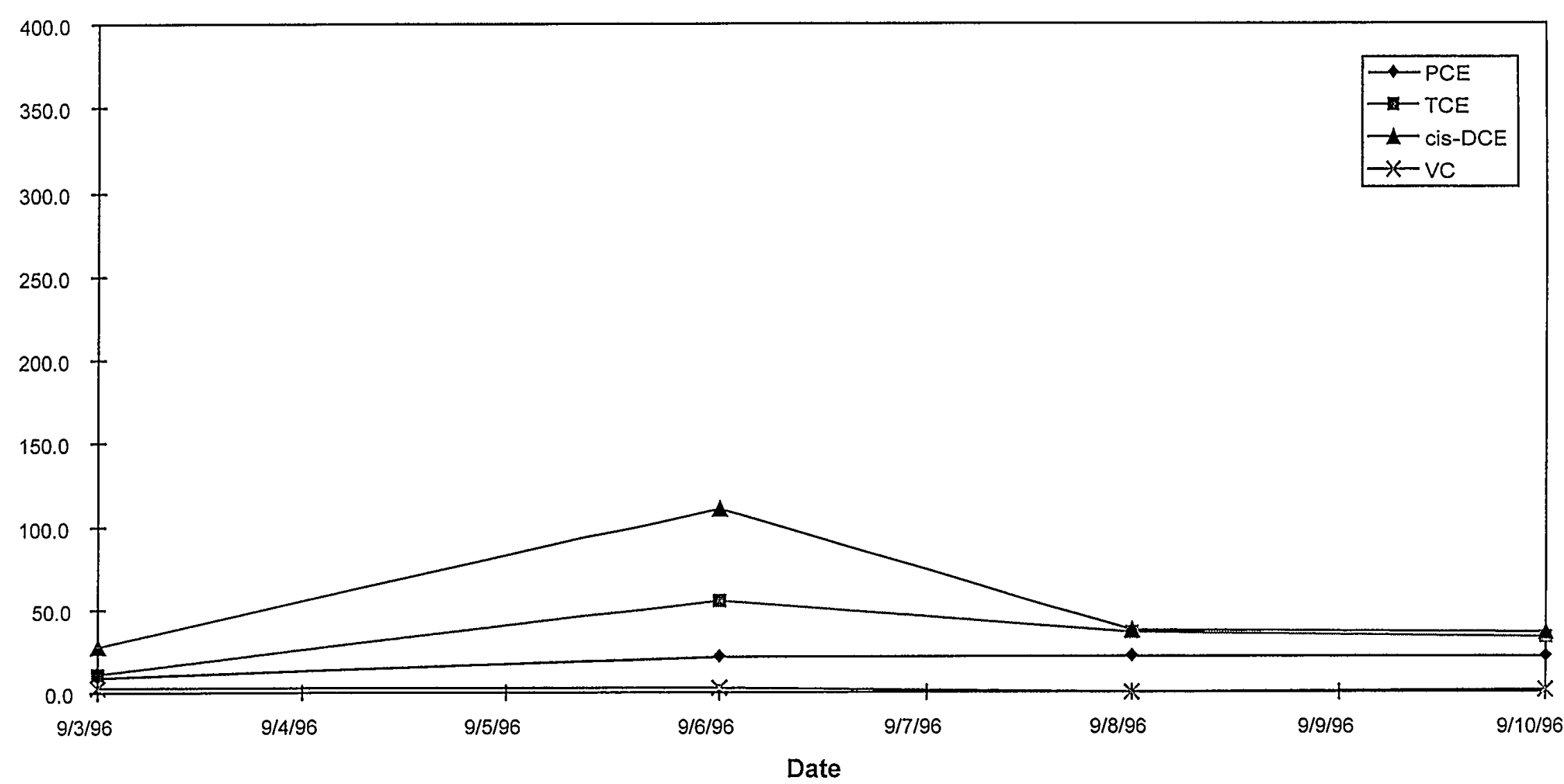


Figure 49

cis-DCE Concentrations

Well 2

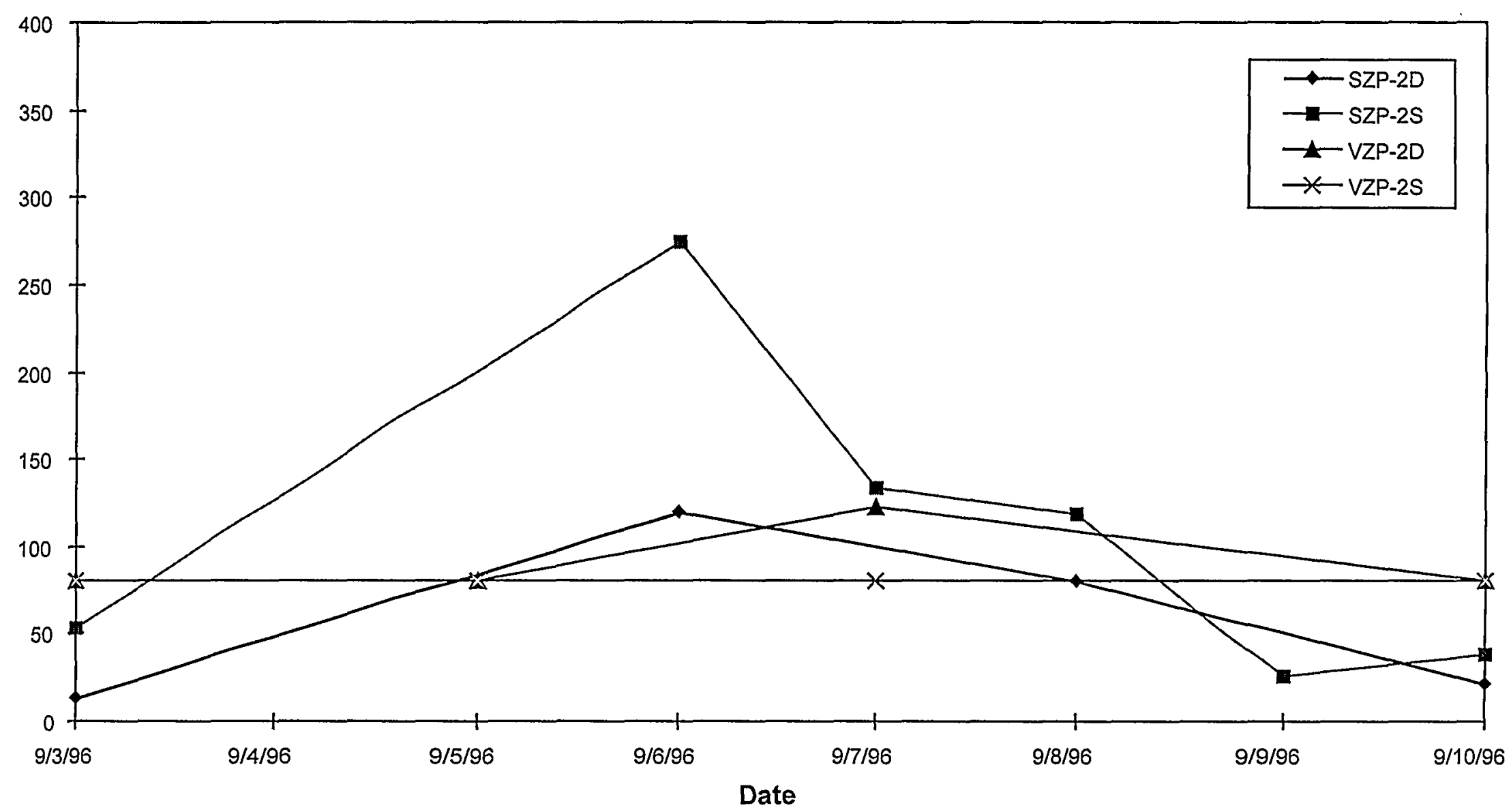


Figure 50

cis-DCE Concentrations

Well 4

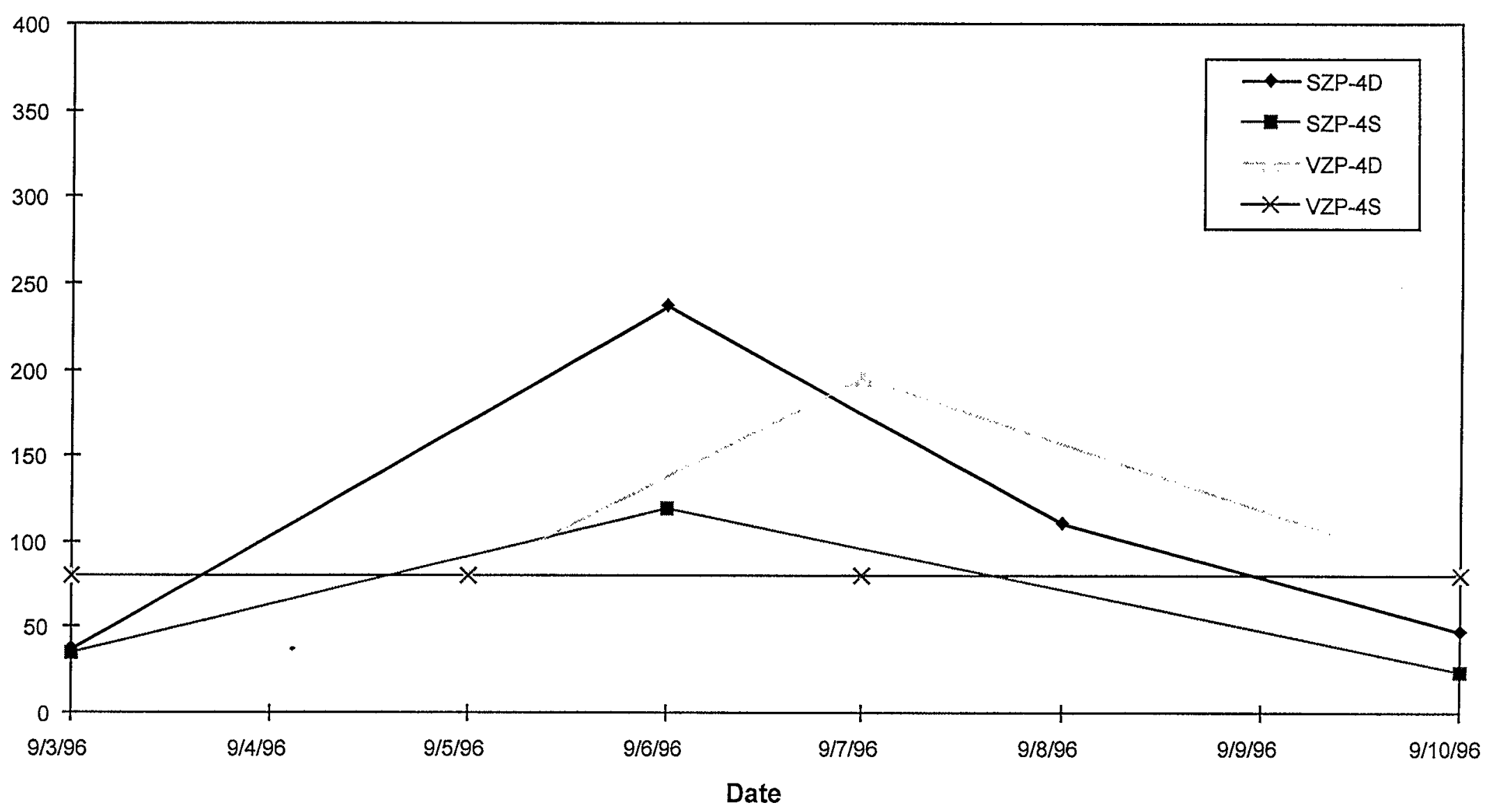


Figure 51

cis-DCE Concentrations

Well 7

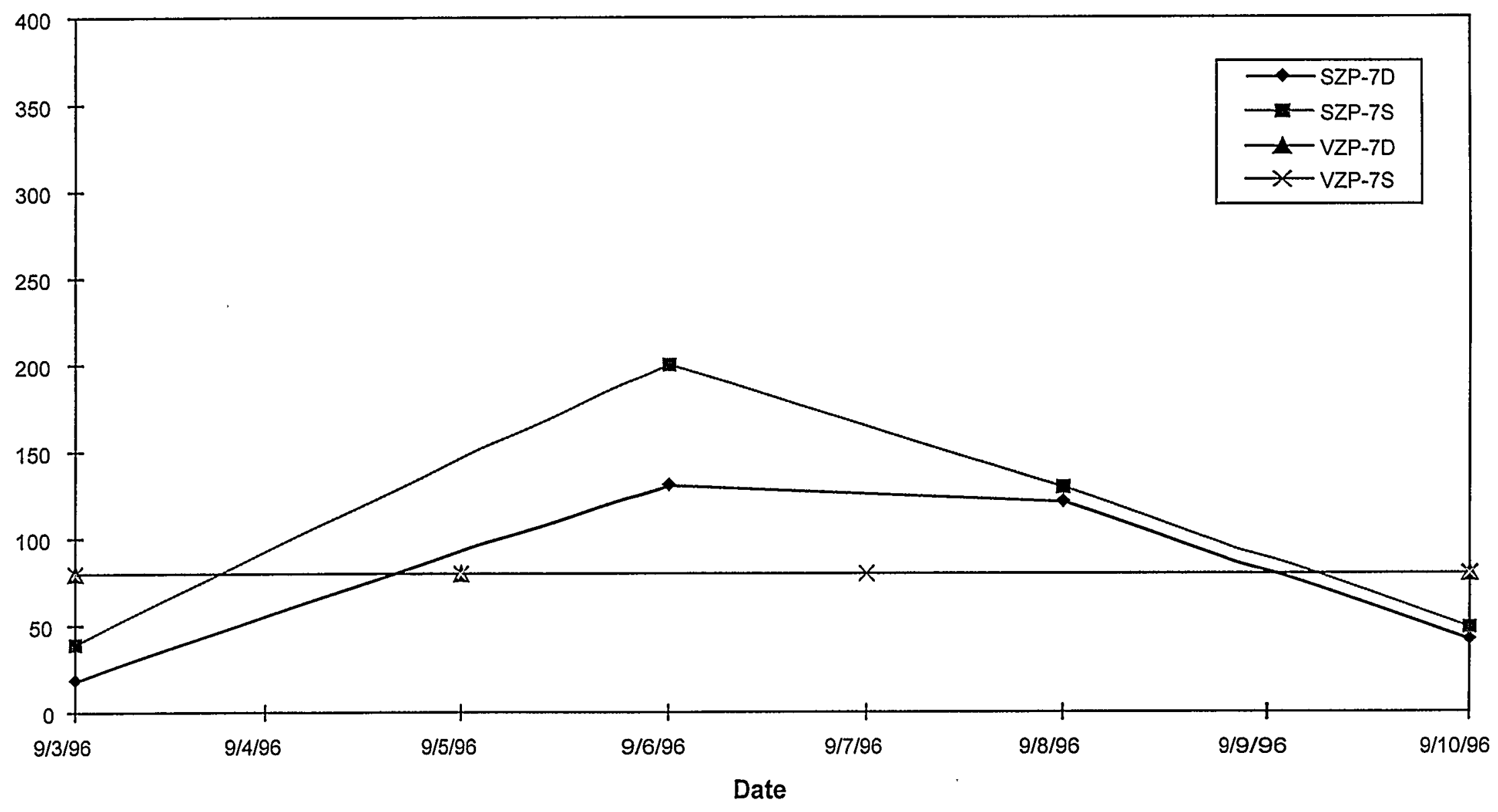


Figure 52

cis-DCE Concentrations

Well 13

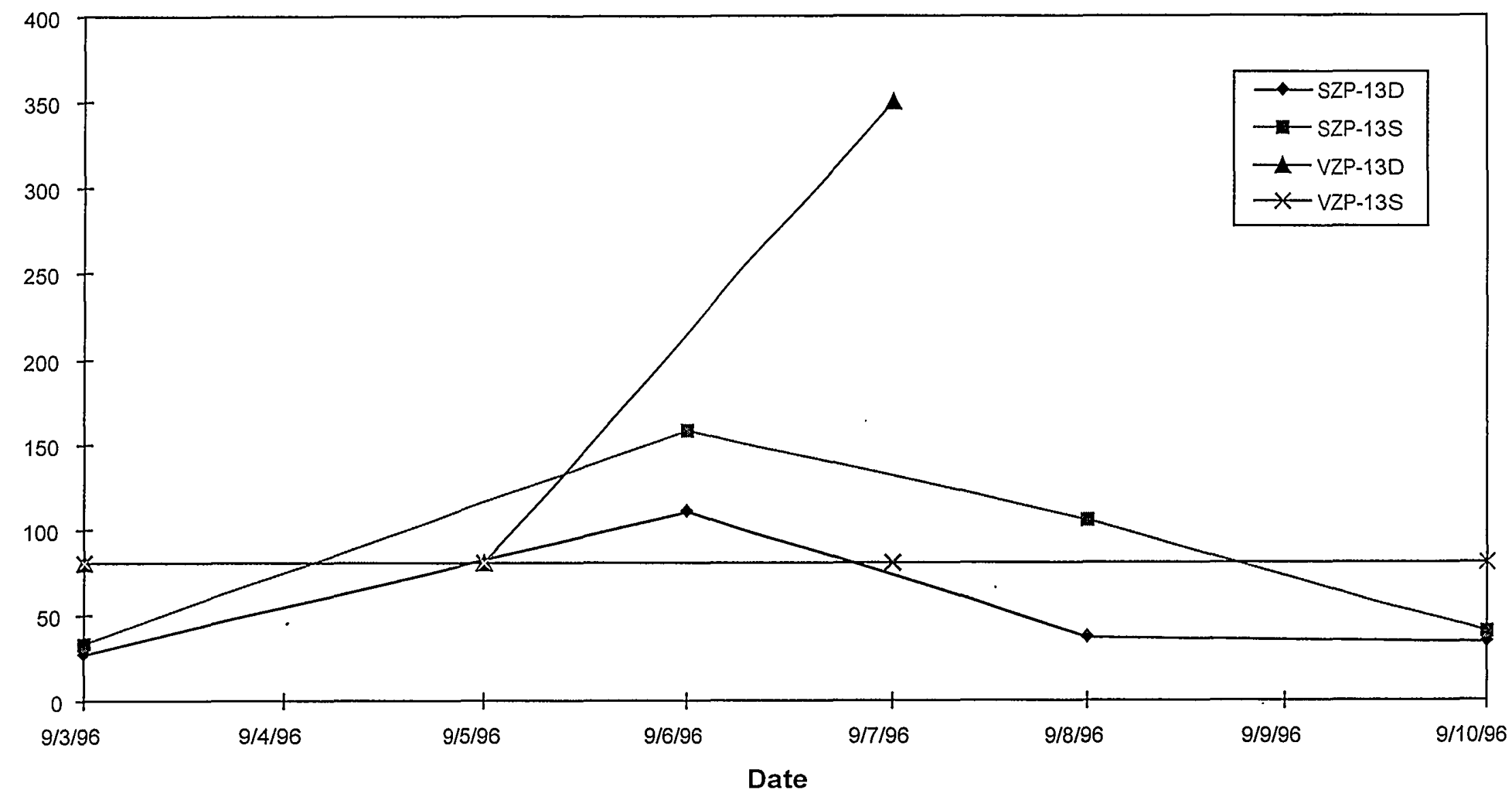

